DOE/ER/52139--91

DE93 013261

THE PROPERTIES AND WELDABILITY OF MATERIALS FOR

FUSION REACTOR APPLICATIONS

by

B.A. Chin, C.K. Lee, (Auburn University), S.J. Zinkle (Oak Ridge National Laboratory), and R.C. Wilcox (Auburn University)

November 15, 1991

Department of Mechanical Engineering

Auburn University, AL 36849-5341.

Phone: (205) 844-3323

Fax: (205) 844-3307

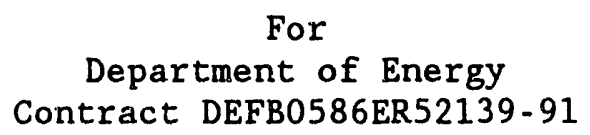

6. 


\section{THE PROPERTIES AND WELDABILITY \\ OF MATERIALS FOR \\ FUSION REACTOR APPLICATIONS}

FINAL REPORT

TABLE OF CONTENTS

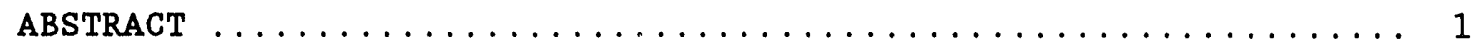

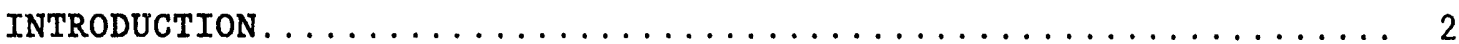

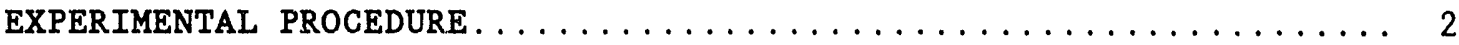

Materials Choice and Sample Preparation................. 2

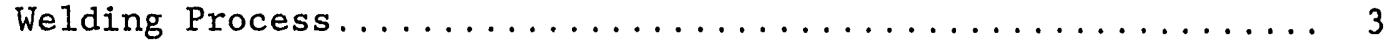

Microstructural Characterization...................4

Mechanical Testing......................... 5

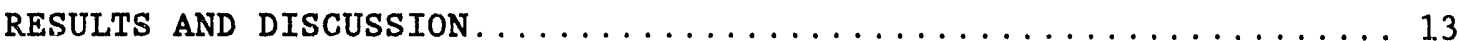

Microstructure and Phase Identification............... 13

Mechanical Properties.......................... 35

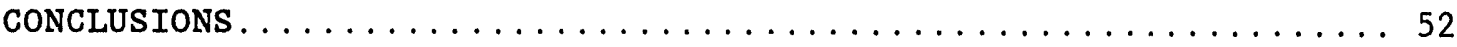

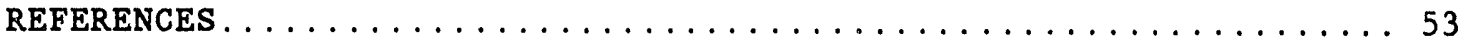

PAPERS PRESENTED AT ICFRM $-5 \ldots \ldots \ldots \ldots \ldots \ldots \ldots \ldots \ldots \ldots$

Flectrotransport and Radiation Effects in Alumina Insulators During High Temperature Reactor

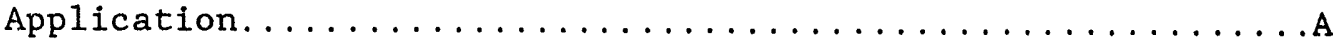

Brazing of Copper-Alumina Alloys ...................

Abstract Infrared Thermography for Non-Destructive

Monitoring of Weld Penetration Variations...............

The Welding of Niohi-ium to Stainless Steel..............

Suppression of Haz Cracking During Welding of Helium-Containing Materials...................

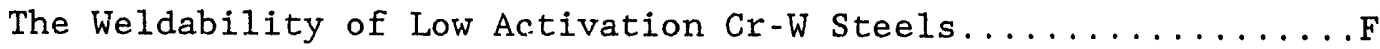

Multiple Ion Implantation Effects on Fatigue

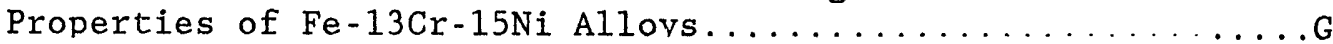

\section{DISCLAIMER}

This report was prepared as an account of work sponsored by an agency of the United States Government. Neither the United States Government nor any agency thereof, nor any of their employees, makes any warranty, express or implied, or assumes any legal liability or responsibility for the accuracy, completeness, or usefulness of any information, apparatus, product, or process disclosed, or represents that its use would not infringe privately owned rights. Reference herein to any specific commercial product, process, or service by trade name, trademark, manufacturer, or otherwise does not necessarily constitute or imply its endorsement, recommendation, or favoring by the United States Government or any agency thereof. The views and opinions of authors expressed herein do not necessarily state or reflect those of the United States Government or any agency thereof. 


\title{
THE PROPERTIES AND WELDABILITY OF MATERIALS FOR FUSION REACTOR APPLICATIONS
}

\begin{abstract}
Low-activation austenitic stainless steels have been suggested for applications within fusion reactors. The use of these nickel-free steels will help to reduce the radioactive waste management problem after service. one requirement for such steels is the ability to obtain sound welds for fabrication purposes. Thus, two austenitic $\mathrm{Fe}-\mathrm{Cr}-\mathrm{Mn}$ alloys were studied to characterize the welded microstructure and mechanical properties. The two steels investigated were a Russian steel (Fe-11.6Cr19.3Mn-0.181C) and an U.S. steel (Fe-12.1Cr-19.4Mn-0.24C). Welding was performed using a gas tungsten arc welding (GTAW) process.

Microscopic examinations of the structure of both steels were conducted. The as-received Russian steel was found to be in the annealed state. Only the fusion zone and the base metal were observed in the welded Russian steel. No visible heat affected zone was observed. Examination revealed that the as-received U.S. steel was in the cold rolled condition. after welding, a fusion zone and a heat affected zone along with the base metal region were found.

Microhardness data indicated only a small change in the hardness from the fusion zone to the base metal of the Russian steel. The hardness profile of the U.S. steel was that of a typical cold worked metal that was welded and then fast cooled. the hardness in the heat affected zone was slightly lower than that of the fusion zone and of the base metal. Weld bend tests were conducted on both of the welded steels. Both steels had excellent toughness and ductility, because no cracks or failure were found during the initial or final bending tests.

Strength data of the Russian steel indicated no loss of strength during welding. A weak interface between the fusion zone and the base metal of the weld was not found. The steel failed randomly in either the fusion zone or in the base metal. The U.S. steel showed a decrease in strength as a result of welding. The strength of the fusion zone and the heat affected zone were almost equal but were much less than the strength of the base metal. All welded U.S. steels failed randomly, either in the fusion zone or in the heat affected zone. The strength properties of the U.S. steel were governed by the properties of the weld because the initial condition was cold rolled.

Fracture surfaces were examined in both steels. Only necking, equiaxed dimples and a $45^{\circ}$ shear lip, which are all typical of ductile failure, were observed in the original and welded Russtan steel. Also, ductile fracture dominated in the original and welded U.S. steel.
\end{abstract}


THE PROPERTIES AND WELDABILITY OF MATERIALS FOR

FUSION REACTOR APPLICATIONS

\section{INTRODUCTION}

Several criteria have been proposed and discussed for the development of first wall and blanket materials of tokamak fusion reactor. Lowactivation $\mathrm{Fe}-\mathrm{Cr}-\mathrm{Mn}-\mathrm{C}$ steels are being developed for possible use in this reactor. One of the requirements is sound joining. Welding is an important method for fabricating engineering alloys into structural components [1].

Therefore, the objective of this study was to characterize the welded microstructure and mechanical properties of two $\mathrm{Fe}-\mathrm{Cr}-\mathrm{Mn}-\mathrm{C}$ steels. In order to explore the weldability of these steels, the structure and properties of autogenous bead-on-plate welds produced using the gas tungsten arc welding (GTAW) process was evaluated. Microhardness, weld bend and tensile test were performed for the base metal, the heat affected zone and the fusion zone of the welded materials.

\section{EXFERIMENTAL PROCEDURES}

\section{Materials Choice and Sample Prefiaration}

Two austenitic stainless steels, a Russian steel (Fe-12Cr-19Mn$0.081 \mathrm{C})$ and an U.S. steel (Fe-12Cr-19Mn-.24C) were investigated in this study. These steels, prepared by Combustion Engineering, Inc, were received from Oak Ridge National Laboratory (ORNL). The as-received stainless plates were sheets $0.76 \mathrm{~mm}$ thick. Table 1 shows the composition of the as-received Russian and U.S. steels. 


\section{Welding Process}

Autogenous bead-on-plate welds were produced using the gas tungsten arc welding (GTAW) process. The bead-on-plate welds were used to evaluate the weldability of the two steels. The welding power supply was a Miller Synchrowave $500 \mathrm{AC} / \mathrm{DC}$ welding power source which was manufactured by the Miller Electric MFG. Co., Appleton, WI. Table 2 shows the settings of the welding power supply which were used in this study. These conditions were used in a similar study [2]. The water-cooled welding torch was manipulated using a Heath Engineering Company ESAB X-Y positioning table, model No. MCD/600-MODFD, controlled by a ECT-150 Tracing Control System, manufactured by Steward-Warner Electronics, Chicago, IL. The electrodes used were $1.59 \mathrm{~mm}$ ( $1 / 16$ inch) diameter, 28 thoriated tungsten.

Before welding, the plates were cleaned with acetone to remove any surface contamination and all edges were machined. Welds were produced under a fully constrained condition. The weld plates were laterally constrained by two pieces of $11 \mathrm{~mm}$ square plain carbon steel bars. This constrain was used to simulate the restraint condition encountered in the maintenance and repair of structural components. In order to initiate and terminate the arc, two pieces of plate (start and runoff tabs) were placed in front and in the rear of the weld plates so a uniform weld could be obtained over the entire plate lengths. To reduce oxidation, welding was performed within a plexiglass chamber with an argon atmosphere.

A welding voltage of $10 \mathrm{~V}-\mathrm{DC}$ and a current of $38 \mathrm{~A}$ were used to obtain full weld penetration of the plates. Two torch travel speeds of 3.8 and $4.7 \mathrm{~mm} / \mathrm{sec}$ along with an argon gas flow of $20 \mathrm{cu} . \mathrm{ft} / \mathrm{hr}$ from the torch and $10 \mathrm{cu} . \mathrm{ft} / \mathrm{hr}$ from the bottom of the plexiglass chamber were used. 
Table 3 summarizes the welding conditions used in this study. The welding heat input, defined by the voltage multiplied by the current divided by the torch travel speed, was $82.6 \mathrm{~J} / \mathrm{mm}$. A full penetration weld with approximately a $2.5 \mathrm{~mm}$ fusion zone was obtained.

\section{Microstructure Characterization}

The welded plates were sectioned into $43 \mathrm{~mm} \times 8 \mathrm{~mm} \times 0.76 \mathrm{~mm}$ specimens. The long dimension of the samples were transverse to the welding direction. This size sample included all structural features of the weld (fusion zone, heat affected zone and base metal) for microstructure and microhardness characterizations. Specimens were hotmounted in phenolic powder followed by mechanical grinding, using silicon carbide grinding papers down to 4000 grit. For final polishing, a 0.05 micron alpha alumina mixed with distilled water was used. The etching solution used in this investigation contained one part $\mathrm{HNO}_{3}$, two parts $\mathrm{HF}$ and three parts glycerin [2]. A MC-63 Ziess Optical Microscope and a JOEL 840 Scanning Electron microscope (SEM) were used for microstructural examination.

To investigate the composition of the phases present and to determine the structure of the two Fe-Cr-Mn-C steels, a Rigaku D/MaxB X-ray Diffractometer was used. Both as-received and welded specimens were studied. Welded specimens of these steels were etched using a solution of one part of $\mathrm{HNO}_{3}$, two parts of $\mathrm{HF}$ and three parts of glycerin to study the precipitate distribution in both the fusion zone and the base metal [2].

A JOEL 840 scanning electron microscope (SEM) equipped with an Energy Dispersive X-ray Spectrometer (EDX) was used to study the composition within the grains and to help identify phases in the samples. 
Also, a JEOL 1200 scanning transmission electron microscopy (STEM) equipped with EDX was used to study the composition and structure of phases present at the grain boundaries. For STEM specimens, the sheets of Fe-Mn-Cr-C steels were cold-mounted and polished to the thickness approximately $0.25 \mathrm{~mm}(10 \mathrm{mils})$. For further jet thinning, three millimeter diameter discs were punched from the $0.25 \mathrm{~mm}$ thick sheets. A commercial jet polisher was used to polish the discs until perforation occurred. Jet electropolishing was accomplished using an electrolyte of $108 \mathrm{HClO}_{4}, 908 \mathrm{CH}_{3} \mathrm{COOH}$ and $20 \mathrm{~g} / 1 \mathrm{CrO}_{3}$ at $25^{\circ} \mathrm{C}$ and $30 \mathrm{~V}$ for about 2 minutes.

\section{Mechanical Testing}

To determine the hardness of the individual phases and to aid phase identification, diamond pyramid microhardness (DPH) measurements were conducted across the weld regions, using a LECO DM-400 Hardness Tester. The hardness tests were performed using a load of 50 or 100 grams (depending on the indentation size) for a duration of 10 seconds. Hardness measurements were made $0.1 \mathrm{~mm}$ apart to minimize the effect of strain hardening caused by neighboring indentations. Measurements close to external surfaces also were a minimum of $0.1 \mathrm{~mm}$ away from the surface to avoid edge effects.

Tensile test specimens were fabricated by punching in a die at ORNL. Specimens were punched perpendicular to the weld and had a reduced gage section of $12.7 \mathrm{~mm}$ long by $3.175 \mathrm{~mm}$ wide (Figure 1) [3]. An Instron Mechanical Testing Machine using cross head speed of $0.508 \mathrm{~mm} / \mathrm{minute}$ was used to evaluate the tensile properties [3]. The 0.28 offset yield 
strength and the ultimate tensile strength were evaluated in all tensile tests.

A three-point guide-bend test was used as an index to evaluate the weld soundness. Specimens used in this test had dimensions of $43 \mathrm{~mm} \times 8$ $\mathrm{mm} \times 0.76 \mathrm{~mm}$. Figure 2 shows the setups for the initial and the final bending tests [2]. The initial three-point bend test (Figure 2a) was performed on a model 1125 Instron Machine, equipped with a screw-driven crosshead. A plunger head was pushed against the fusion zone of the welded specimens to produce an angle of approximately $100^{\circ}$ between the specimen ends. The crosshead had a travel speed of $0.508 \mathrm{~mm} / \mathrm{min}$ and the supporting span distance was $20 \mathrm{~mm}$. After the initial bend specimens were placed in a vise for final bending (Figure 2b). A $1.5 \mathrm{~mm}$ thick space bar was placed between the two ends of the specimen. During the test, special care was taken so that the load on both ends of the specimen maintained a symmetrical loading distribution in the fusion zone. Testing continued until the specimen broke into two pieces or laterally contacted with the space bar (i.e. a $180^{\circ}$ bend).

A JOEL 840 Scanning Electron microscope (SEM) was used to investigate fracture morphology and deformation of the weld bend test sperimens. All the observations were conducted using accelerating voltage of $20 \mathrm{kV}$. 
Table 1. Composition of the As-Received Russian and U.S. Steels.

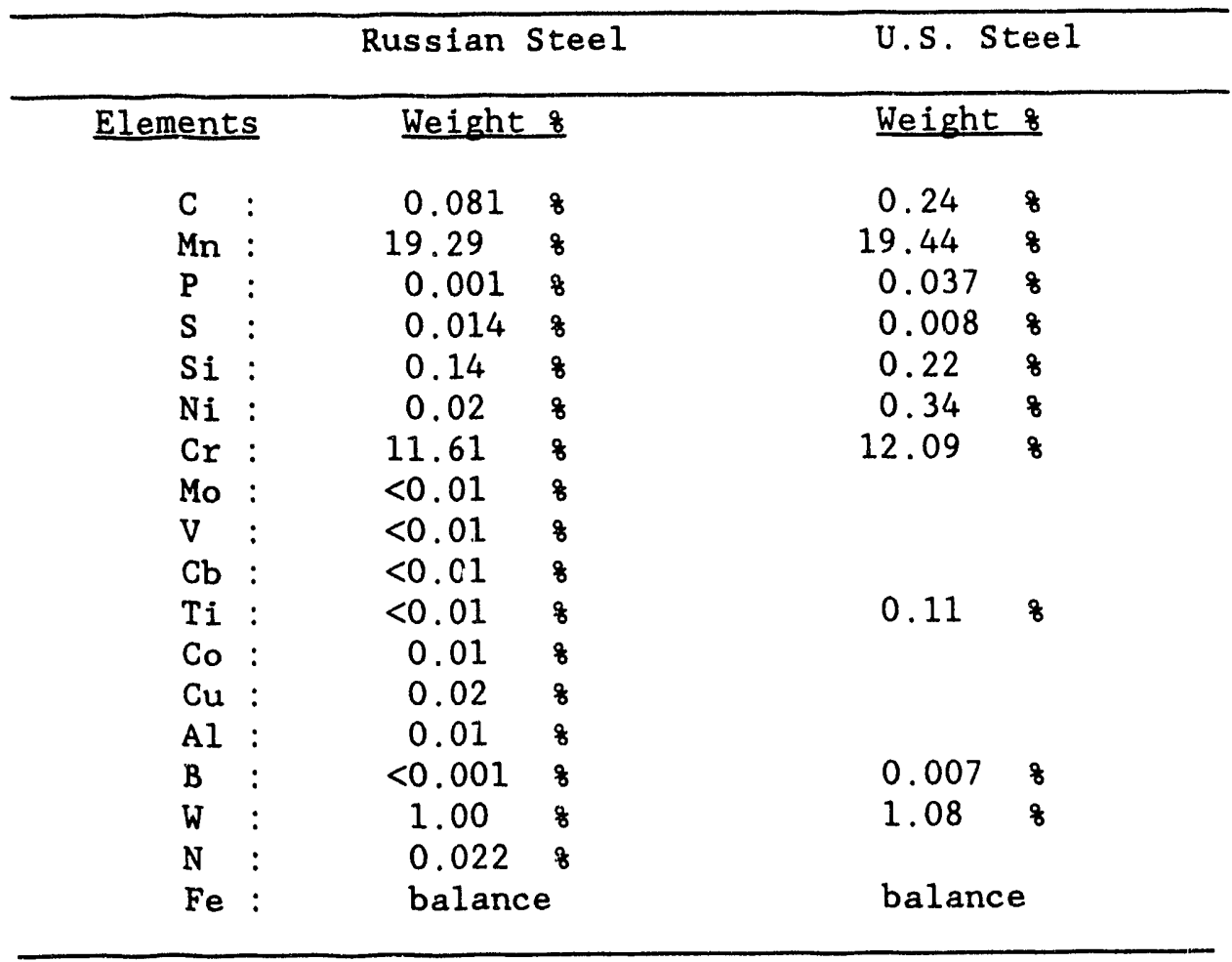


Table 2. Welding Power Supply Settings [2].

\begin{tabular}{ll} 
1. Contractor & Remote \\
2. Current & Remote \\
3. Hi Frequency & On \\
4. Crater Fill & Out \\
5. Start Current & On, 1 A \\
6. AC Balance & Balanced \\
7. Post Flow Time & 6 Second \\
8. Polarity & DC, Straight \\
9. Pulser & Out \\
\hline
\end{tabular}


Table 3. Welding Conditions for Full Penetration ivelding [2].

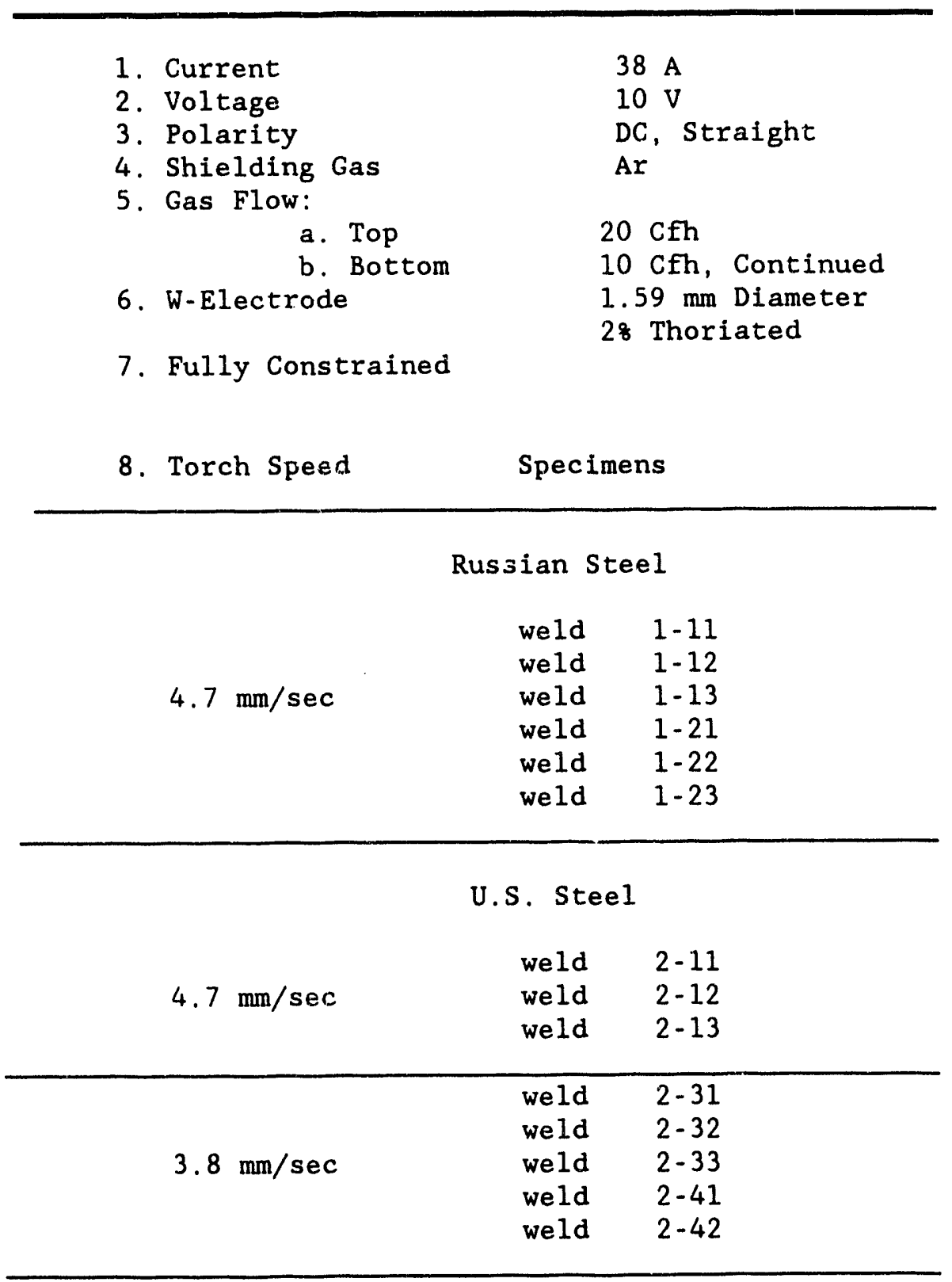




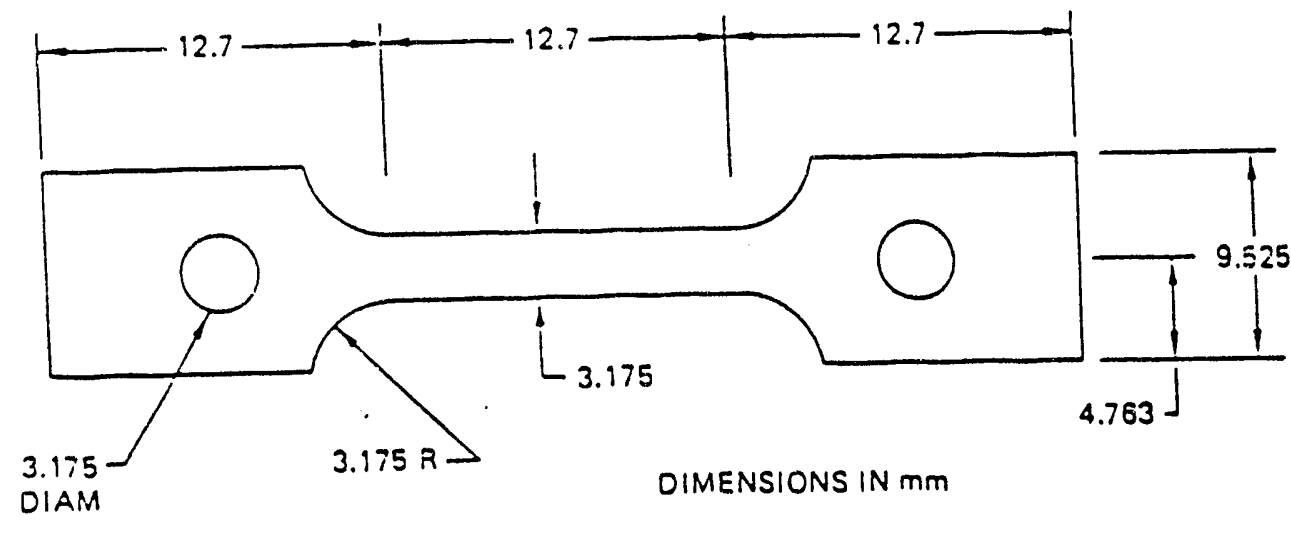

Figure 1. Tensile test specimen. 

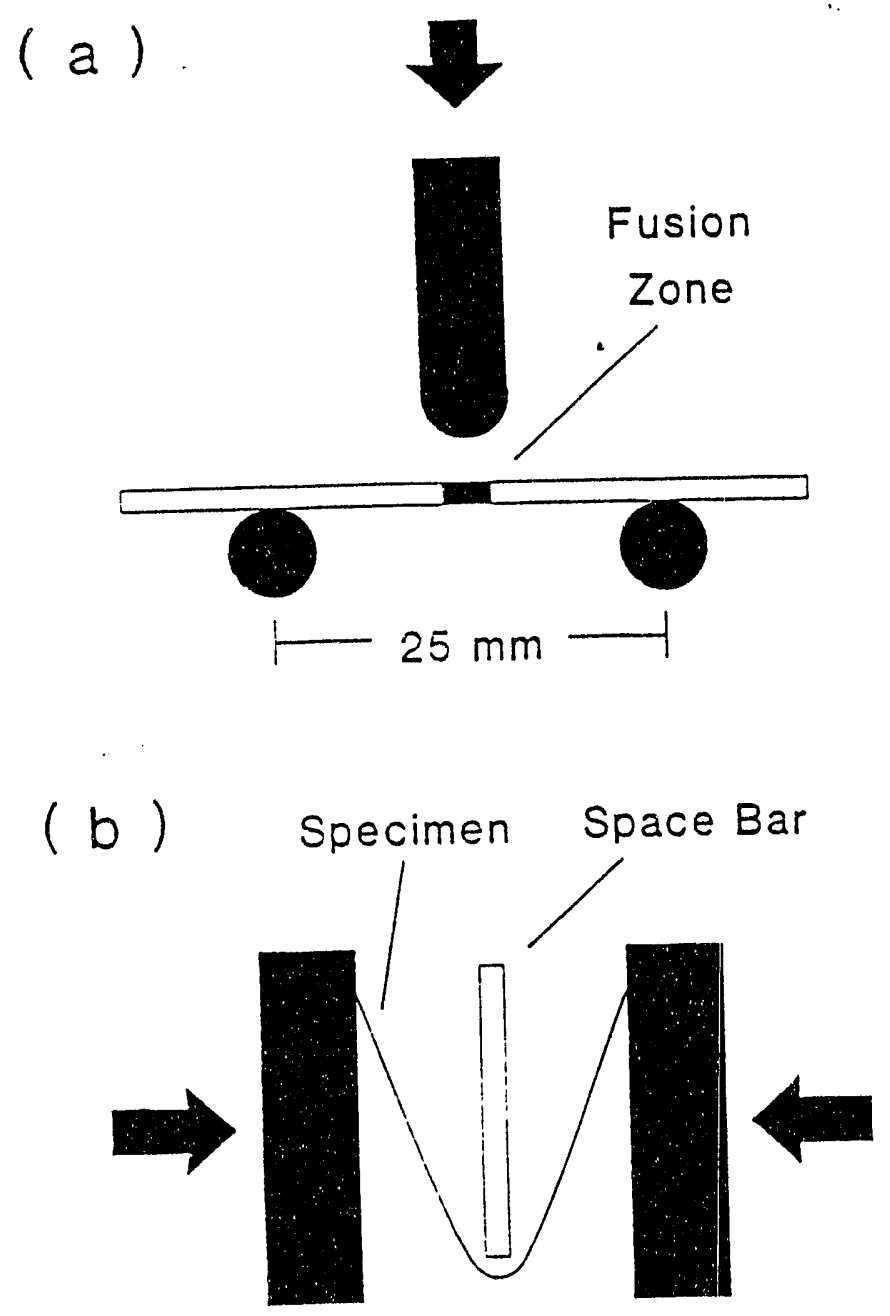

Figure 2. Configurations of the weld-bend test: (a) Initial bend; (b) Final bend (after Chin-An Wang, "Weldability of Low Activation Ferritic Steels for Fusion Reactor Applications", [2]) 


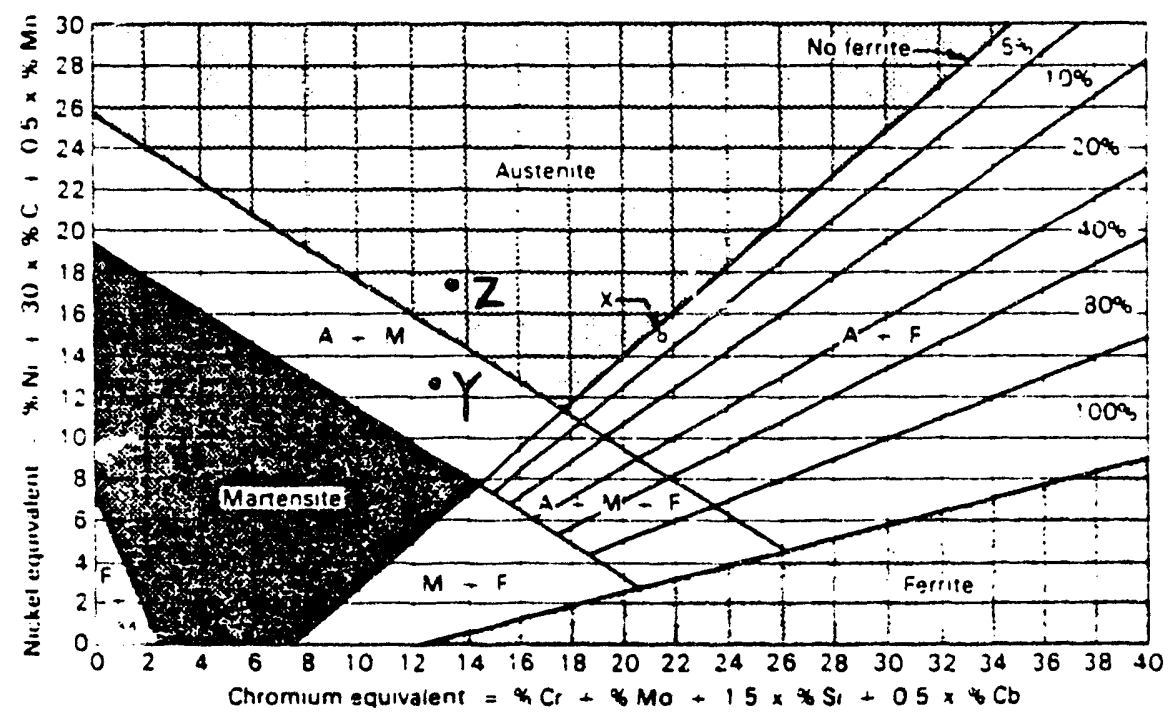

Figure 3. Schaeffler diagram for estimating ferrite content from composition (after R.A. Lula, "Stainless Steel", [4]) 
RESULT AND DISCUSSION

Microstructure And Phase Identification

The structures of the as-received Russian steel and the U.S. steel were tentatively determined by use of the Schaeffler diagram (Figure 3) [4]. Table 1 listed the composition of the as-received steels. Both steels are fast induced-radioactivity decay (FIRD) austenitic steels. Manganese was added to these steels to replace the high-nickel content of stainless steels used in fusion applications [5]. The chromium equivalent has been empirically determined using the most common ferrite-forming elements [6]:

$$
\begin{array}{r}
\mathrm{Cr}_{\text {oq }}=(\mathrm{Cr})+2(\mathrm{Si})+1.5(\mathrm{Mo})+5(\mathrm{~V})+5.5(\mathrm{Al})+1.75(\mathrm{Nb}) \\
+1.5(\mathrm{Ti})+0.75(\mathrm{~W})
\end{array}
$$

while the nickel equivalent has likewise been determined with the familiar austenite forming elements [6]:

$$
\left.\mathrm{Ni}_{\mathrm{eq}}=(\mathrm{Ni})+(\mathrm{Co})+0.5(\mathrm{Mn})+\right) .3(\mathrm{Cu})+25(\mathrm{~N})+30(\mathrm{C}) .
$$

All concentrations in these two equations are expressed in weight percent. The as-received Russian steel had a $\mathrm{Cr}$ equivalent of 12.7 and a $\mathrm{Ni}$ equivalent of 12.67 using equations (1) and (2). Theoretically, from the Schaeffler diagram (point $Y$ in Figure 3), the as-received Russian steel was expected to be compose of austenite and martensite. Actually, from the experimental results, the steel consisted of all austenite and no martensite. The as-received U.S. steel had a $\mathrm{Cr}$ equivalent of 13.51 and the $\mathrm{Ni}$ equivalent of 17.26. From the Schaeffler diagram (point $\mathrm{Z}$ in Figure 3), the structure of the as-received U.S. steel was expected to be austenite. Also, the experimental results showed that only austenite was present. 
Figure 4 shows the microstructure of the as-received Russian steel both parallel and perpendicular to the rolling direction. Only large equiaxed grains were observed, therefore, the as-received steel was in the annealed condition and not in a cold-worked state. Also, only deep etching was observed with no preferential grain boundary attack. This suggested that the steel was quenched after annealing.

Figure 5 shows the microstructure of the as-received U.S. steel both parallel and perpendicular to the rolling direction. The elongated grains in Figure $5 a$ indicated that a preferred orientation had been developed in the rolling direction. Figure 5b shows equiaxed grains perpendicular to the rolling direction. This indicated that the as-received U.S. steel had been cold-worked. Figure 5 also shows that the grain boundaries had been favorably attacked by the etchant. This preferential attack signified that this steel likely had a second phase at the grain boundaries.

The Fe-Cr-Mn-C steels were welded using gas-tungsten arc welding techniques. Figures 6 and 7 show the as-welded microstructures of the U.S. and the Russian steels, respectively. Figure 6 shows three distinct regions in the U.S. steel: the fusion zone, the heat-affected zone (grain growth and grain refined regions), and the unaffected base metal. The maximum grain size in the heat affected zone always occurred adjacent to the fusion zone, because the highest temperature was reached at this point [7]. Therefore, within the heat affected zone, the grain size increased steadily from the base metal region to the weld interface.

Figure 7 shows only the fusion zone and the base metal for the Russian steel. The Russian steel was received in the annealed and quenched condition, and thus, the thermal cycle beyond the weld fusion 
zone did not change the grain size or microstructure of the base metal. Figure 7 shows no visible heat affected zone in the welded Russian steel.

To investigate the composition distribution of the as-received and the welded Fe-Cr-Mn-C steels a scanning electron microscope equipped with an Energy Dispersive X-ray Spectrometer (EDX) was used. Also a JEOL 1200 scanning transmission electron microscope (STEM) equipped with EDX was used. Figures 8 and 9 show typical EDX spectra and quantitative composition analysis of $\mathrm{Fe}, \mathrm{Cr}$ and $\mathrm{Mn}$ for the as-received Russian steel and the U.S. steel, respectively. Figure 8 is a $x$-ray spectrum from an area $30 \mathrm{~nm}$ by $40 \mathrm{~nm}$ of the as-received Russian steel. Figure 8 contains three elemental major peaks ( $\mathrm{Fe}, \mathrm{Mn}$ and $\mathrm{Cr}$ ) giving the quantitative analysis of $66.318 \mathrm{Fe}, 21.28 \mathrm{Mn}$, and $12.488 \mathrm{Cr}$. This composition closely corresponded to the accepted values of the as-received Russian steel. The EDX spectrum in Figure 9 shows a position in the U.S. steel with a relatively high amount of $\mathrm{Mn}$ (30.09 wtz) and $\mathrm{Cr}$ (18.49 wtz), and a lower amount of $\mathrm{Fe}$ (51.43 wtz).

Figures 10 and 11 give a summary of the quantitative composition analysis of the as-received Russian steel and U.S. steel, respectively. Each point is a test was from an area of $30 \mathrm{~nm}$ by $40 \mathrm{~nm}$. No composition change occurred in the as-received Russian steel (Figure 10). For this steel, the average value for $\mathrm{Fe}$ was 66.5 wtz, 21.5 wtz for Mn and 12 wt8 for $\mathrm{Cr}$. These compositions were close to the as-received steel.

Figure 11 shows that the Mn content increased from 20 to 30 wts at positions between $30 \mu \mathrm{m}$ and $40 \mu \mathrm{m}$, and between 75 and $80 \mu \mathrm{m}$ from the reference point $(0 \mu \mathrm{m})$ of the as-received U.S. Steel. Also, at the same positions, the $\mathrm{Cr}$ content increased from 13 to 18 wto; while, the Fe 
content decreased from 67 to $52 \mathrm{wtz}$. The compositional change at the position $48 \mu \mathrm{m}$ and at position $75 \mu \mathrm{m}$ (Figure 11) indicated that a second phase may exist. These data along with the microstructural examination places indicated that precipitated carbides were not present in the asreceived Russian steel. However, the compositional change in the asreceived U.S. steel indicated that some type of precipitate was present.

Figures 12 and 13 summarize the composition analysis of $\mathrm{Fe}, \mathrm{Cr}$ and $\mathrm{Mn}$ of the welded Russian and U.S. steels, respectively. Each point represents an area of $20 \mu \mathrm{m}$ by $27 \mu \mathrm{m}$. The data in Figure 12 show no composition change in either the fusion zone or the base metal of the welded Russian steel. The average composition values were 67 wt $\mathrm{Fe}, 20.5$ wtz $\mathrm{Mn}$, and 12.5 wtz $\mathrm{Cr}$, which were close to the accepted overall composition. In addition, Figure 13 shows that no composition change occurred in either the fusion zone, the heated-affected zone, or in the base metal of the welded U.S. steel. The average values in this steel were $66 \mathrm{wtz} \mathrm{Fe}, 21 \mathrm{wtz} \mathrm{Mn}$, and $1.3 \mathrm{wtz} \mathrm{Cr}$. These values also were very close to the accepted overall composition of the as-received steel. These data suggested that mass diffusion or compositional changes did not occurred during the welding of either steel.

In an effort to identify the possible grain boundary precipitate in the U.S. steel, x-ray diffraction techniques were used. Figures 14a and $15 a$ are typical $x$-ray diffraction patterns from the as-received Russian and U.S. steels, respectively. Figures $14 \mathrm{~b}, \mathrm{c}$ and $15 \mathrm{~b}, \mathrm{c}$ are diffraction patterns from the fusion zone and base metal before etching, while Figures $14 \mathrm{~d}, \mathrm{e}$ and $15 \mathrm{~d}, \mathrm{e}$ are diffraction patterns from the fusion zone and base metal of these welded steels after strong etching. 


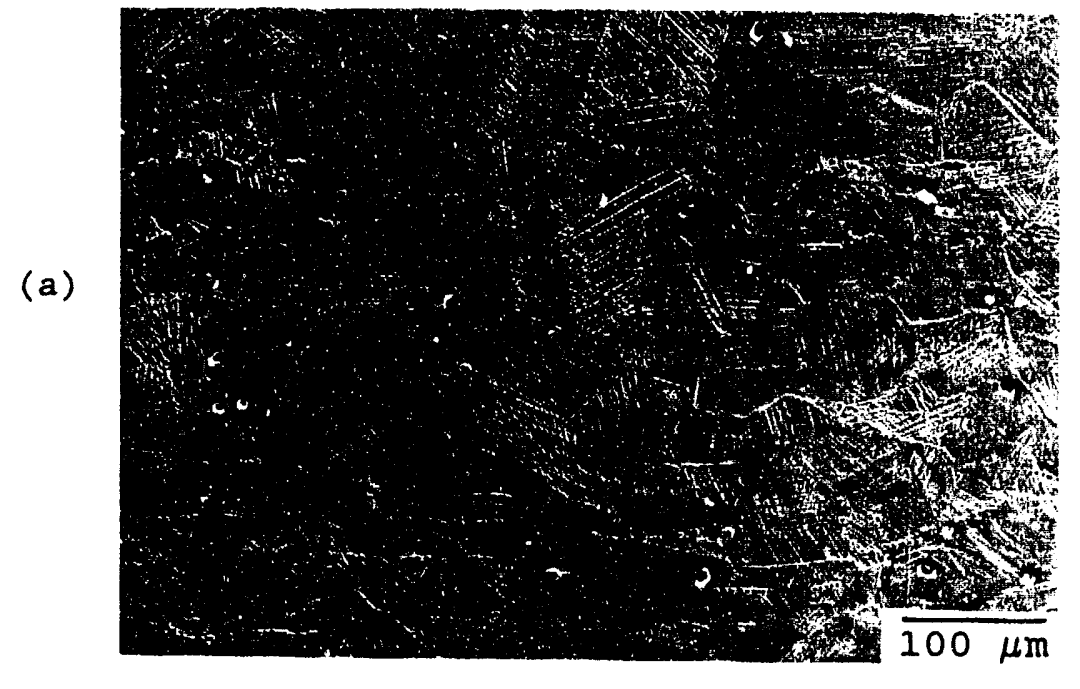

(b)

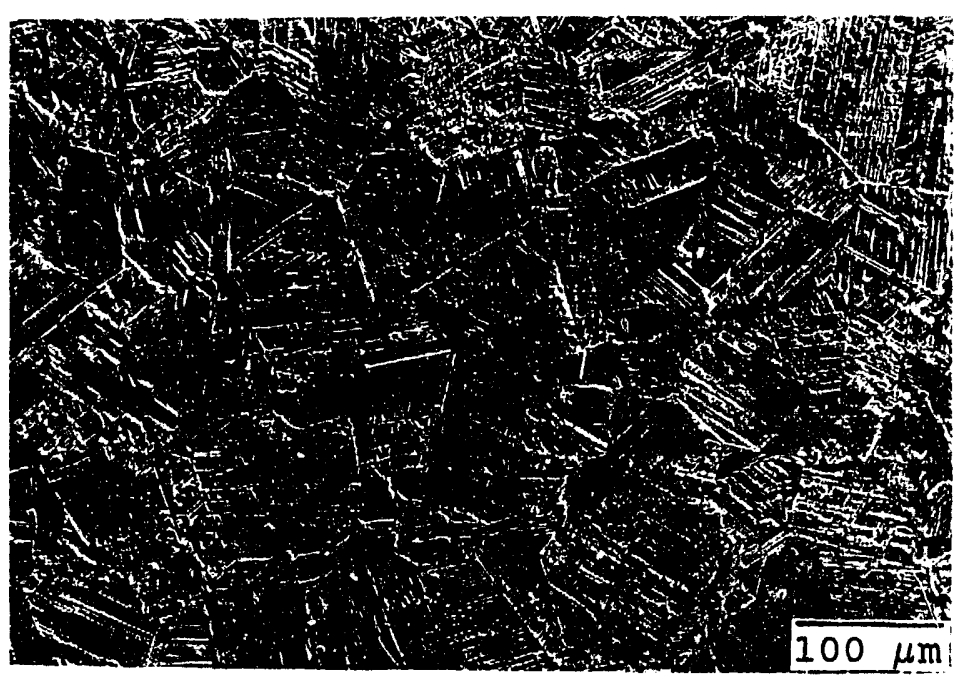

Figure 4. The microstructure of the as-received Russian steel:

(a) parallel; (b) perpendicular to the rolling direction. 
(a)

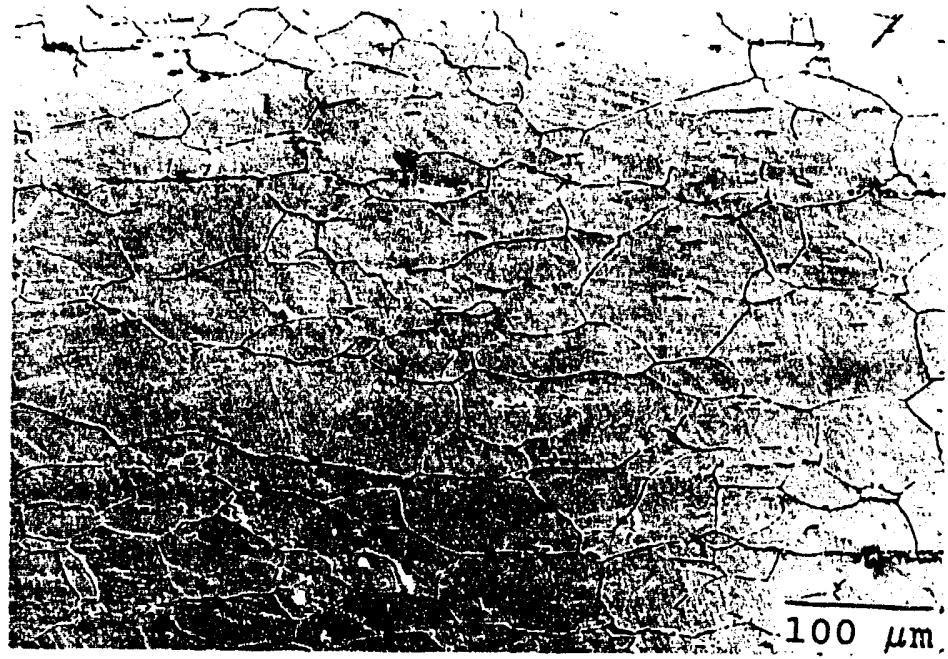

(b)

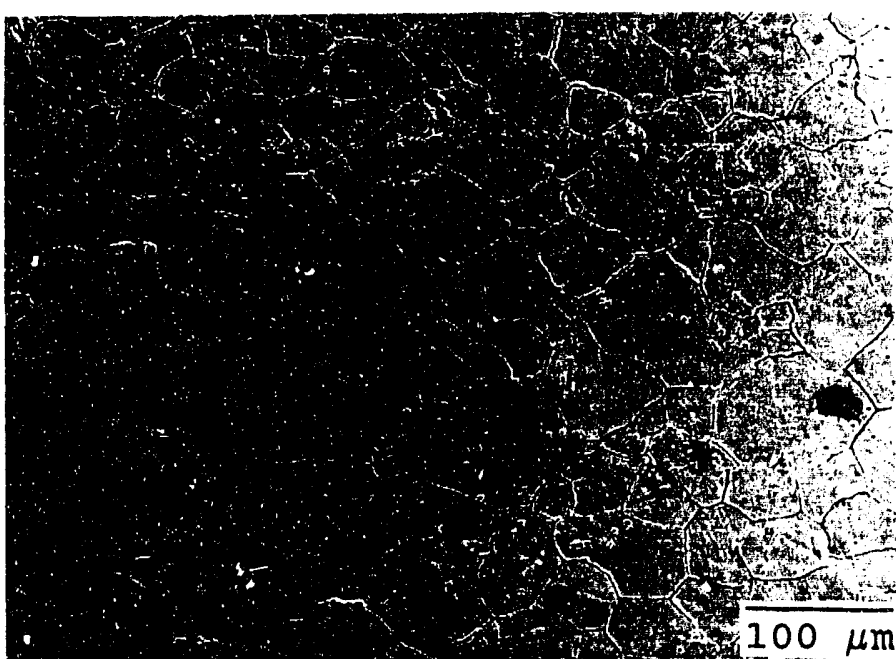

Figure 5. The microstructure of the as-received U.S. steel: (a) parallel; (b) perpendicular to the rolling direction. 


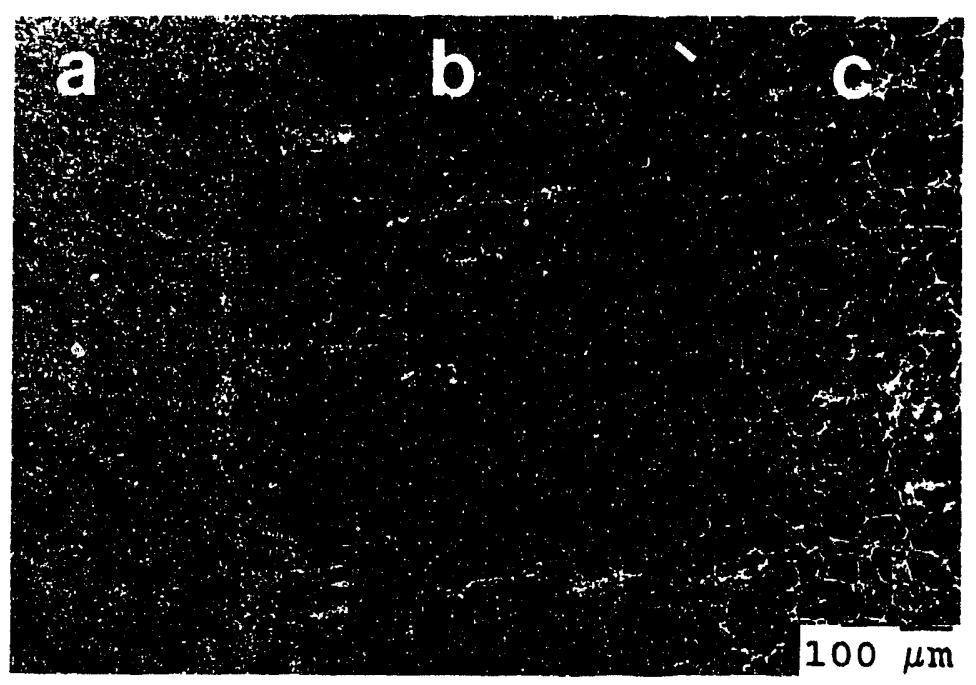

Figure 6. The microstructure of the welded U.S. steel:

(a) fusion zone; (b) heat affected zone;

(c) base metal. 


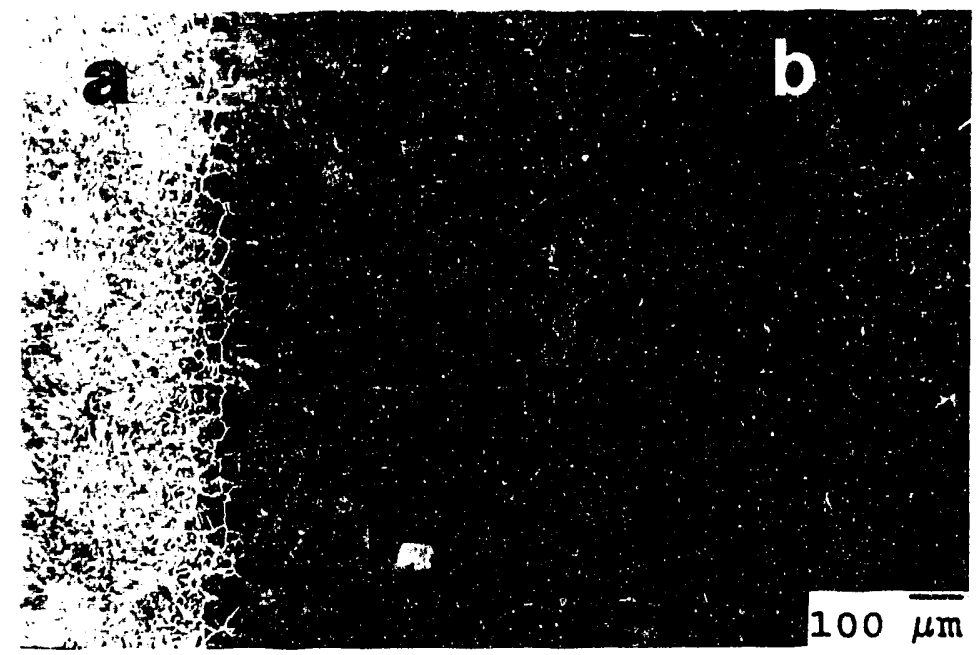

Figure 7. The microstructure of the welded Russian steel: (a) fusion zone; (b) base metal. 
$T N-\equiv E: 0$

'-ursor: D. Dakevi = 0

FOI

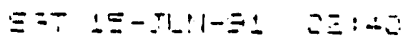

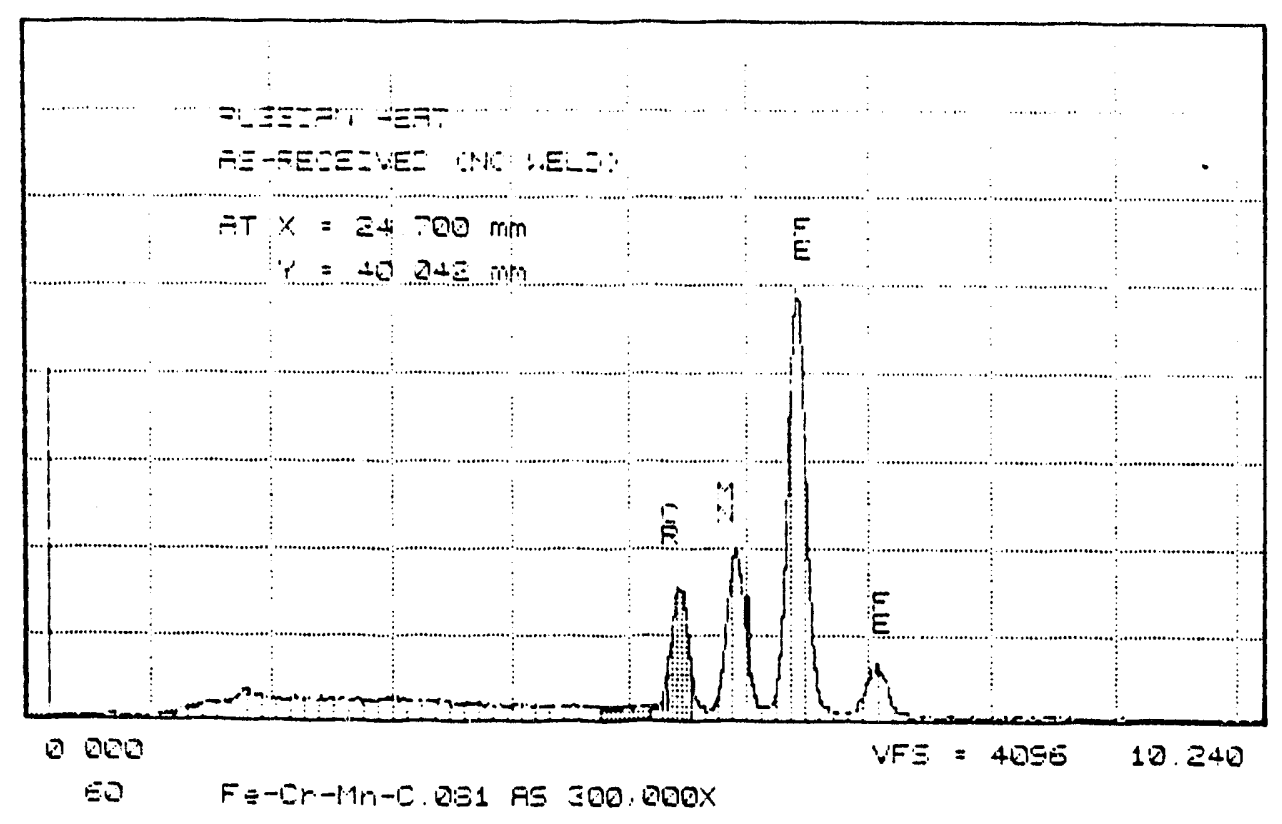

Figure 8. Typical EDX spectrum of the as-received Russian steel. 


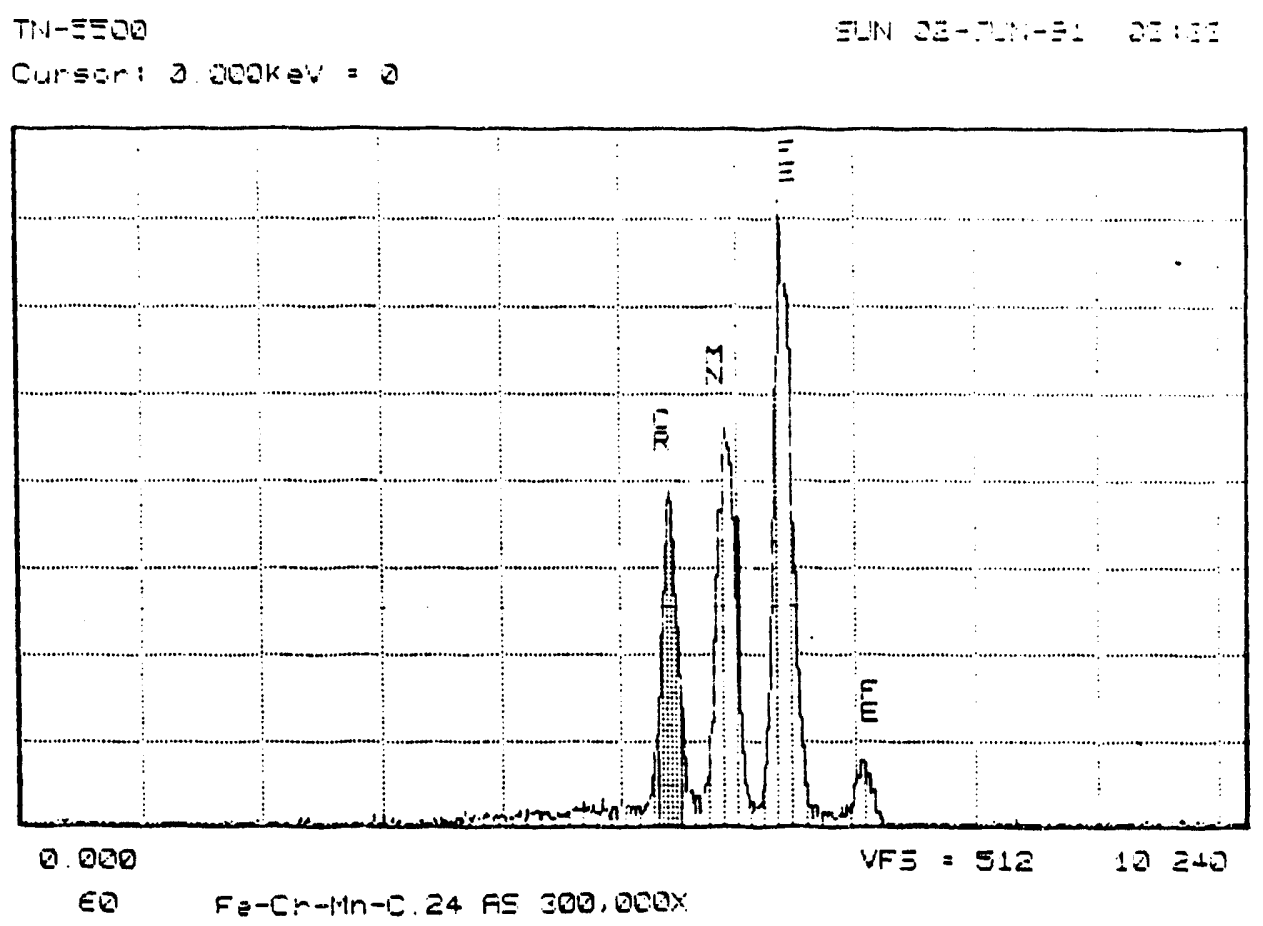

Figure 9. Typical EDX spectrum of the as-received U.S. steel. 


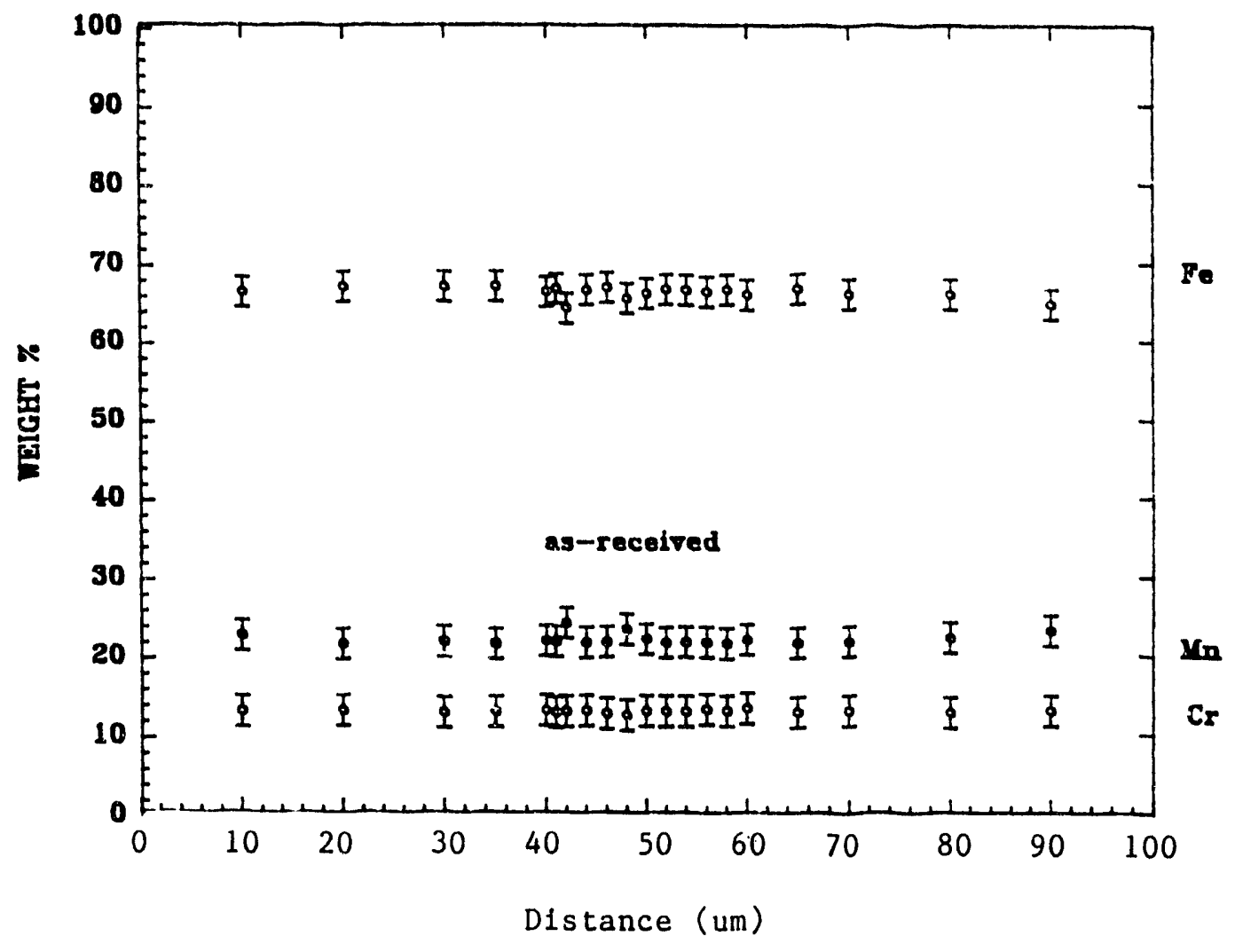

Figure 10. A sumnary EDX analysis of the as-received Russian steel. Distance is measured from an arbitrary position within the matrix. 


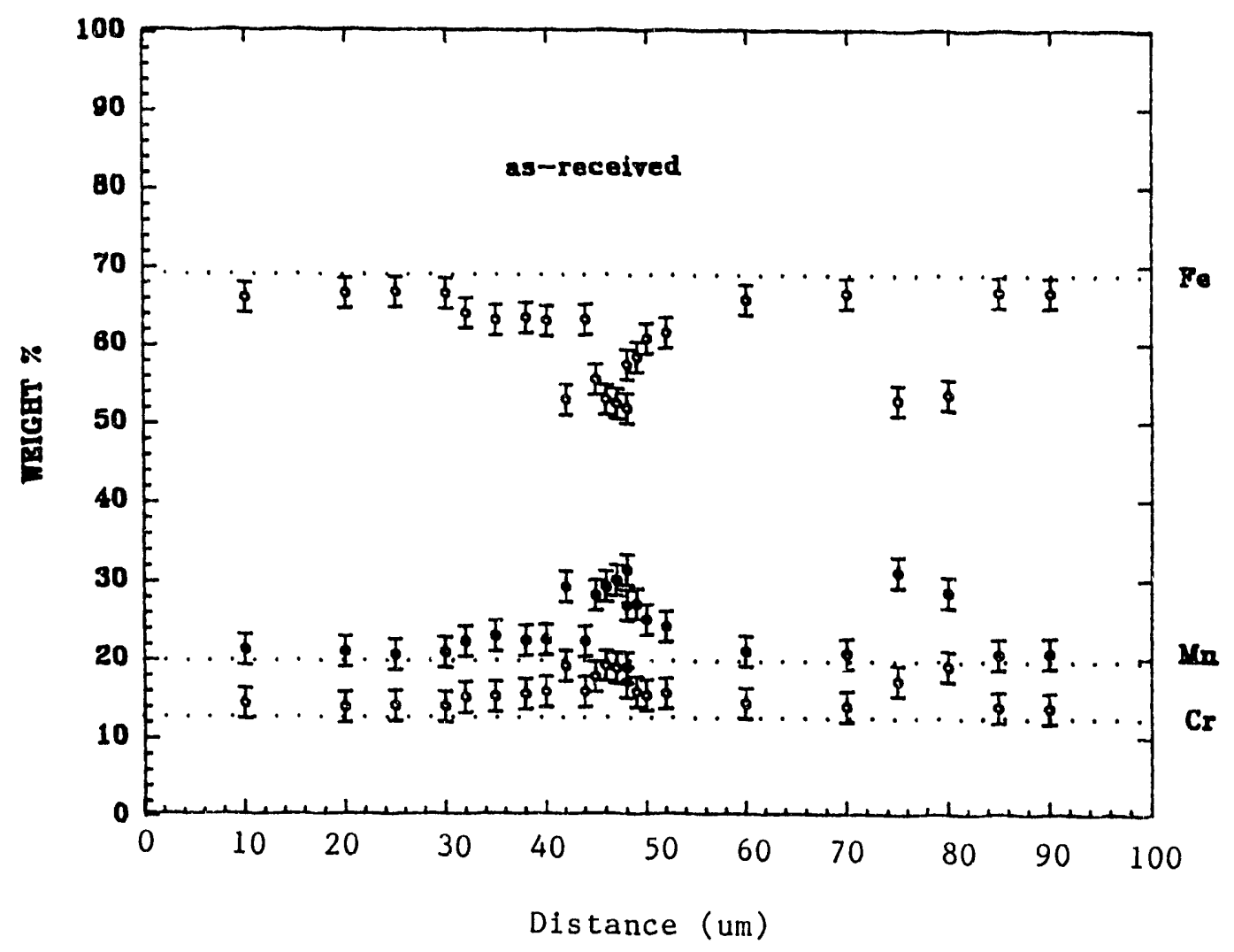

Figure 11. A summary EDX analysis of the as-received U.S. steel. Distance is measured from an arbitrary position within the matrix. 


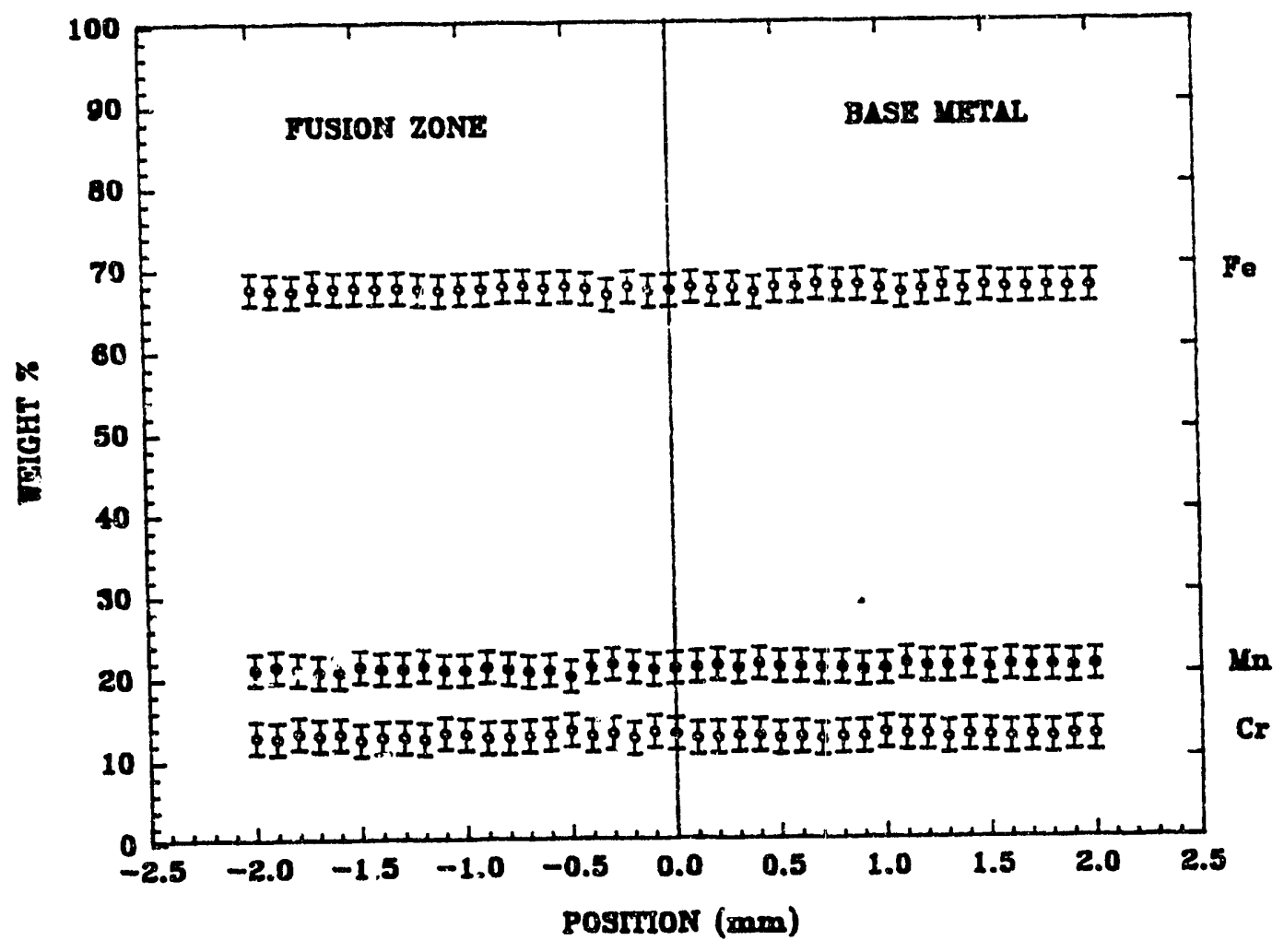

Figure 12. A summary EDX analysis of the welded Russian steel. Position is the distance measured from the fusion zone/base metal interface. 


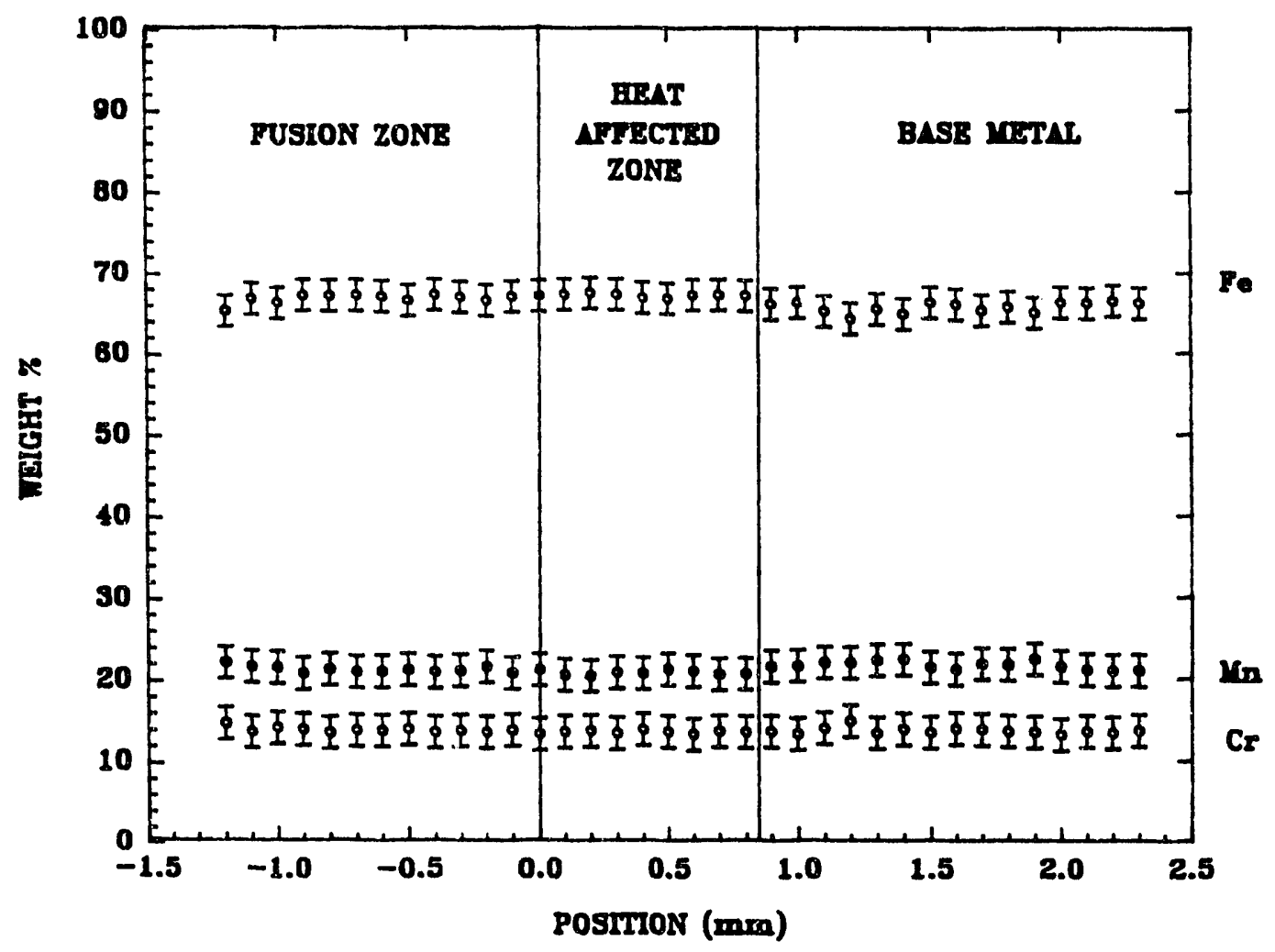

Figure 13. A summary EDX analysis of the welded U.S. steel. Position is the distance measured from the fusion zone/heat affected zone interface. 

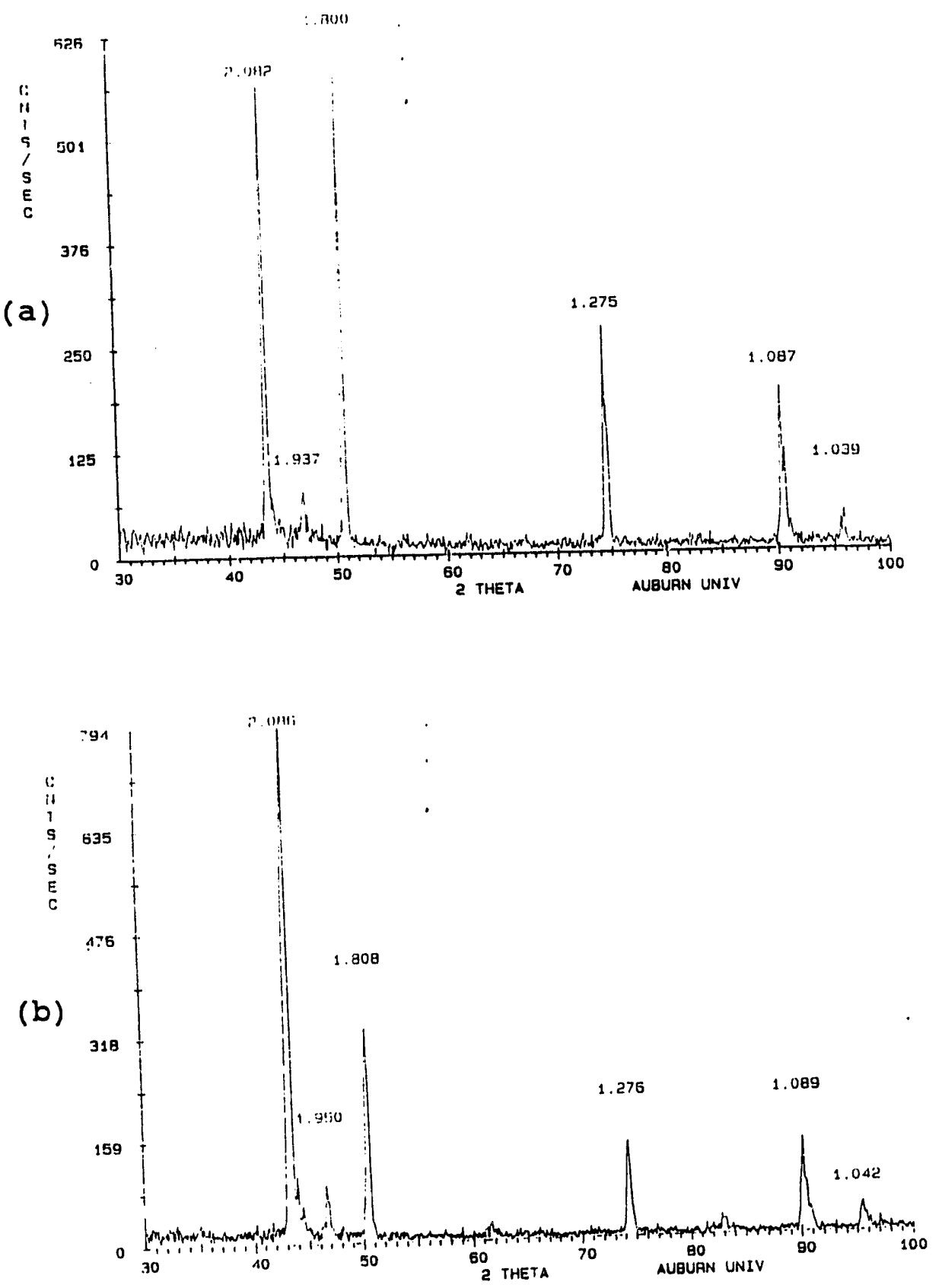

Figure 14. Typical $x$-ray diffraction patterns from the Russian steel: (a) as-received; (b) fusion zone before etching; (c) base metal before etching; (d) fusion zone after etching;

(e) base metal after etching. 

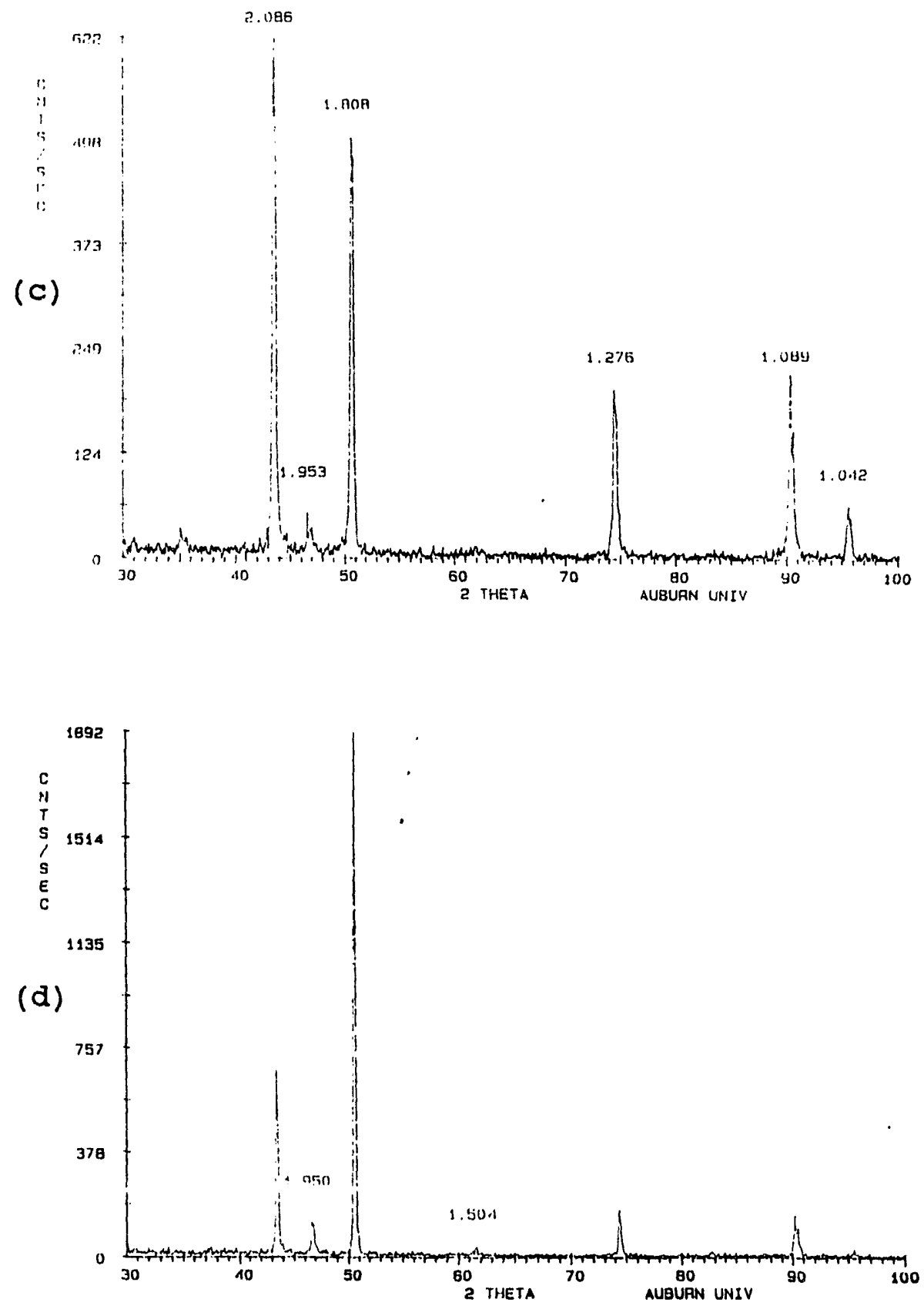

Figure 14. (Continued) 


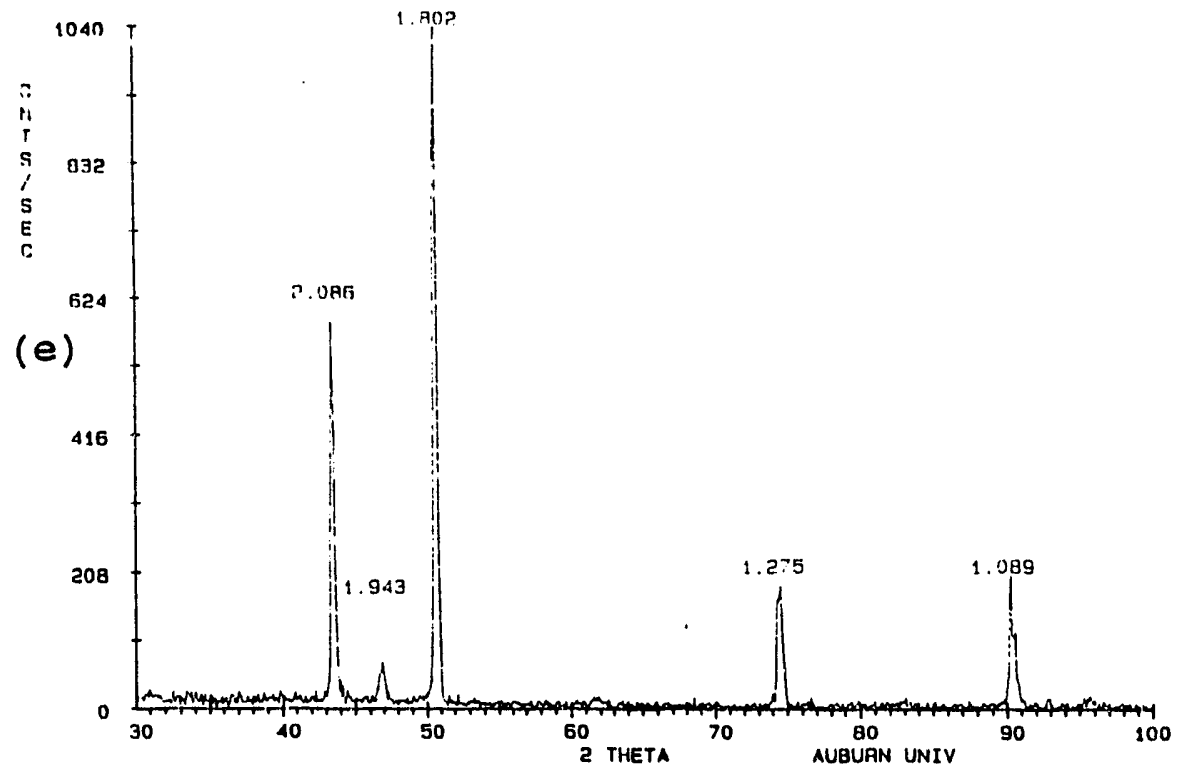

Figure 14. (Continued) 

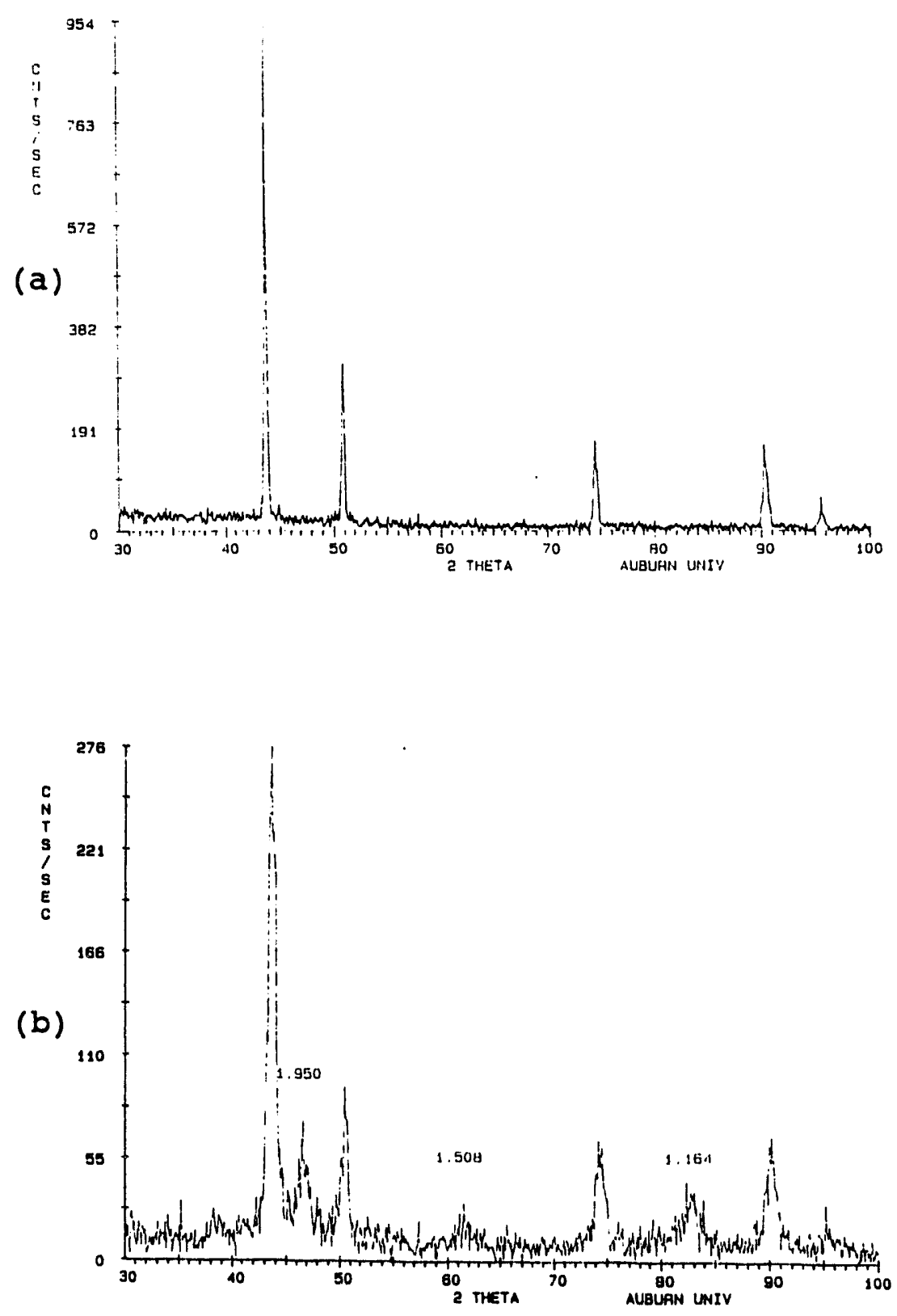

Figure 15. Typical $x$-ray diffraction patterns from the U.S. steel: (a) as-received; (b) fusion zone before etching; (c) base metal before etching; (d) fusion zone after etching;

(e) base metal after etching. 

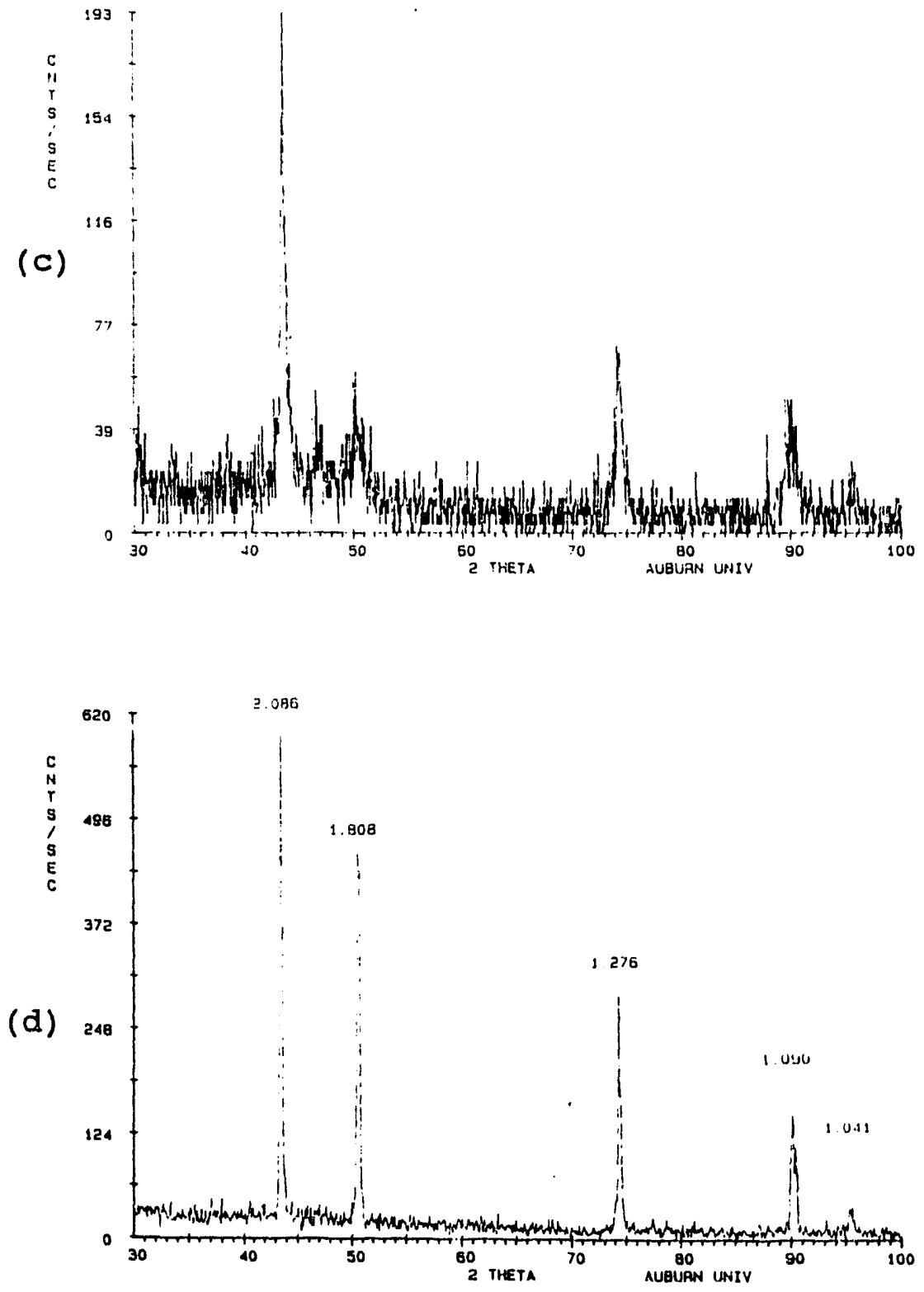

Figure 15. (Continued) 


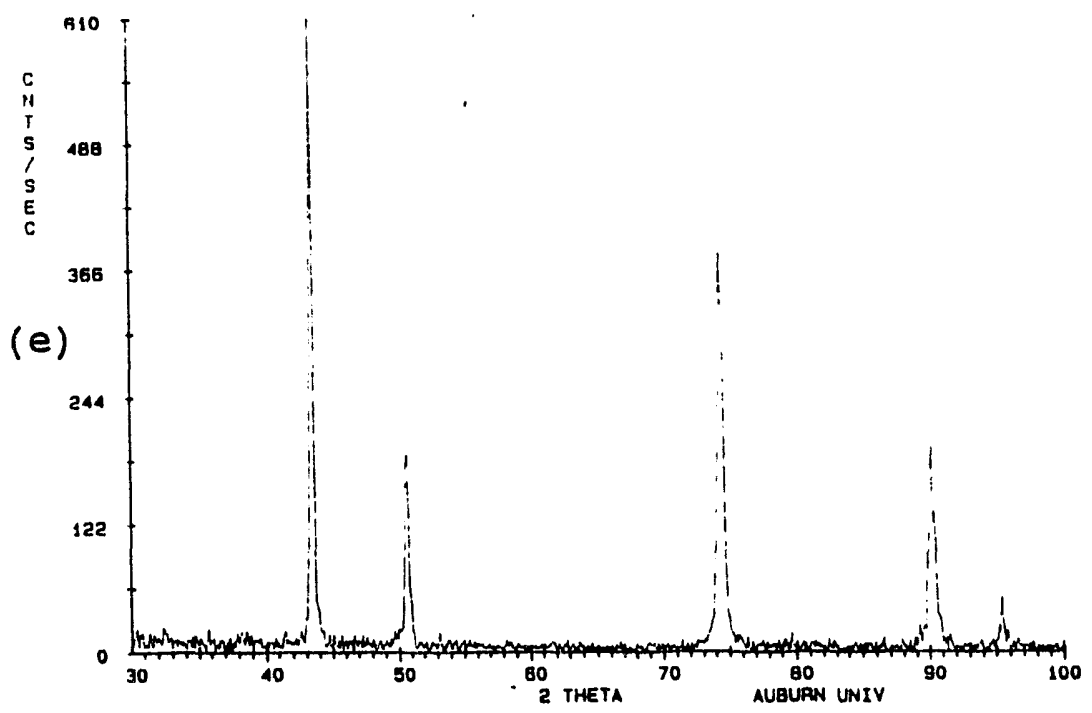

Figure 15. (Continued) 


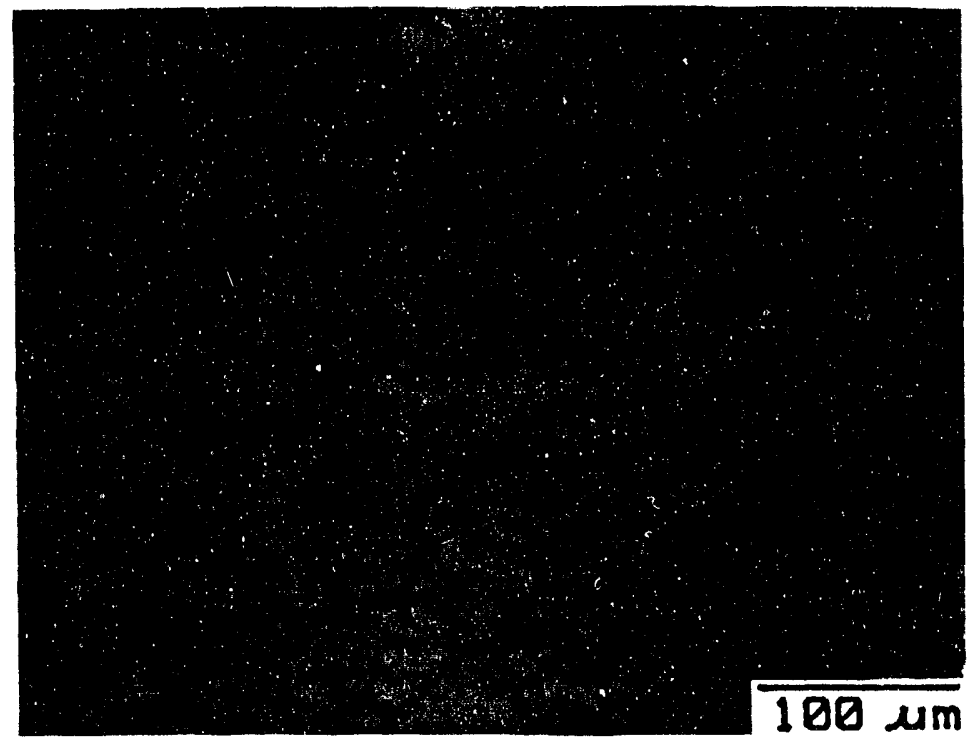

Figure 16. Optical micrograph of the as-received U.S. steel. 
In each of the different situations represented in Figure 14 (for the Russian steel) the diffraction patterns were the same. By comparing the JCPD cards and the diffraction patterns, four major peaks (2-theta at $44^{\circ}, 50^{\circ}, 74^{\circ}$ and $\left.91^{\circ}\right)$ of a face centered cubic structure $[(111),(200)$, (222), (311)] were identified. The peak at 2-theta of $47^{\circ}$ which corresponds to a d-spacing of 1.94 A suggested some fine precipitate existed, either in the grains or at the grain boundaries.

Figure 15 shows four major peaks (2-theta at $44^{\circ}, 50^{\circ}, 74^{\circ}$ and $91^{\circ}$ ) of a face centered cubic structure, and also a peak ( 2 -theta at $47^{\circ}$ ) corresponding to the d-spacing of $1.95 \mathrm{~A}$. This latter peak was observed in the as-received (Figure 15a) and the unetched welded base metal (Figure 15b) of the U.S. steel. Figure 15 also shows that only four major peaks (2-theta at $44^{\circ}, 50^{\circ}, 74^{\circ}$ and $\left.91^{\circ}\right)$ for a face centered cubic structure were observed in the unetched fusion zone (Figure 15c), the etched base metal (Figure 15d) and the etched fusion zone (Figure 15e). Additionally, the use of optical microscopy, along with the results from figure 15 indicated that a precipitate or second phase existed at the grain boundaries in the as-received austenitic U.S. steel and was preferentially attacked by the etchant. This second phase did not form in the fusion zone which was cooled quickly after welding preventing precipitation reactions.

The scanning electron micrographs in Figure 5 and 6 indicate that an unidentified "second" phase was present at the grain boundaries of the U.S. steel. This "second" phase was present before and after welding. To resolve the question as to the identity of this "second" phase further analyses were made. First, a microprobe analyses were conduced at Oak 
Ridge National Laboratory. Several analyses were made of the matrix and of the grain boundaries. A small increase in the amount of carbon present at the grain boundaries was the only noticeable different between the two regions.

Second, to determine if the original etchant used in metallographic preparation of the steels may have produced a type of artifact, a different etchant was tried. The as-received material was etched electrolytically using a 108 chromic acid solution. An optical microscopy study revealed a structure very similar to that reported [8] for this same alloy. As a result of both the microprobe analysis and the optical microscopy study, the grain boundary phase was considered to be a carbide as reported previously [8].

\section{Mechanical Properties}

Vickers Hardness measurements were made on all samples to obtain information relating to wear resistance and to aid in phase identification. Figure 17 shows the microhardness in the fusion zone and in the base metal of the Russian steel. Only a small change occurred in the microhardness from the fusion zone (332 VHN) to the base metal (309 VHN).

Figure 18 shows the microhardness in the fusion zone, the heat affected zone, and the base metal of the U.S. steel. The hardness of the heat-affected zone (259 VHN) was slightly lower than that of the fusion zone (280 VHN) and the base metal (267 VHN). The lowest hardness (242 VHN) was observed in the heat affected zone adjacent to the fusion zone. The hardness then increased slightly through the heat-affected zone to the 
interface adjacent to the base metal (268 VHN). The loss in hardness was due to recrystallization and grain growth in the heat-affected area. This hardness profile is typical of cold-worked metals that have been welded and then cooled quickly [9].

The FCC austenitic stainless steels have excellent ductility, formability, and corrosion resistance. Strength is obtained by extensive solid solution strengthening. Austenitic stainless steels also may be cold-worked to higher strengths than the ferritic stainless steels [9].

Tables 4 and 5 contain tensile data such as yield strengths, ultimate tensile strengths, and elongations for the two Fe-Cr-Mn-C steels tested. For sample identification, the sample number contains three digits:

The first digit identifies the metal;

1 - Russian steel, 2 - U.S. steel.

The second digit identifies the test group;

0 - as-received samples,

1,2 - welding speed of $4.7 \mathrm{~mm} / \mathrm{sec}$,

3,4 - welding speed of $3.8 \mathrm{~mm} / \mathrm{sec}$.

The third digit distinguishes the number of the specimen with the same condition as other samples.

These tensile data are plotted in Figures 19 and 20. The strength data of the Russian steel (Table 4 and Figures 19 and 20) indicated that the welded specimens had an average 0.28 offset yield strength (YS) of 316 $\mathrm{MPa}$ and a tensile strength (TS) of $770 \mathrm{MPa}$ with an uniform elongation of 40.18. This roughly conformed to the average properties of the asreceived specimens (YS - $290 \mathrm{MPa}$, TS - $727 \mathrm{MPa}$, and uniform elongation - 
$40.38)$.

The average property values for the Russian steel specimens failing in the fusion zone were a YS of $317 \mathrm{MPa}$ and TS of $768 \mathrm{MPa}$ with an uniform elongation of 41.08 . These data were almost identical to the average property values of the welded specimens which failed in the base metal (Figures 19 and 20). The average tensile values for these latter specimens were: YS - $315 \mathrm{MPa}$, TS - $770 \mathrm{MPa}$, and uniform elongation 39.68 .

Because failure did not occur at the fusion zone/base metal interface, the interface was not considered to be weak. Also, both regions had equal tensile strengths. Therefore, the welded specimens of the Russian steel failed randomly either in the fusion zone or in the base metal. Excellent ductility (>408) also was observed in the Russian steel.

The tensile strength data summary of the U.S. steel (Table 5 and Figures 19 and 20) showed that the welded specimens had a lower YS (538 $\mathrm{MPa})$, TS ( $851 \mathrm{MPa}$ ) and elongation (14.38) compared to the YS (798 MPa), TS (1063 $\mathrm{MPa}$ ) and elongation (16.98) of the as-received specimens. The average YS (526 MPa), TS (861 MPa) and uniform elongation (14.88) of the specimens failing in the fusion zone was almost equal to the average YS (539 $\mathrm{MPa})$, TS (840 MPa) and uniform elongation (13.78) of those welded specimens which failed in the heat-affected zone (Figures 19 and 20). Generally, the strength of the samples which failed in the fusion zone or the heat affected zone were almost equal but were much less than the strength of the base metal. All welded specimens failed randomly, either in the fusion zone or in the heat-affected zone. Thus, the strength properties of the U.S. steel were governed by the properties of the weld. 


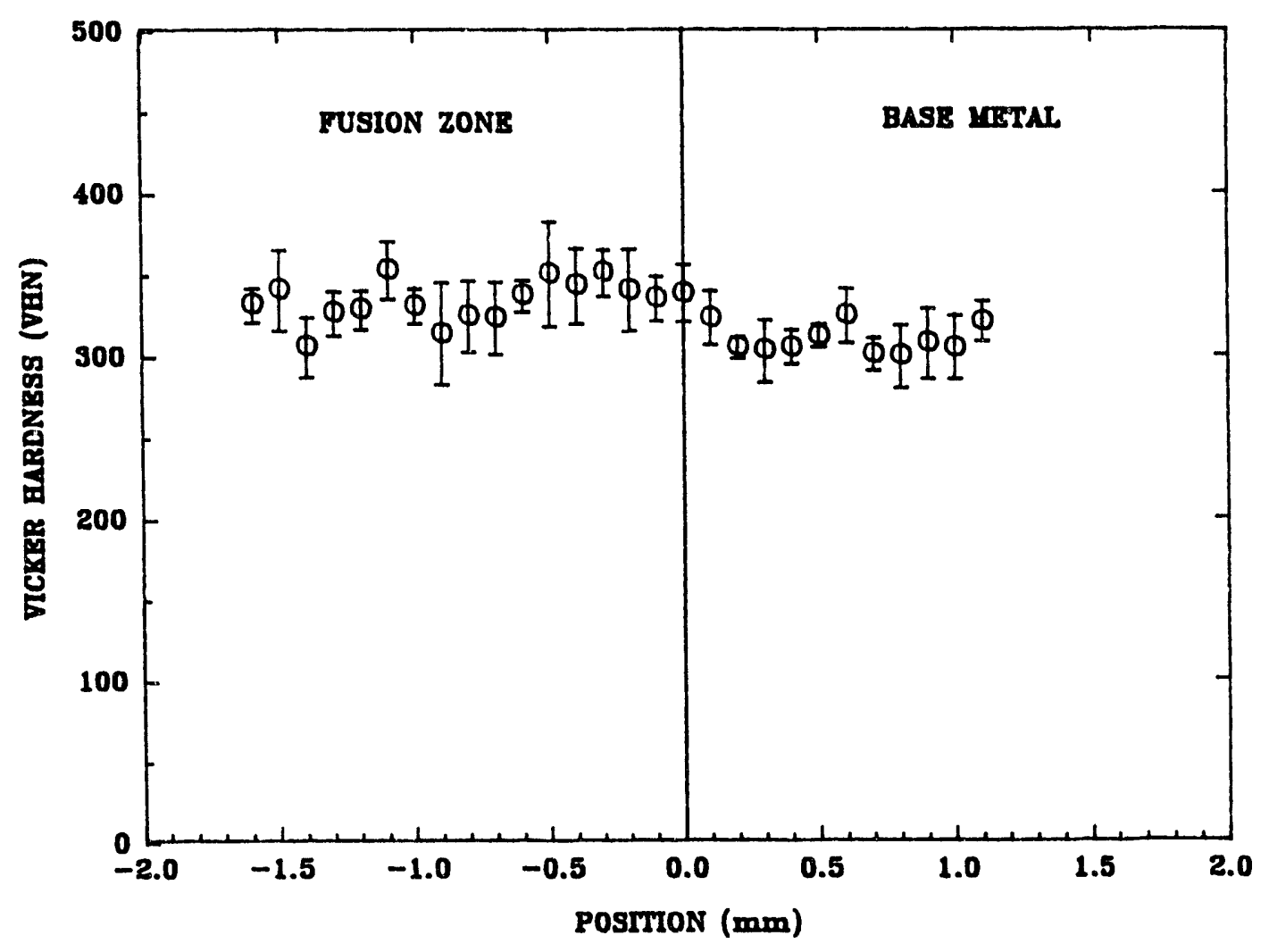

Figure 17. Microhardness of the welded Russian steel. 


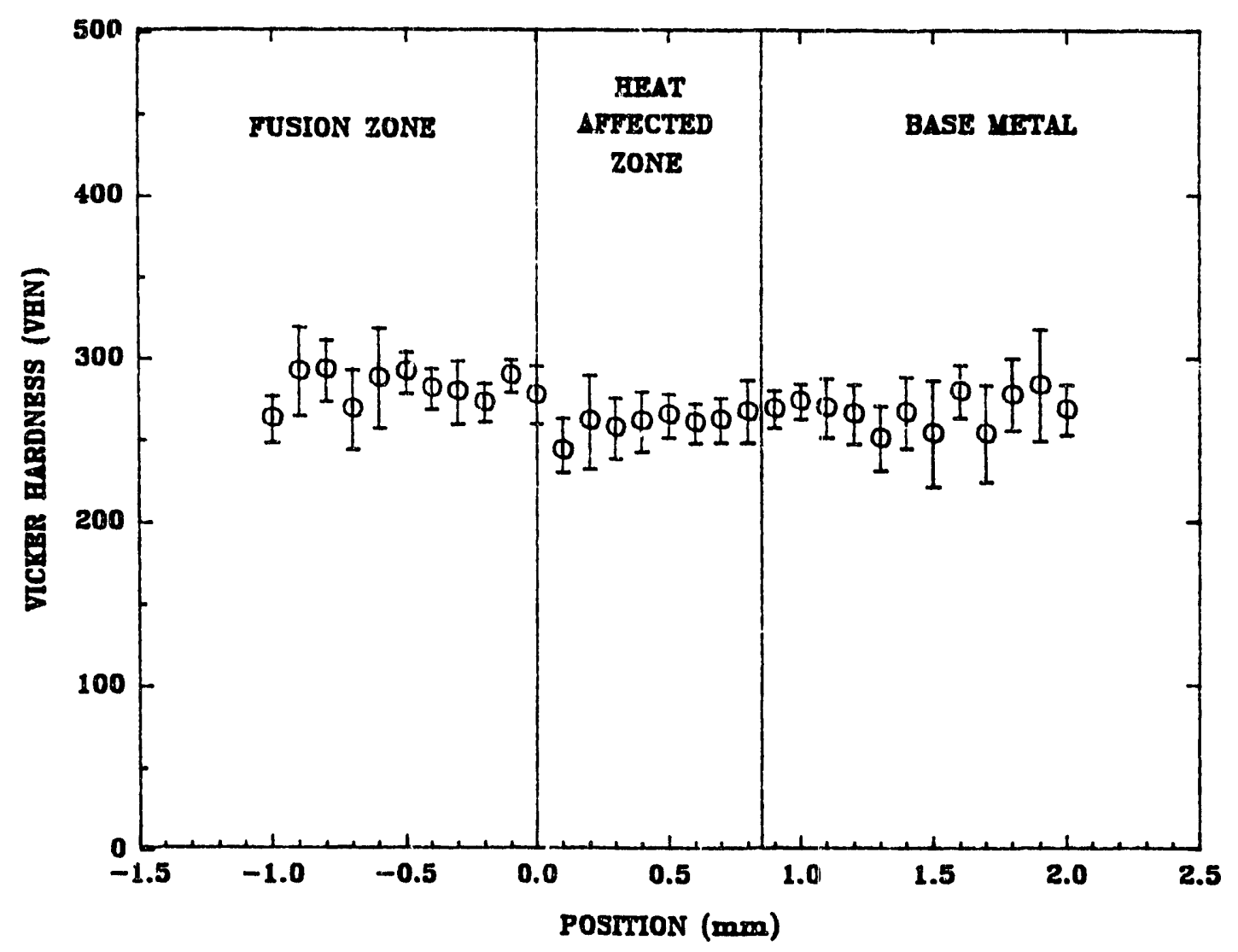

Figure 18. Microhardness of the welded U.S. steel. 
Table 4. Room Temperature Tensile Tests for the Russian Steel.

\begin{tabular}{|c|c|c|c|c|c|c|}
\hline Condition & $\begin{array}{c}\text { Sample } \\
\text { No. }\end{array}$ & $\begin{array}{l}\text { Strength } \\
0.28 \text { YS }\end{array}$ & $\begin{array}{c}(\mathrm{MPa}) \\
\mathrm{TS}\end{array}$ & $\begin{array}{l}\text { Elongatic } \\
\text { Uniform }\end{array}$ & $\begin{array}{l}\text { on }(8) \\
\text { Total }\end{array}$ & Failure \\
\hline as - received & $1-01$ & 267 & 725 & 39.8 & 42.0 & \\
\hline as-received & $1-02$ & 304 & 743 & 49.2 & 51.2 & \\
\hline as-received & $1-03$ & 304 & 751 & 42.5 & 44.7 & \\
\hline as-received & $1-04$ & 294 & 727 & 37.0 & 39.8 & \\
\hline as - received & $1-05$ & 294 & 707 & 35.4 & 37.8 & \\
\hline as-received & $1-06$ & 276 & 710 & 37.8 & 39.1 & \\
\hline weld & $1-11$ & 313 & 764 & 38.4 & 40.2 & in base ${ }^{1}$ \\
\hline we1d & $1-12$ & 313 & 767 & 39.1 & 40.6 & in base \\
\hline weld & $1-13$ & 340 & 766 & 39.4 & 40.9 & in F.Z. ${ }^{2}$ \\
\hline weld & $1-21$ & 294 & 769 & 42.5 & 44.7 & in $F . Z$. \\
\hline weld & $1-22$ & 304 & 767 & 39.4 & 41.7 & in base \\
\hline weld & $1-23$ & 331 & 782 & 41.6 & 43.8 & in base \\
\hline
\end{tabular}

1 Base metal. 2 Fusion zone. 
Table 5. Room Temperature Tensile Tests for the U.S. Steel.

\begin{tabular}{|c|c|c|c|c|c|c|}
\hline Condition & $\begin{array}{c}\text { Sample } \\
\text { No. }\end{array}$ & $\begin{array}{l}\text { Strength } \\
0.28 \text { YS }\end{array}$ & $\begin{array}{l}(\mathrm{MPa}) \\
\mathrm{TS}\end{array}$ & $\begin{array}{l}\text { Elongatio } \\
\text { Uniform }\end{array}$ & $\begin{array}{l}\text { on (8) } \\
\text { Total }\end{array}$ & Failure \\
\hline as-received & $2-01$ & 828 & 1067 & 17.0 & 17.2 & \\
\hline as-received & $2-02$ & 773 & 1058 & 16.5 & 16.7 & \\
\hline as-received & 2.03 & 818 & 1095 & 17.6 & 18.0 & \\
\hline as-received & $2-04$ & 773 & 1031 & 15.4 & 15.7 & \\
\hline weld & $2-11$ & 530 & 905 & 17.5 & 18.1 & in F.Z. ${ }^{1}$ \\
\hline weld & $2-12$ & 506 & 828 & 12.8 & 13.1 & in F.Z. \\
\hline weld & $2-13$ & 534 & 865 & 13.9 & 14.6 & in F.Z. \\
\hline weld & $2-31$ & 537 & 856 & 14.2 & 14.4 & in $\mathrm{HAZ}^{2}$ \\
\hline weld & $2-32$ & 543 & 865 & 16.2 & 16.4 & in $\mathrm{HAZ}$ \\
\hline weld & $2-33$ & 534 & 847 & 15.0 & 15.1 & in F.Z. \\
\hline weld & $2 \cdot 41$ & 524 & 773 & 9.6 & 10.2 & in $\mathrm{HAZ}$ \\
\hline weld & $2-42$ & 552 & 865 & 14.8 & 15.1 & in $\mathrm{HAZ}$ \\
\hline
\end{tabular}

${ }^{1}$ Fusion Zone. ${ }^{2}$ Heat Affected Zone. 


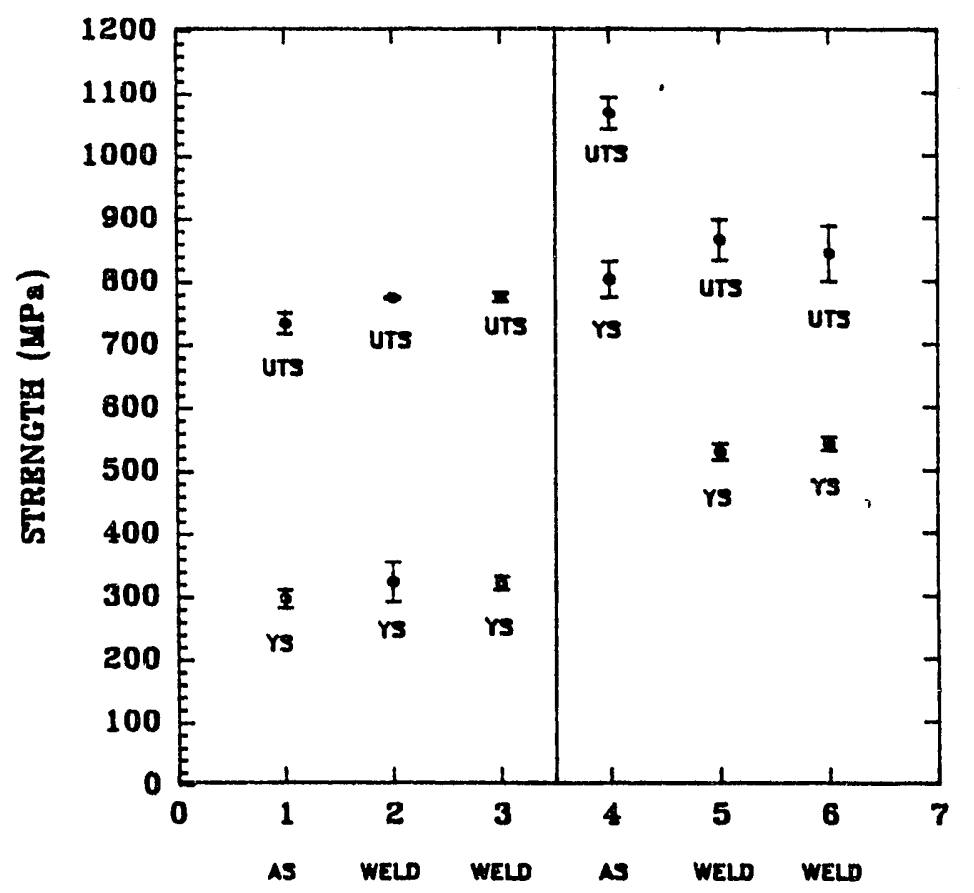

SAMPLE \#:

1. Russian: As-received

2. Russian: Weld failed in fusion zone

3. Russian: Weld failed in base metal

4. U.S.: As-received

5. U.S.: Weld failed in fusion zone

6. U.S.: Weld failed in heat affected zone

Figure 19. Strength data from the Russian and U.S. steels. 


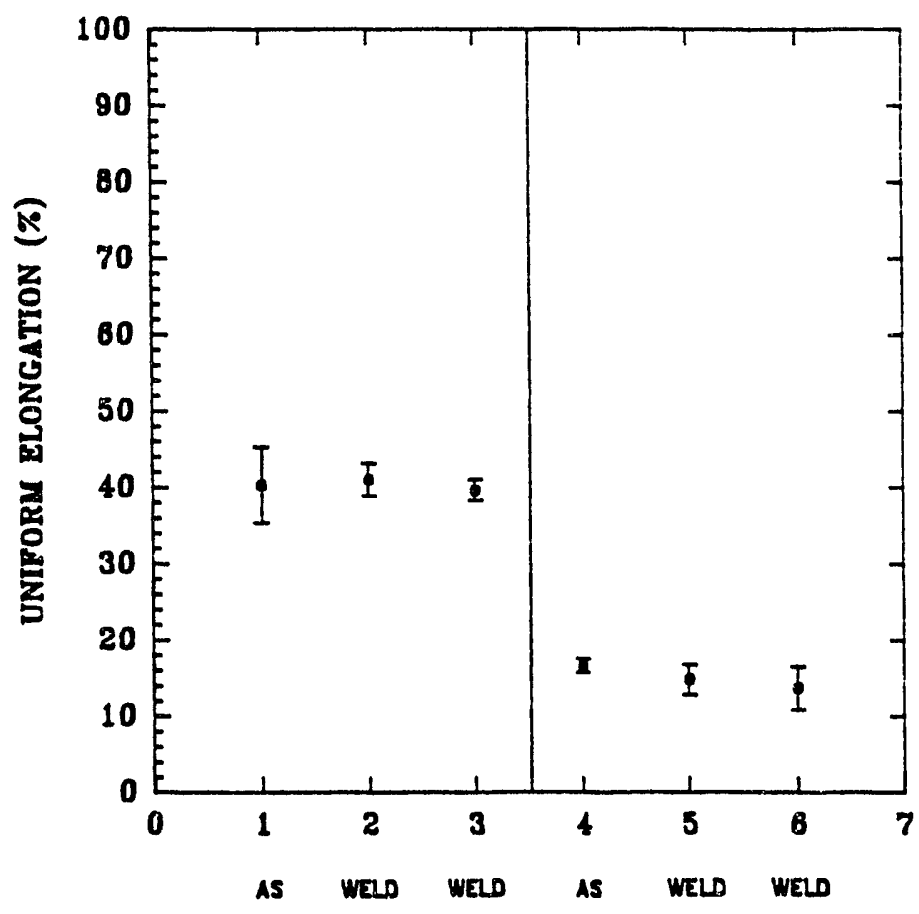

SAMPLE \#:

1. Russian: As-received

2. Russian: Weld failed in fusion zone

3. Russian: Weld failed in base metal

4. U.S.: As-received

5. U.S.: Weld failed in fusion zone

6. U.S.: Weld failed in heat affected zone steels.

Figure 20. Uniform elongation data from the Russian and U.S. 
Table 6. Weld Bend Test for Fe-Cr-Mn-C Steels.

Russian Steel

Sample No.

Weld Bend Test

\begin{tabular}{|c|c|c|}
\hline As-received & $\begin{array}{l}1-01 \\
1-02 \\
1-03\end{array}$ & $\begin{array}{l}\text { no cracks or failure } \\
\text { no cracks or failure } \\
\text { no cracks or failure }\end{array}$ \\
\hline $\begin{array}{l}\text { Torch speed } \\
4.7 \mathrm{~mm} / \mathrm{sec}\end{array}$ & $\begin{array}{l}1-11 \\
1-12 \\
1-21\end{array}$ & $\begin{array}{l}\text { no cracks or failure } \\
\text { no cracks or failure } \\
\text { no cracks or failure }\end{array}$ \\
\hline \multicolumn{3}{|c|}{ U.S. Steel } \\
\hline Sample No. & & Weld Bend Test \\
\hline As-received & $\begin{array}{l}2-01 \\
2-02 \\
2-03\end{array}$ & $\begin{array}{l}\text { no cracks or failure } \\
\text { no cracks or failure } \\
\text { no cracks or failure }\end{array}$ \\
\hline $\begin{array}{l}\text { Torch speed } \\
4.7 \mathrm{~mm} / \mathrm{sec}\end{array}$ & $\begin{array}{l}2-11 \\
2-12\end{array}$ & $\begin{array}{l}\text { no cracks or failure } \\
\text { no cracks or failure }\end{array}$ \\
\hline $\begin{array}{l}\text { Torch speed } \\
3.8 \mathrm{~mm} / \mathrm{sec}\end{array}$ & $\begin{array}{l}2-31 \\
2-32 \\
2-41 \\
2-42 \\
2-43\end{array}$ & $\begin{array}{l}\text { no cracks or failure } \\
\text { no cracks or failure } \\
\text { no cracks or failure } \\
\text { no cracks or failure } \\
\text { no cracks or failure }\end{array}$ \\
\hline
\end{tabular}


(a)

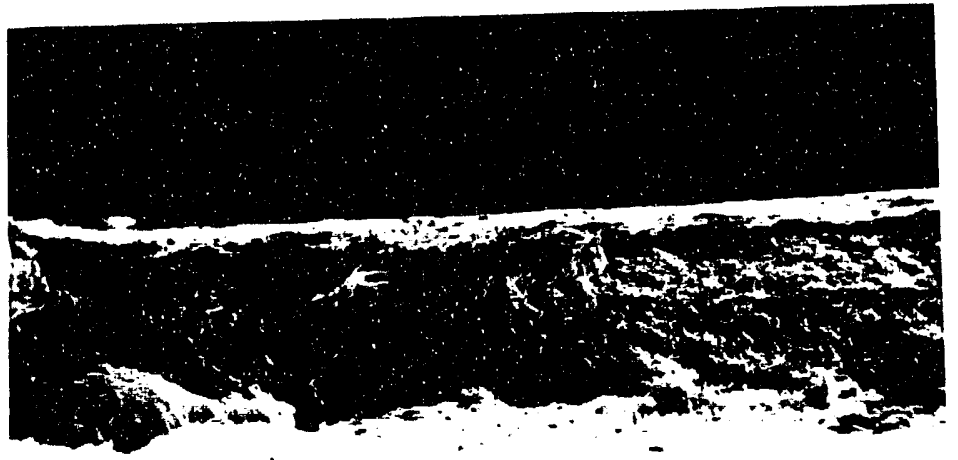

(b)
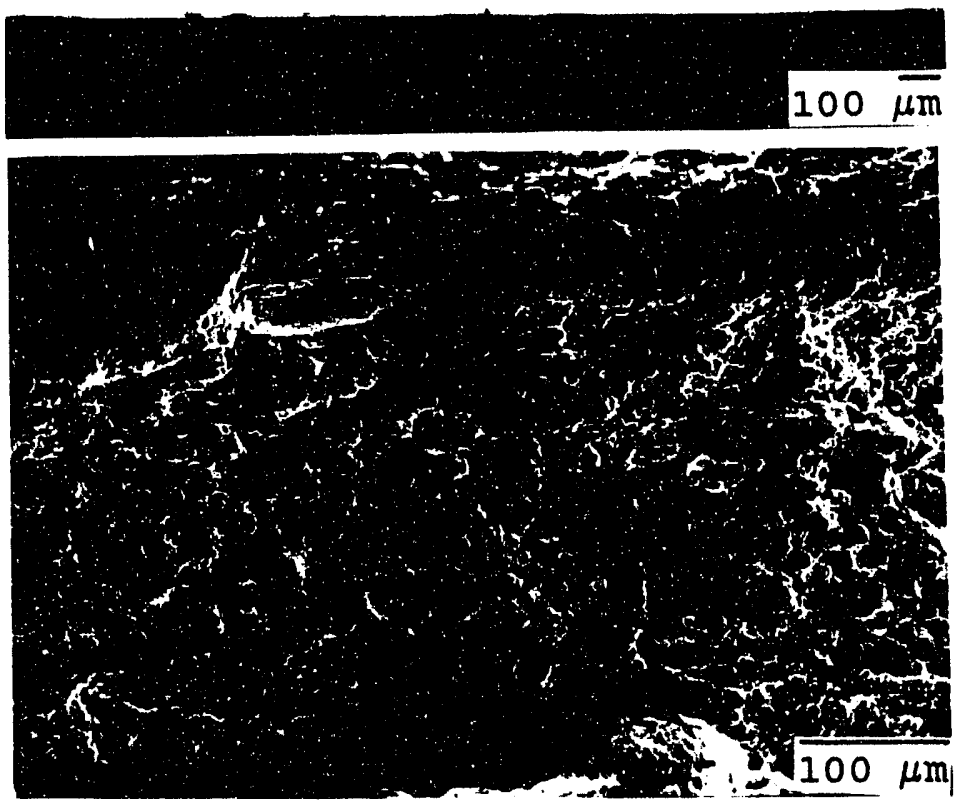

(c)

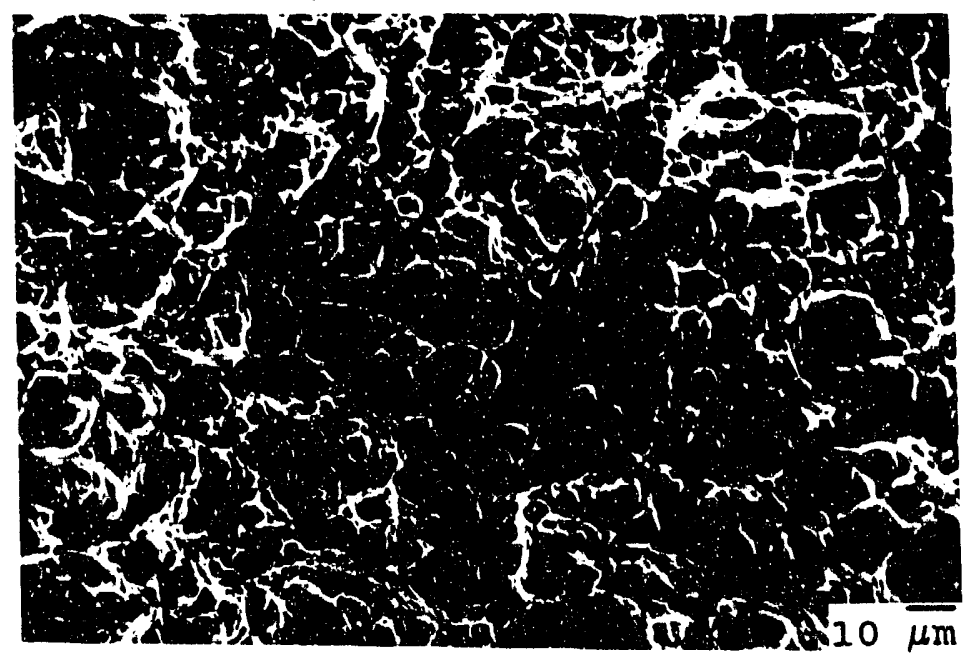

Figure 21. The fracture surface from the base metal of a Russian steel at various magnifications. 

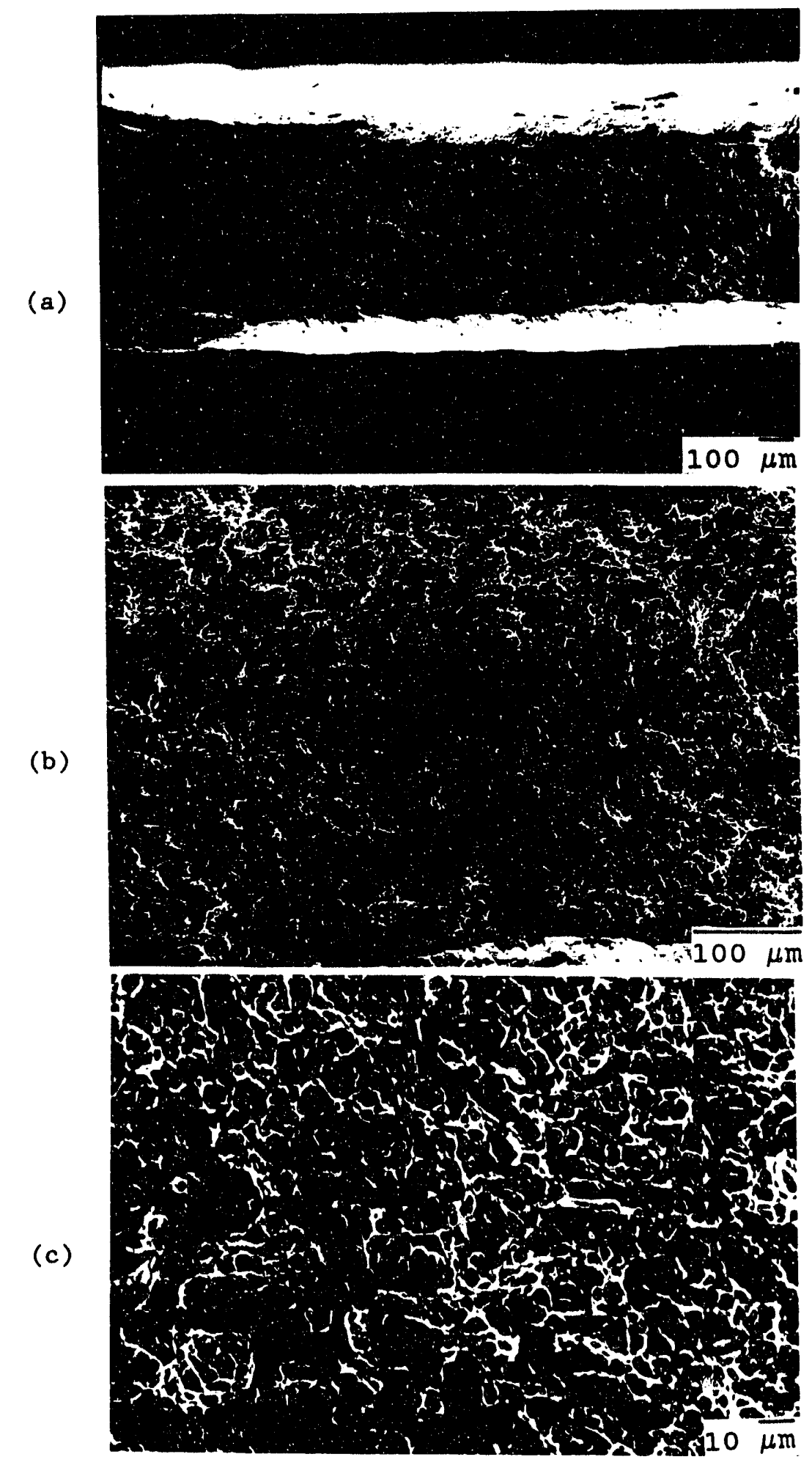

Figure 22. The fracture surface from the fusion zone of a welded Russian steel at various magnifications. 


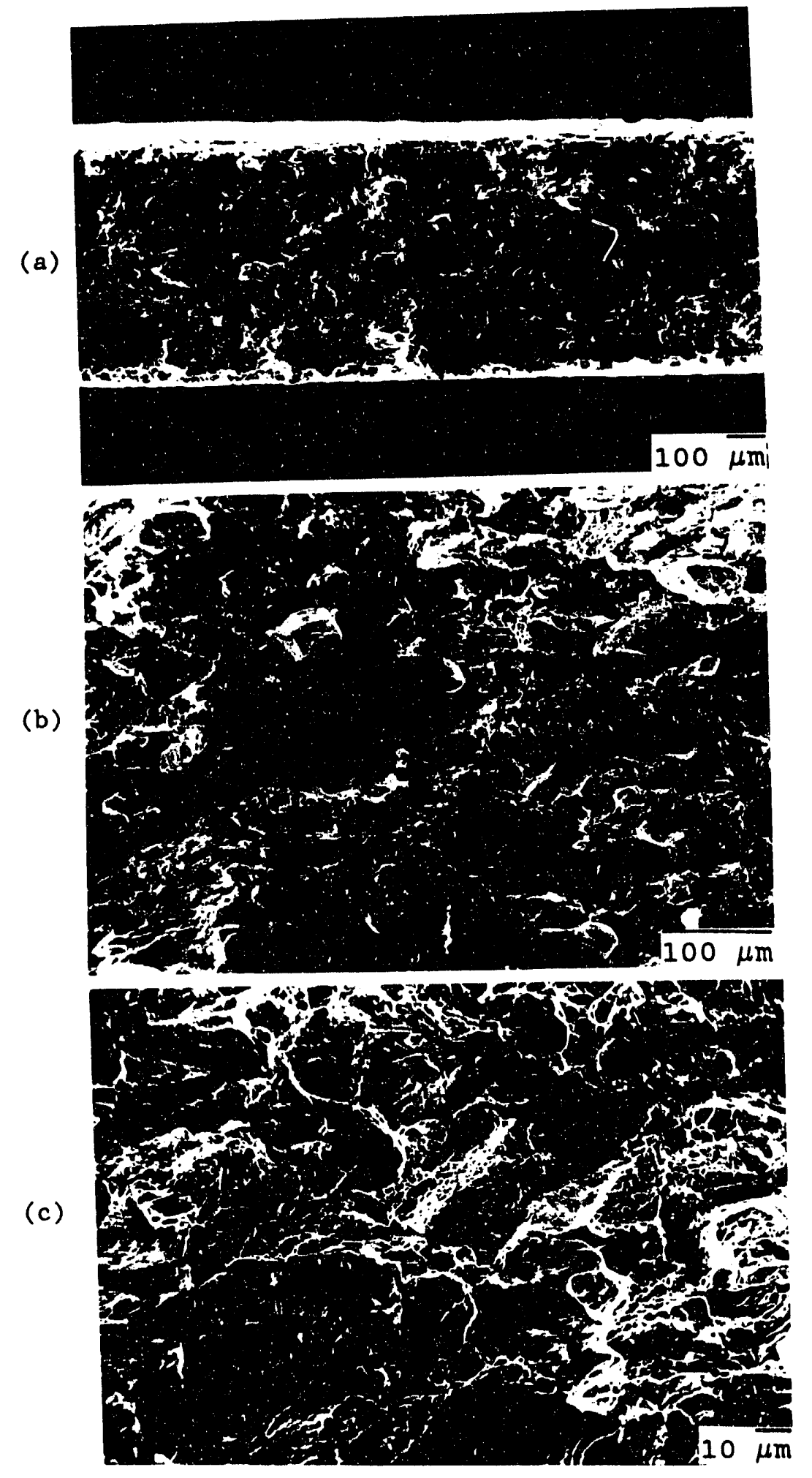

Figure 23. The fracture surface an as-received U.S. steel at various magnifications. 
(a)

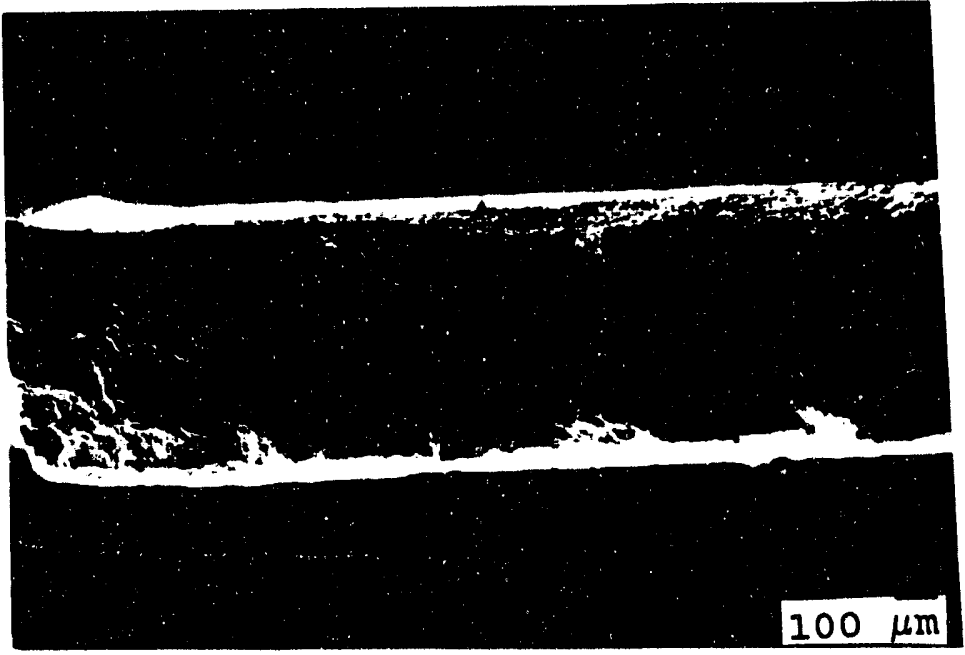

(b)

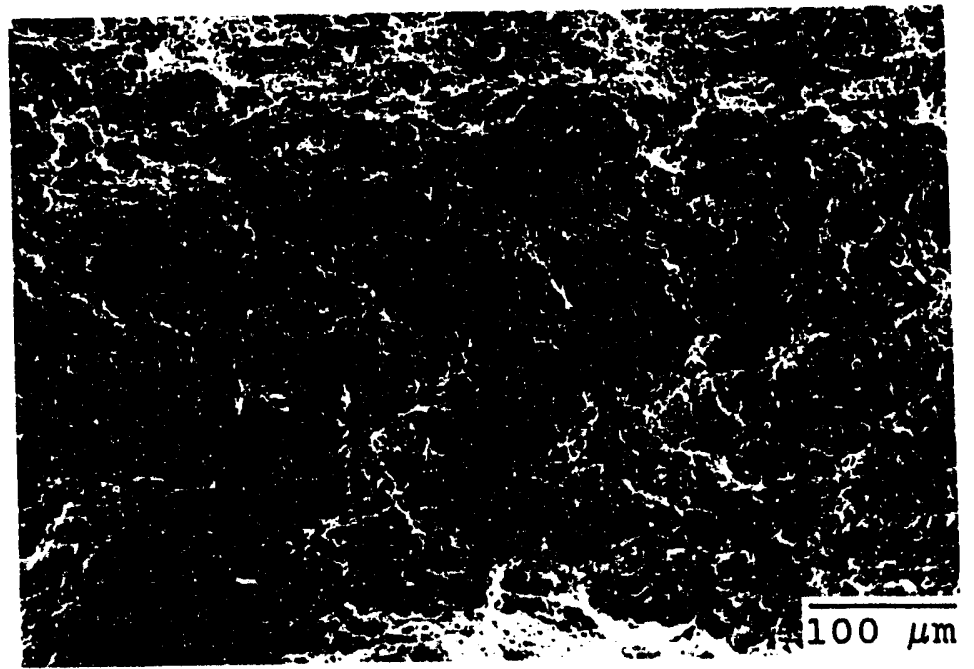

(c)

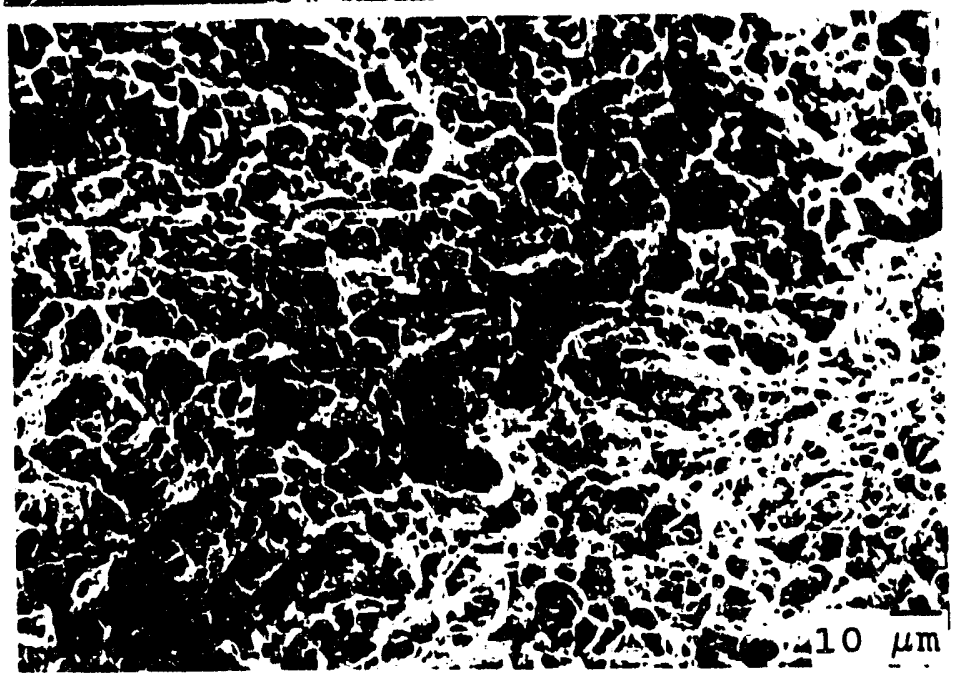

Figure 24. The fracture surface from the fusion zone of a welded U.S. steel at various magnifications. 


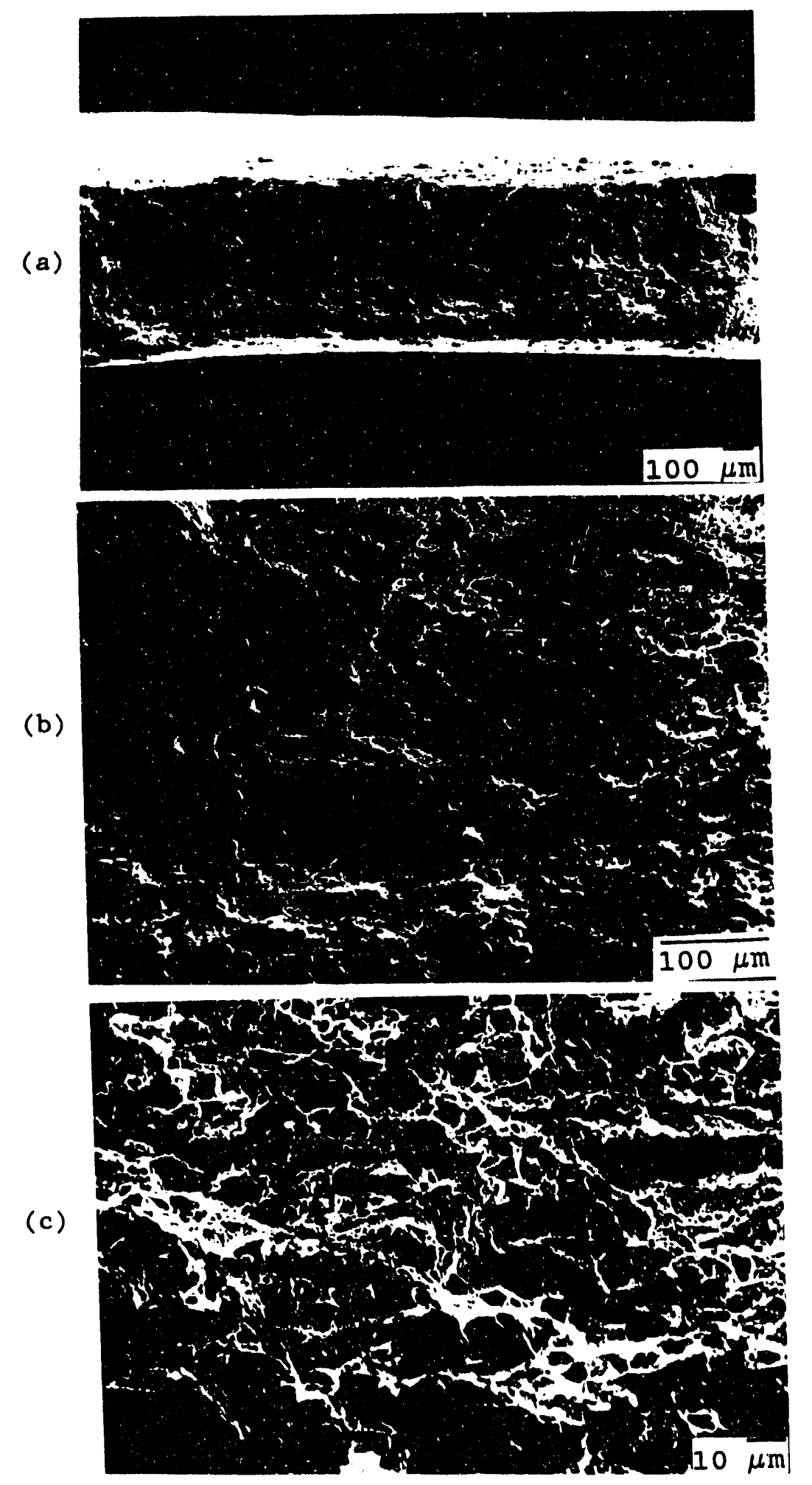

Figure 25. The fracture surface from the heat affected zone of a welded U.S. steel at various magnifications. 
The microstructure (Figure 5) indicated that the as-received U.S. steel has been cold-worked. Thus, Figures 19 and 20 suggested that the as-received U.S. steel had a higher strength than the welded. In the fusion zone and heat-affected zone of the welded samples, the structure was changed and the properties were reduced by the heat of the welding process.

Table 6 shows the results of the three-point bending tests on the Russian and U.S. steels. Gross weld flaws that are inherently oriented parallel to the weld axis, such as incomplete fusion, inadequate joint penetration, or undercuts were not observed. Both the Russian and U.S. steels had excellent toughness and ductility, because no cracks or failure were found in either the initial or final bending tests.

To investigate the failure mechanisms, each tensile test sample was examined using the JEOL-840 scanning electron microscope (SEM). Shown in Figures 21-25 are typical tensile fracture surfaces of the Russian and U.S. steels at different specimen positions (fusion zone, heat affect zone, and base metal).

The as-received and some welded Russian steel samples failed in the base metal. Figure 21 is the fracture surface from the base metal of a Russian steel. The specimen in Figure 2la exhibited necking and a shear 1ip $45^{\circ}$ to the applied tensile stress. Figures $21 \mathrm{~b}$ and $21 \mathrm{c}$ show equiaxed dimples in the center of the fracture surface. Necking, the shear lips, and equiaxed dimples are all characteristic of ductile failure [10].

Figure 22 is the fracture surface from the fusion zone of a welded U.S. steel sample. Figure 22 a revealed necking and a shear 1 ip $45^{\circ}$ to the applied tensile stress, which are typical of ductile failure. Figures 22b 
and $22 \mathrm{c}$ also show equiaxed dimples.

Figure 23 is the fracture surface of a as-received U.S. steel specimen. Examination of the fracture surface at high magnification (Figure 23c) revealed ductile fracture (equiaxed dimples). Figure 24 is the fracture surface from the fusion zone of a welded U.S. steel sample. Figures $24 \mathrm{~b}$ and $24 \mathrm{c}$ show equiaxed dimples in the center, and the structure in Figure 24a displayed necking along with a shear lip $45^{\circ}$ to the applied tensile stress. Ductile failure was again the fracture mechanism. Figure 25 is the fracture surface from the heat-affected zone of a welded U.S. steel sample. Equiaxed dimples were observed in the center of the fracture surface (Figures $25 b$ and $25 c$ ). The structure in Figure 25a had a region of necking, coupled with a shear lip which are typical ductile failure characteristics.

Dimples are traces of microvoids produced during fracture; and if the dimples are equiaxed, they indicate that the failure mode was ductile fracture [10]. Examination of the fracture surfaces at high magnifications revealed the presence of equiaxed dimples in the matrix of all the welded Russian and U.S. steels. Only the ductile failure mode was observed in the Russian steel. Also, the ductile fracture mechanism dominated in the as-received and the welded U.S. steel. 
CONCLUSIONS

This investigation of two Fe-Cr-Mn-C steels has lead to the following conclusions:

- Sound welds were achieved by gas tungsten arc welding in both the Russian and the U.S. steels.

- Mechanical properties did not change after welding of the Russian steel.

- Cold-worked strength was reduced by the welding process of U.S. steel. 


\section{REFERENCE}

1. D. R. Harries, "Ferritic/Martensitic Steels for Use in Near-Term and Commercial Fusion Reactors", Proc. of Topical Conference on Ferritic Alloys for Use in Nuclear Energy Technology, TME/AIME, June 19-23, 1983, Snowbird, Utah, pp. 141-155.

2. Chin-An Wang, "Weldability of Low Activation Ferritic Steels for Fusion Reactor Application", MS Thesis-Auburn U., August 30, 1990, pp. 3444.

3. "Standard Methods of Tension Testing of Metallic Materials" ASTM E884. 1985 Annual Book of ASTM Standards. Philadelphia: American Society for Testing and Materials, 1985. Vol. 1.02, p. 609.

4. K. A. Lula, "Stainless Steel", American Society for Metals, 1986, pp. 61-62, 108-109.

5. R. I. Klueh and P. J. Maziasz, "The Development of Austenitic Stainless Steels for Fast Induced-Radioactivity Decay", Fusion Reactor Materials-Semiannual Progress Report for Period Ending, U.S. Department of Energy, March 31, 1990, pp. 217-221.

6. R. W. K. Honeycombe, "Steels:Microstructure and Properties", American Society for Metals, 1982, pp. 214-215.

7. Metals Handbook, Ninth Edition, "Volume 6 : Welding, Brazing, and Soldering", American Society for Metals, 1983, pp. 35-36.

8.

9. Donald R. Askeland, "The Science and Engineering of Materials", PWS Engineering, Boston, Massachusetts, 1984, pp. 225-227, 387.

10. G.E. Dieter, Mechanical Metallurgy, Third Edition, McGraw-Hill, Inc, 1986, pp. $262-265$.

17. R.L. Klueh and P.J. Maziasz, "The Development of Austenitic Stainless Steels for Fast Induced-Radioactivity Decay", Fusion Reactor Materials-Semiannual Progress Report for Period Ending, U.S. Department of Energy, March 31, 1987, p. 173 
APPENDIX A 


\title{
ELECTROTRANSPORT AND RADIATION EFFECTS IN ALUMINA INSULATORS \\ DURING HIGH TEMPERATURE REACTOR APPLICATIONS
}

by

\author{
Ralph H. Zee, Wei Y. Wu and Bryan A. Chin \\ Material Engineering Program \\ Auburn University \\ Auburn, AL 36849
}

\begin{abstract}
The effects of electric field and neutron irradiation on alumina insulators at elevated temperatures were examined. Neutron irradiation has been demonstrated to result in anisotropic growth of individual alumina crystals leading to the generation of internal stress in polycrystalline alumina. This phenomenon was modeled using a stress compliance method based on the ANSYS finite element code. The effect of irradiation conditions and operating temperature were examined. Additional relaxation due to long term creep and effect of irradiation enhanced creep were also included. Stress induced failure was predicted using Griffith's fracture theory. The electrotransport effect of alumina was determined based on the preferential migration of the aluminum and the oxygen ions. The driving force for the separation of the species was electrostatic in nature. The preferential diffusion of the ions coupled with the rapid aluminum migration resulted in the formation of oxygen bubbles at the anode in accord with experimental observation.
\end{abstract}




\section{INTRODUCTION}

Alumina $\left(\mathrm{Al}_{2} \mathrm{O}_{3}\right)$ is commonly used as insulators in nuclear reactors. In certain applications, such as fusion reactors, these insulators must be able to sustain radiation damage, high electric fields and high temperature simultaneously. The electrical and mechanical responses of alumina to these stimuli are therefore of great importance to its suitability for thermionic nuclear reactor applications. This paper is devoted to an analysis of these effects in polycrystalline alumina.

Results from previous experimental studies have shown that the electrical resistivity of alumina changed with time when subjected to a high electric field at elevated temperatures (in excess of $1100 \mathrm{~K}$ ). In addition, mechanical instability, in terms of generation of internal stresses, was found to be the dominating factor for failure in alumina when it was irradiated in a fast neutron environment [1]. The change in electrical property under an applied electric field is believed to be due to a change in the chemical structure as well as the microstructure of the insulator with time. However, the analysis has been limited to a qualitative approach and detailed modeling has yet to be performed. The mechanical instability is due to the anisotropic growth of the hexagonal structure of alumina under neutron irradiation. This paper seeks to obtain mathematical solutions to above problems.

\section{IRRADIATION STRESS IN ALUMINA}

Extensive experimental results on the effect of fast neutron irradiation on single or polycrystalline alumina and other materials have been given by Ranken and Clinard, et al $(1-4)$. Qualitative explanations were provided by those authors. These experimental results show that single crystal $\mathrm{Al}_{2} \mathrm{O}_{3}$ 
grains grow anisotropically along the $\langle c\rangle$ and the $\langle a\rangle$ directions under neutron irradiation although the lattice parameters remain almost unchanged. The temperature dependence of the change in the $\langle a\rangle$ and the $\langle c\rangle$ axes is summarized in Table 1 [1]. In polycrystalline alumina, each individual grain grows anisotropically. This results in the mechanical instability of the sheath insulator in the nuclear reactor. Both tensile and compressive stresses are generated in these grains according to the compliance imposed by their neighboring grains. When the generated stress, especially tensile, exceeds the critical value which corresponds to the tensile strength of the material, cracks occur mainly at the grain boundaries which are the weakest locations in the material. Such cracking has been frequently observed [1]. In this study, the magnitude of the stress generated within the polycrystalline alumina was modeled by embedding an anisotropic grain into an isotropic alumina sample. This model simplifies the original problem of an anisotropic multi-grain system to a single anisotropic grain in an isotropic medium. Due to the anisotropic growth of the grain as opposed to the isotropic growth of the medium, an externally applied stress is now required to provide the strain compliance between the two subsystems (grain and medium). This deformation mismatch contributes to the stress generation in the material under neutron irradiation. If the medium is assumed to be completely rigid where no deformation of the medium is allowed, the shape of the grain must be changed from $\left(1+\beta_{1}\right) 2 a$ and $\left(1+\beta_{2}\right) 2 c$ to $(1+\alpha) 2 a$ and $(1+\alpha) 2 c$ respectively in the $\langle a>$ and the $\langle c\rangle$ directions. The parameters a and $c$ are the size of the grain whereas $\beta_{1}$ and $\beta_{2}$ are the irradiation expansion coefficients of alumina crystal in the $\langle a\rangle$ and the $\langle c\rangle$ directions respectively, $\alpha$ is the average irradiation expansion coefficient and is related to the beta values. The stresses 
required to induce such changes can be calculated. In this analysis, the $x$ direction corresponds to the $\langle c\rangle$ axis whereas the $y$-direction to the $\langle a\rangle$ axis of the crystal. In three dimensions, these stresses can be written as:

$$
\begin{aligned}
& \sigma_{x}^{\circ}=\frac{[A(1-\nu)+2 B \nu] E}{(1+\nu)(1-2 \nu)} \\
& \sigma_{y}^{\circ}=\sigma_{z}^{\circ}=\frac{[A \nu+B] E}{(1+\nu)(1-2 \nu)}
\end{aligned}
$$

where $E$ and $\nu$ are the Young's modulus and the Poisson's ratio of the material respectively. Both are functions of temperature. A and $B$ are defined as:

$$
\begin{aligned}
& A=\frac{\left(\alpha-\beta_{1}\right)}{\left(1+\beta_{1}\right)} \\
& B=\frac{\left(\alpha-\beta_{2}\right)}{\left(1+\beta_{2}\right)}
\end{aligned}
$$

Figure 1 shows the linear increase with fluence in the stress in the $x$ (or $\langle a\rangle$ ) direction and the $y($ or $\langle c\rangle$ ) direction. No material would be useful at such high stress levels. Fortunately, the real medium is rather elastic and this stress relaxation effect could be determined using a finite element method (FEM) due to the complex stress and geometrical nature of the problem. This relaxation results in a gradual change of stress states as a function of position. The ANSYS routine [5] was used to calculate the stress contours under the above boundary conditions. Also illustrated in figure 1 is the maximum stress in the alumina generated during fast neutron irradiation at $1073 \mathrm{~K}$ and $1273 \mathrm{~K}$ after matrix relaxation. The maximum tensile stress occurs near the $\langle a\rangle$ direction whereas the compressive stress near the $\langle c\rangle$ direction. It can be seen that more than two thirds of the original stress is relaxed, 
and the magnitude of the stress generated from irradiation is approximately a linear function of neutron fluence. Furthermore, the stress in the unrelaxed state at $1273 \mathrm{~K}$ is higher than that for $1073 \mathrm{~K}$ due to larger beta values for the former. Due to the small temperature dependence of the modulus and Poisson's ratio, the difference in relaxation between the two temperatures is insignificant as illustrated in figure 1.

The stress level, even including stress relaxation of the medium, is still high. According to figure 1, the increase in stress is a linear function of neutron fluence. The slope of these curves is a function of $\alpha$, $\aleph_{1}, \beta_{2}$ and irradiation flux $\Phi$. Mathematically, this can be expressed as:

$$
\sigma=k \Phi t=k t
$$

It is anticipated these insulators usually operate at high temperatures under intense irradiation and electric field. During long term operation, such as from 7 to 10 years, the creep of the material can not be ignored in mechanical stress analysis. Limited experimental data are available on the creep of alumina as a function of temperature and stress. According to those experiments, the creep of alumina can be expressed in the form of a power law as :

$$
\dot{\epsilon}_{\text {creep }}=C_{\text {creep }} \sigma^{n}
$$

where $C_{c r e \theta p}$ and $n$ are material creep parameters. From the data given in reference 6 , the creep coefficient for alumina is a function of temperature and has the form: 


$$
C_{\text {creep }}=4.774 \times 10^{6} \exp (-52330 / T)
$$

This creep coefficient $\mathrm{C}_{\text {creep }}$ has the unit of $\mathrm{s}^{-1} \mathrm{MPa}^{-1.5}$ and $\mathrm{T}$ in Kelvin. The exponent $\mathrm{n}$ for alumina is approximately 1.5 at $1000 \mathrm{~K}$ [7]. Creep can be further enhanced by the presence of irradiation which can be represented by:

$$
\dot{\epsilon}_{\mathrm{irr}}=\sigma \dot{\mathrm{S}} / \mathrm{Y}+0.5 \sigma \phi / \mathrm{E}
$$

where $\dot{S}$ is the rate of swelling, $Y$ is the yield stress, $\phi$ is displacement rate and the other terms have been defined earlier.

The governing differential equation describing the simultaneous generation of stress by neutron irradiation and creep relaxation can be obtained by combining equations 5,6 and 8 . This can be written as:

$$
(\mathrm{d} \sigma / \mathrm{d} t)=\mathrm{K}-\mathrm{EC}_{\mathrm{creep}} \sigma^{\mathrm{n}}-\mathrm{E} \sigma \dot{S} / Y-0.5 \sigma \phi
$$

Equation 9 is a non-linear ordinary differential equation. For a given set of $\mathrm{K}, \mathrm{E}, \mathrm{C}_{\mathrm{creep}}, \mathrm{n}$ and other irradiation creep parameters, the solution of equation 10 can be obtained through numerical integration as illustrated in figure 2. These calculations were performed using a yield stress of $2.07 \mathrm{MPa}$, a swelling rate of $2.78 \times 10^{-10} \mathrm{~s}^{-1}$, an irradiation value $\mathrm{K}$ of $6.18 \times 10^{-9} \mathrm{MPa} / \mathrm{s}$, a displacement rate $1.39 \times 10^{-7} \mathrm{dpa} / \mathrm{s}$ and a modulus of $3.1 \times 10^{5} \mathrm{MPa}$. These values were obtained from the literature for alumina $[1-4,8,9]$ at $1073 \mathrm{~K}$. In this figure, two calculations were made: one with and one without irradiation creep. It is evident that using the parameters appropriate for alumina, stress relaxation due to irradiation creep plays a dominant role in preventing 
cracking in the material. The lifetime of the material can be defined as the time when the stress generated by irradiation reaches the fracture stress $\sigma_{f}$. When this condition is satisfied, cracks will occur and the integrity of the material will be compromised. The prediction of the lifetime of alumina prior to stress induced fracture caused by irradiation can be estimated based on the Griffith's fracture theory as described by:

$$
\sigma_{f}=\sqrt{ }((E \gamma) /(2 r))
$$

$\sigma_{f}$ is fracture stress, $\tau$ is the surface energy of alumina, $r$ is the preexisting crack or flaw size. Griffith's criterion for fracture is applicable in alumina due to the brittle nature of the material.

For a given flaw size $r$, the lifetime of alumina can be obtained by equating the fracture stress $\sigma_{f}$ and the stress generated by irradiation for different conditions given in figure 2. When the radiation stress reaches this level, fracture occurs. Figure 3 illustrates the correlation between flaw size and lifetime using stress generation with and without irradiation creep. A $r$ value of $1 \mathrm{~J} / \mathrm{m}^{2}$ was used. It is evident that there is a critical flaw size below which fracture never occurs and above which fracture occurs very early. This critical value increases from $0.7 \mu \mathrm{m}$ for the case without irradiation creep to $54 \mu \mathrm{m}$ for the case with irradiation creep. Such a lifetime-flaw size relation can be adapted for quality control purposes.

\section{ELECTROTRANSPORT IN ALUMINA AT HIGH TEMPERATURES}

Under intense electric field, electrotransport may occur and contribute to the conductivity of the material. This can be written in a mathematical 
form for this diffusion process:

$$
\frac{\partial c}{\partial t}=D \frac{\partial^{2} c}{\partial x^{2}}+\mu E \frac{\partial c}{\partial x}
$$

with the initial condition that the concentration is uniform across the specimen, ie: $c=c_{0}$ at $t=0$.

The boundary conditions are that there is no net solute flux (either aluminum or oxygen ions) at the two ends which implies that the atoms are conserved. This can be presented mathematically as:

$$
D \frac{\partial C}{\partial x}+\mu E C=0
$$

where $\mathrm{C}$ is the concentration of $\mathrm{O}^{--}$or $\mathrm{Al}^{+++}, \mathrm{E}$ is the electric field intensity and $\mu$ is the mobility of the ions which is defined as:

$$
\mu=\frac{e Z D}{k T}
$$

Here $D$ is the diffusivity of either $\mathrm{Al}^{+++}$or $\mathrm{O}^{--}, \mathrm{T}$ is the absolute temperature and $k$ is the Boltzmann constant. $Z$ is the charge state of the ions of interest. The charge states of aluminum and oxygen are $3+$ and 2 -

respectively. The solution to equation 1 with the appropriate boundary and initial conditions is in the form of an infinite series $[10,11]$. The concentration profiles of the electrotransport ions at increasing times for a positive ions are shown in figure 4. One feature of particular importance is that the depletion layer grows at a rate of $\mu \mathrm{E}$.

At $1000 \mathrm{~K}$, the diffusivity of $\mathrm{Al}^{+++}$is approximately four orders of 
magnitude higher than that of $0^{--}$due to the presence of high concentration of cation vacancies ( 33.38 vacancies). This means that the diffusion of $0^{--}$ anions in alumina under electric field can be ignored and only the motion of the $\mathrm{Al}^{+++}$needs to be considered. In this case, the aluminum ions will be driven away from the positive terminal (anode) and a depletion layer will be formed. Free oxygen will be produced in this aluminum deficient layer forming pressurized oxygen bubbles. The growth rate of this aluminum deficient layer is governed by the product of the mobility of the aluminum ions and the applied electric field.

Chin and Messick [12] have conducted an electrotransport experiment at $1500 \mathrm{~K}$ using a trilayer alumina cylinder. In this geometry, a thin alumina cylinder $(0.25 \mathrm{~mm}$ thick) was coated both inside and outside by niobium measuring $0.5 \mathrm{~mm}$ thick as ohmic contacts. A potential of $100 \mathrm{~V}$ was applied giving an electric field of $400 \mathrm{~V} / \mathrm{mm}$. The positive terminal was attached to the outside niobium contact. The assembly was processed for $5313 \mathrm{~h}$. The thickness of alumina swelled by $0.1 \mathrm{~mm}$ in 5313 hours at an electric field of $400 \mathrm{~V} / \mathrm{mm}$ corresponding to a radial expansion strain of 408 . This radial expansion must be accompanied by a radial creep of the outer niobium layer with a creep rate of $7.2 \times 10^{-10} \mathrm{~s}^{-1}$ in the tangential direction. From the creep data for niobium at $1473 \mathrm{~K}$ [13], this creep rate corresponds to a radial stress of $1.0 \mathrm{MPa}$. This stress can only originate from the free oxygen bubble formation which generates a hydrostatic pressure tending to expand the ring. If half of the volume at the interface between the alunina and outer niobium is occupied by the free oxygen bubbles, the oxygen pressure required for the observed expansion will be $2.07 \mathrm{MPa}$. Using the Ideal gas law, the amount of oxygen released is on the order of 1 part per million. This implies the 
composition variation of $\mathrm{Al}^{+++}$is negligible. The increase in the resistance of the insulator with time must therefore be due to a change in the morphology of the conduction path and not a change in the chemical composition. The formation of oxygen bubbles resulted in an effective increase in the length to area ratio of the sample thereby increasing the observed resistance with time.

\section{CONCLUSIONS}

Under fast neutron irradiation, individual polycrystalline alumina grains grow anisotropically and generate stresses inside the material. The stress evolution in alumina was modeled by embedding an anisotropic grain in an isotropic medium using a finite element analysis. The spontaneous relaxation of the elastic medium was found to reduce up to two thirds of the induced stress. The effects of long term creep were also investigated. The stress relaxation due to creep is a strong function of temperature. Lifetime prediction was formulated using the Griffith's theory based on the preexisting flaws. Experiment and theory were found to coincide reasonably. The electrical property of alumina is greatly effected by the intense field anci high temperatures. A simple model based on electrotransport was proposed to explain the observed preferential migration of the aluminum ions in the presence of electric field at $1473 \mathrm{~K}$. The positively charged aluminum ions diffuse to the cathode leading to an excess of immobile oxygen ions at the anode forming pressurized oxygen bubbles there. This results in an expansion of the material and a reduction of the overall resistance due to the formation of more restrictive paths for electronic conduction. 


\section{Acknowledgements}

This work was supported by the Thermionic Space Nuclear Power Program of the U.S. Air Force, Kirtland Air Force Base, NM 87117 through the Center for Commercial Development of Space Power and Advanced Electronics, located at Auburn University. The authors would like to thank Dr. Frank Jankowski and Dr. Michael Schuller of the U.S. Air Force for their technical guidance.

\section{References}

[1] F.W. Clinard, Jr. G.F. Hurley \& L.W. Hobbs, J. Nucl Mater. $108 \& 109$ (1982) 655.

[2] R.B. Roof, Jr. and W.A. Ranken, J. Nucl. Mater. 55 (1975) 357.

[3] W.A. Ranken and A.R. Veca, in: "Space Nuclear Power Systems" 1987, ed. M.S. El-Genke and M.D. Hoover (Orbit Book Company, 1988) pp. 329-339.

[4] W.A. Ranken, T.G. Frank \& G.W. Keiholtz, in: Thermionic Electrical Power Generation, Proc. 3rd ICTEPG (1972) PP. 819-830.

[5] H. Kardestuncer, Finite Element Handbook, McGraw-Hill (New York), 1987

[6] W.D. Kingery, Introduction to Ceramics (John Wiley \& Sons, Inc., New York, 1967).

17) H. Hubner \& J. Stark, in: High Tech Ceramics, Proc. WCHTC, (1986) 1247.

(8) W.H. Gitzen, Alumina as A Ceramic Material, (The American Ceramic Society, 1970).

[9] W.Y. Wu and R.H. Zee, Proc. of 26th Intersociety Energy Conversion Engineering Conference, Boston (1991), Am. Nuclear Society. pp.110-115.

(10) R.H. Zee and G.E. Lee-Whiting, J. Applied Physics 55 (6) (1984) 1444.

[11] R.H. Zee and G.E. Lee-Whiting, J. Applied Physics 57 (6) (1985) 1849.

[12] J. Chin and C.W. Messick, in: IEEE Conference Record of 1969 Thermionic Conversion Specialist Conference, P. 394

(13) H.E. Boyer, Atlas of Creep and Stress-Rupture Curves, ASM International, 1988. 
Table 1. Dimensional change (in 8 ) of alumina per $10^{25} \mathrm{n} / \mathrm{m}^{2}$ irradiation in the two principal directions

$\begin{array}{ccc}\text { Temp }(\mathrm{K}) & <\mathrm{a} \text { direction } & <\mathrm{c}>\text { direction } \\ 923 & 0.11 & 0.17 \\ 1293 & 0.05 & 0.39\end{array}$




\section{FIGURE CAPTIONS}

Figure 1. Stress evolution in polycrystalline alumina during neutron irradiation at $1073 \mathrm{~K}$ and $1273 \mathrm{~K}$, with and without matrix relaxation.

Figure 2. Tensile stress as a function of neutron irradiation with and without irradiation creep contribution to stress relaxation.

Figure 3. Dependence of lifetime of alumina insulator on pre-existing flaw size for two cases: with and without irradiation creep. The Griffith's criterion was used. The two values $(0.7 \mu \mathrm{m}$ and $54 \mu \mathrm{m})$ correspond to the critical flaw size for the two cases.

Figure 4. Concentration profile of a positively charged ion in response to an externaily applied electric field at different times. Note that the motion of the depletion edge equals to $\mu \mathrm{E}$. 


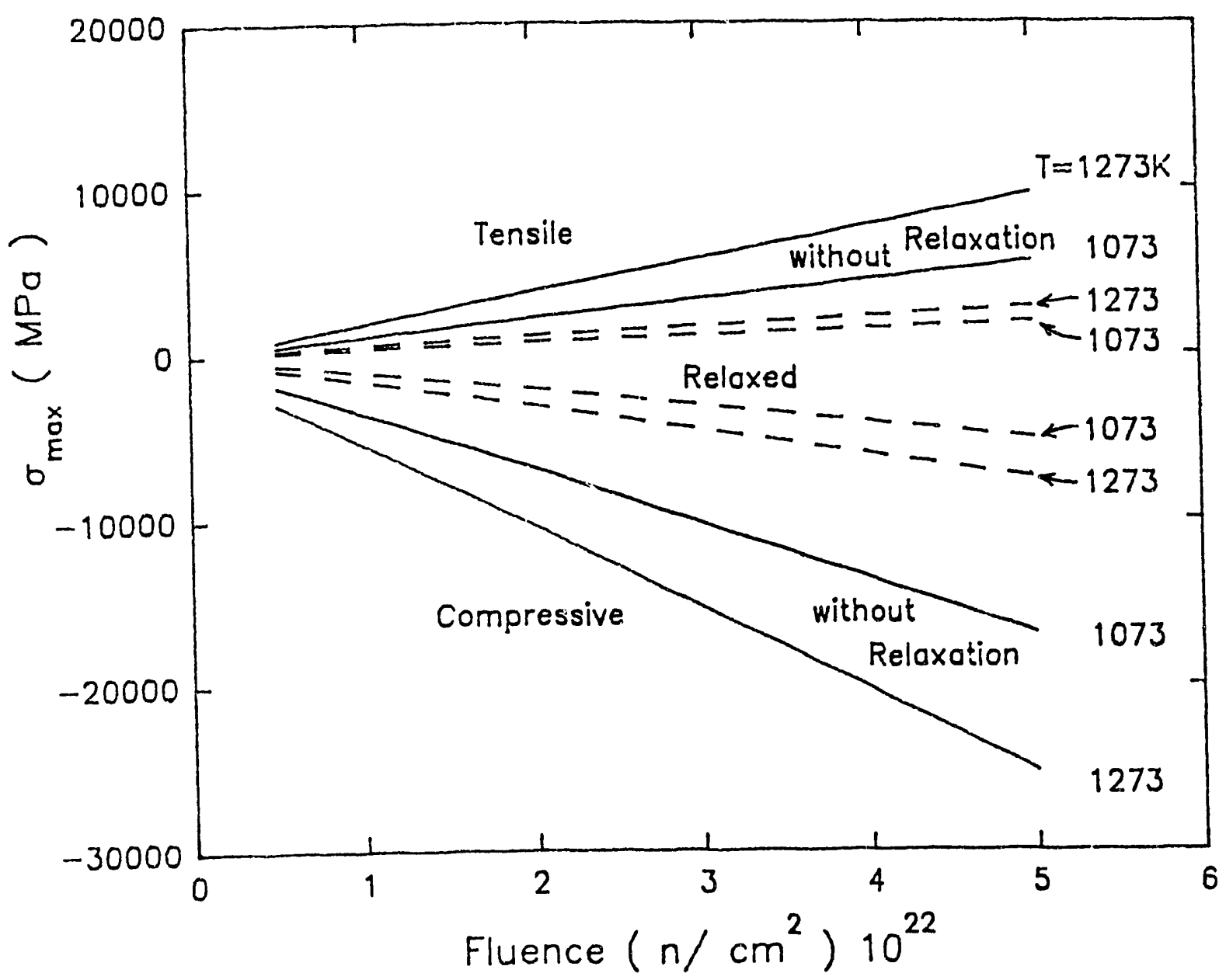

Figure 1 


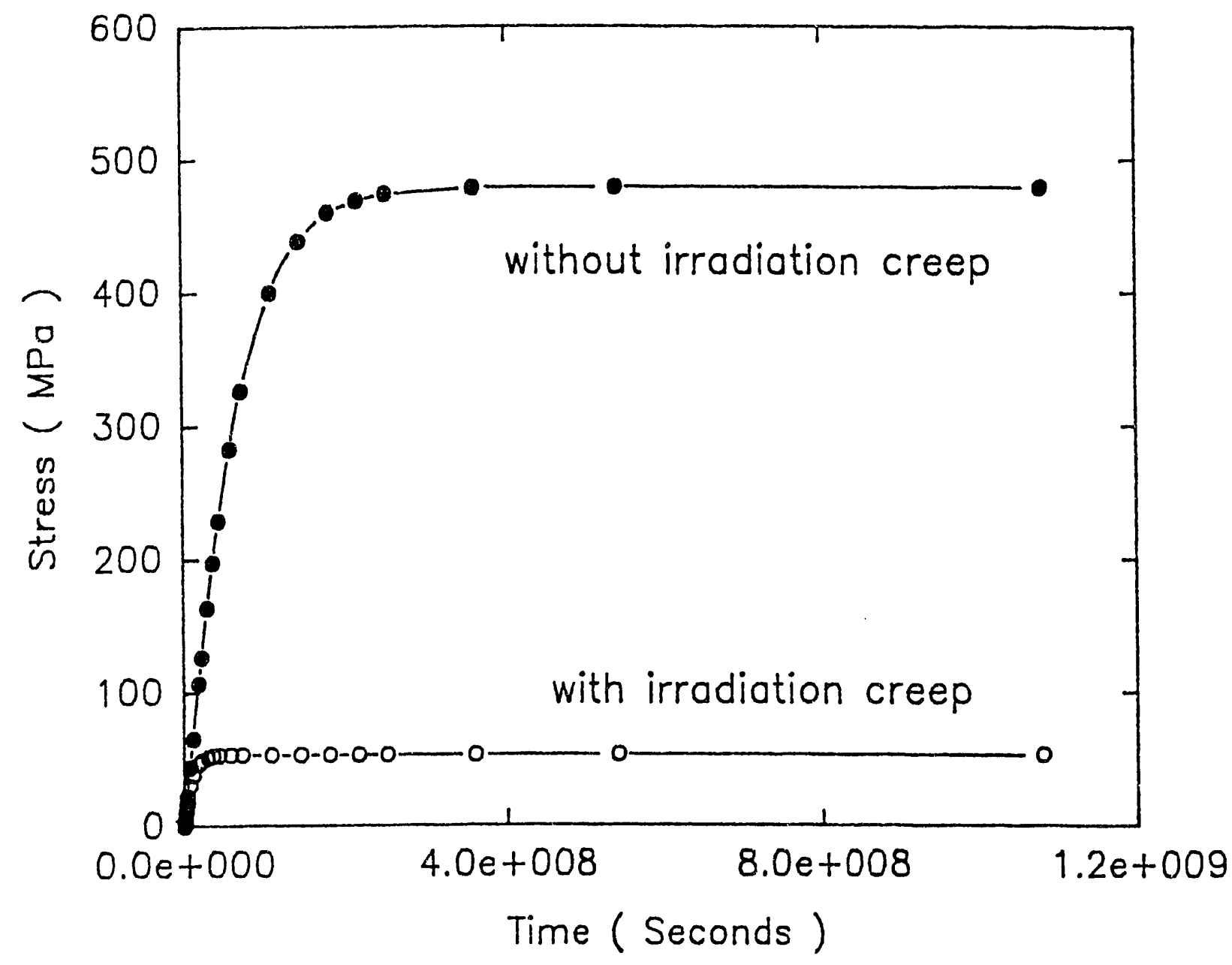

Figure 2 


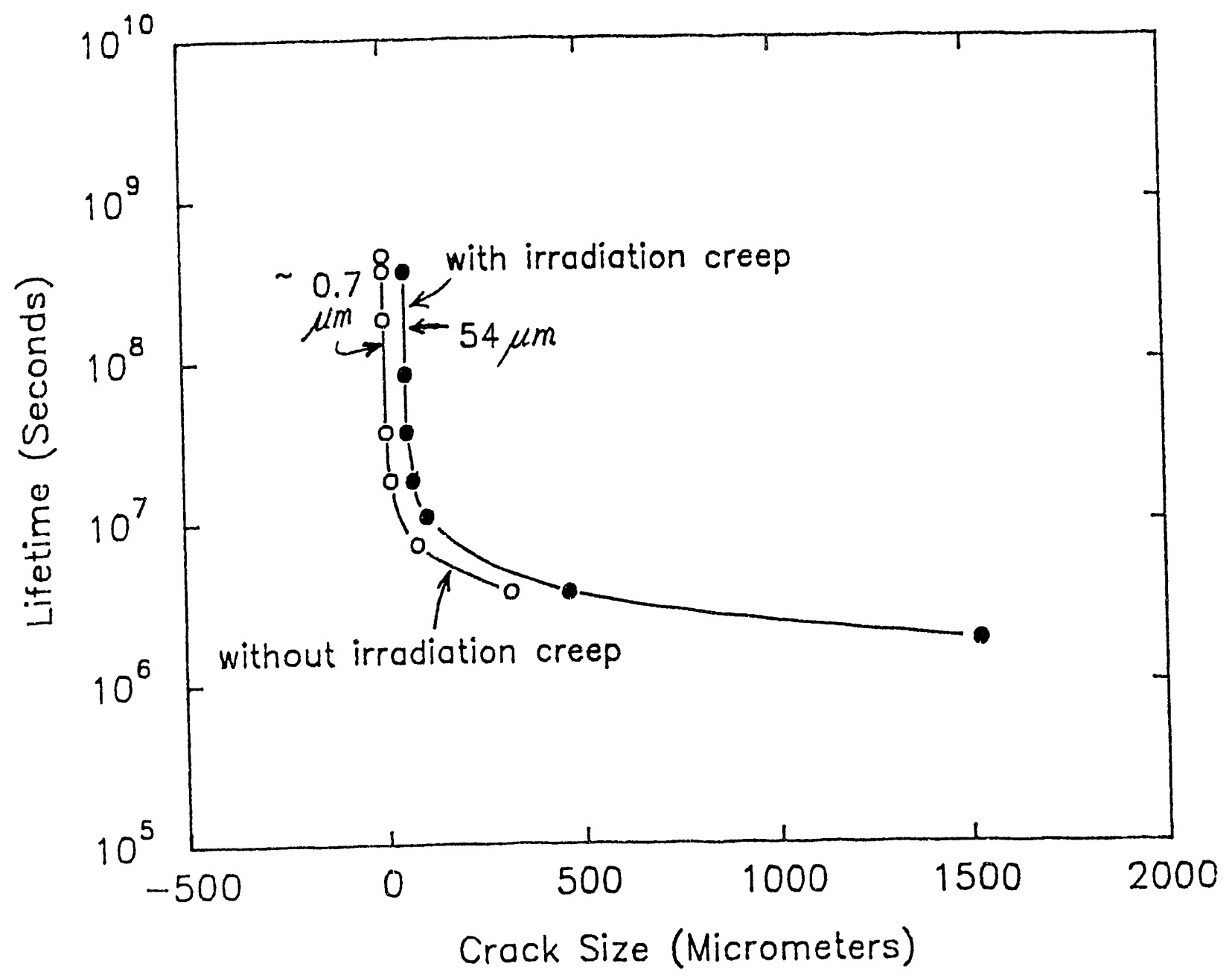

Figure 3. 


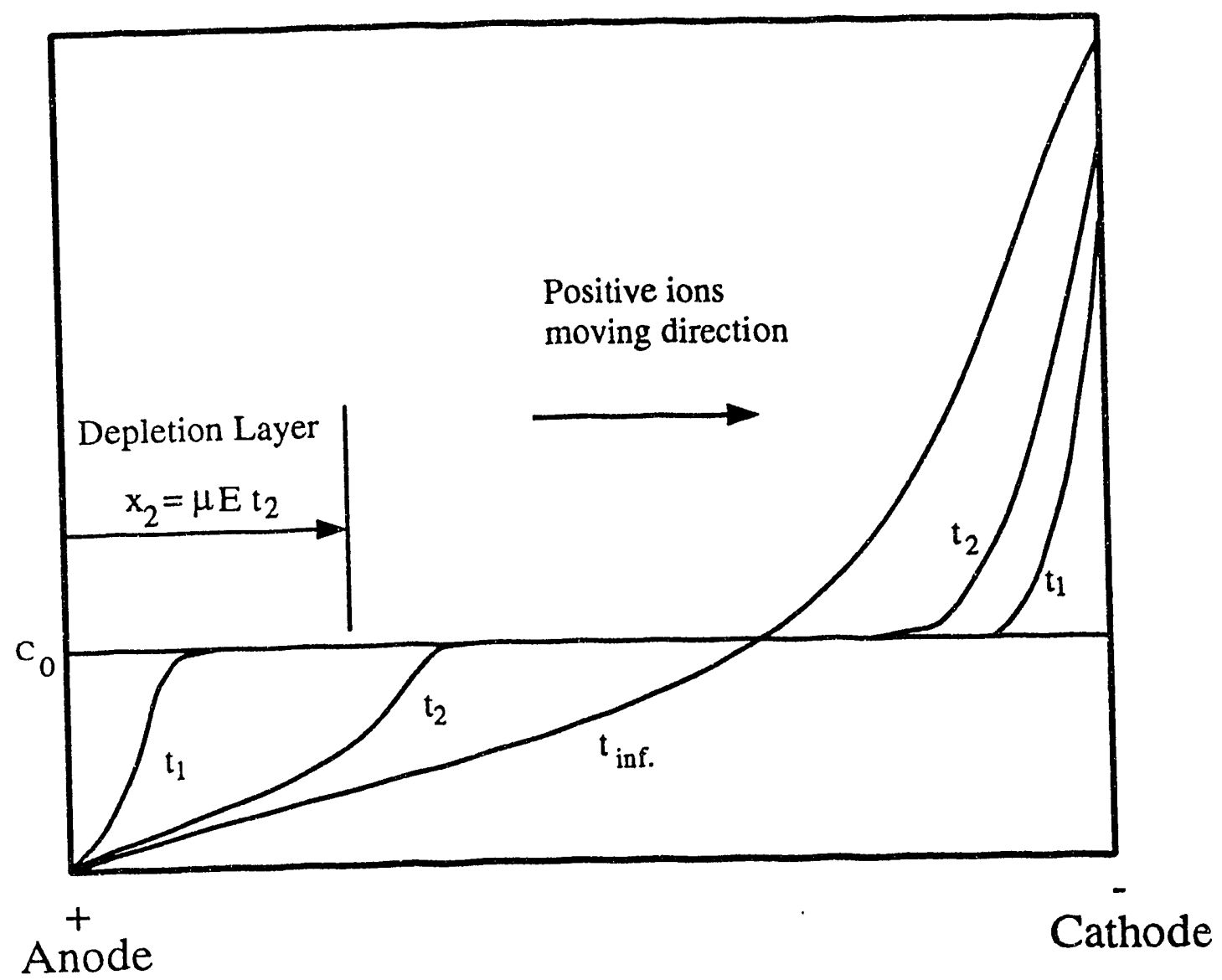

Figure 4 
APPENDIX B 


\section{BRAZING OF COPPER-ALUMINA ALLOYS}

C.K. Lee, B.A. Chin, S. Zinkle, and R.C. Wilcox

Correspondence and proofs to:

Roy C. Wilcox

201 Ross Hall

Department of Mechanical Engineering

Auburn University, AL 36849

(205) $844-3323$ 


\section{BRAZING OF COPPER-ALUMINA ALLOYS}

C.K. Lee ${ }^{1}$, B.A. Chin $^{1}$, S. Zinkle ${ }^{2}$, and R.C. Wilcox ${ }^{1}$ Department of Mechanical Engineering, Auburn University, Auburn, AL 36849 . ${ }^{2}$ Metals and Ceramics Division, Oak Ridge National Laboratory, Oak Ridge, TN 37831

The successful use of GIIDCOP Al-15 in Tokamak fusion reactors depends on the ability to join the alloy during fabrication without destroying its properties. An induction brazing process using a $50 \mathrm{~kW}$ induction furnace with an oval shaped helical coil and the silver-base brazing alloy, BAg-5, has been developed. This process minimizes the time required at elevated temperatures during the brazing process in order to eliminate excessive oxidation associated with furnace brazing. Induction brazing severely restricts the time for silver ingression along the grain boundaries. Examination of the microstructure of induction brazed joints indicated that the brazing procedure produced virtually no diffusion zone at the copper-silver interface. Microhardness measurements indicated little or no difference along the length of the alloy after brazing. Tensile tests of induction brazed lap joints have indicated good braze properties.

\section{Introduction}

According to Nadkarni, et. al. [1] and Bild [2], the dispersion strengthened copper-alumina alloy, GLIDCOP Al-15 (0.15 wt\% Al), has been selected for possible use in the Tokamak fusion reactors because of the alloy's high heat carrying capacity, and high electrical conductivity coupled with the ability to retain 
the cold worked structure after high temperature brazing [3]. The successful use of this alloy depends on the ability to join the alloy during fabrication without destroying these properties. Thus, whitley et. al [4] have stated that a brazing process which does not change the alloy's structure or properties would be desirable. Previous attempts for brazing GLIDCOP Al-15 have centered on furnace brazing techniques. However, the amount of time at elevated temperatures causes excessive oxidation of the base metal and either an inert cover gas or a vacuum furnace must be used. The use of a silver based filler material during furnace brazing requires that the GLIDCOP Al-15 be plated with annealed copper or nickel to prevent loss of the filler material. silver diffuses very rapidly through cold worked copper alloys at high temperatures. Enough silver may actually diffuse away from the joining surfaces, if they are not plated, so that an insufficient amount of filler would be left for brazing.

The objective of this research was the development of an induction brazing process for GLIDCOP Al-15 using a silver-base brazing alloy. This objective centers on minimizing the time required at elevated temperatures during the brazing process in order to eliminate excessive oxidation and diffusion of silver into the base metal.

\section{Experimental procedure}

Brazed joints of GLIDCOP-15 using the BAg-5 brazing alloy (45 wt: Ag, $30 \% \mathrm{Cu}, 25 \% \mathrm{Zn}$ ) [5] were produced by using a $50 \mathrm{~kW}$ induction furnace with an oval shaped helical coil. A range of 
braze times and power settings for consistent brazing were developed. Several furnace brazed joints were produced using the standard Ticusil cycle as outlined by Stephens et.al. [6]. This cycle involved heating at $25^{\circ} \mathrm{C} /$ minute to $815^{\circ} \mathrm{C}$, holding for 20 minutes then heating at $5^{\circ} \mathrm{C} / \mathrm{minute}$ to $870^{\circ} \mathrm{C}$ and holding for 5 minutes. The specimens were then cooled at $2.5^{\circ} \mathrm{C} / \mathrm{minute}$ to room temperature.

Overlap SS-1 type tensile specimens were machined from rectangular strips of GLIDCOP Al-15 obtained from Oak Ridge National Laboratory (ORNL) in the form of cold worked plates $0.762 \mathrm{~mm}$ thick. An Instron Testing Machine (cross head speed of $0.254 \mathrm{~mm} / \mathrm{min}$ ) was used to evaluate tensile properties [7]. subsize cantilever type fatigue specimens were prepared by cutting rectangular pieces from brazed butt joints and then milling to size. The specimens were $0.762 \mathrm{~mm}$ thick with two circular notches of $6.35 \mathrm{~mm}$ radius at the joint. The gage length was $6.35 \mathrm{~mm}$. To eliminate surface scratches, the fatigue specimens were electropolished using a $50 \%$ phosphoric acid, $50 \%$ water electrolyte at room temperature.

Microhardness tests were conducted across the brazed regions, using a LECO DM-400 Hardness Tester with a load of 50 grams for 20 seconds. Microstructures of the brazed joints and the diffusion of silver into copper were studied use an JOEL 840 scanning electron microscope equipped with a Tracor Northern 5500 energy dispersive $x$-ray system. (EDX). 


\section{Results and Discussion}

The optimal brazing time was five seconds for the larger pieces of Glidcop Al-15 from which the overlap ss-1 tensile specimens were prepared. For butt joints from which fatigue specimens were made, the brazing time was from 12 to 15 seconds. Shorter brazing times resulted in incomplete melting of the BAg-5 filler material. Longer brazing times resulted in overheating of the base metal. A protective atmosphere was not required for these short brazing times.

Examination of the brazed interface revealed a small diffusion zone adjacent to the interface in both the induction brazed overlap (Figure 1) and butt joints. On the other hand, a furnace brazed sample contained a large interdiffusion zone at the GIIDCOP Al-15/BAg-5 interface indicating considerable diffusion of silver into the copper alloy (Figure 2). Figures 3 to 5 show the results of the calculated diffusion of silver into copper across the various joints compared to the measured EDX composition of silver. The theoretical calculations were based on the following assumptions:

1. Silver diffused into pure copper with the original concentration of silver in GLIDCOP $A I-15$ as $0 \%$ and the concentration of silver in the BAg-5 brazing alloy as $45 \%$ [6].

2. Fick's second law applied with $D_{0}$ as $0.63 \mathrm{~cm}^{2} / \mathrm{sec}$ (constant for $\mathrm{Ag}$ in $\mathrm{Cu}$ ) [8].

3. The activation energy for surface diffusion was one half of that for volume diffusion $(46.5 \mathrm{Kcal} / \mathrm{mole}$, a constant for Ag impurities in $\mathrm{Cu}$ (8]). 
4. The effective temperature at which diffusion occurred was in the $800-1000^{\circ} \mathrm{C}$ range. Thus, calculations were made for constant temperature diffusion at $1000^{\circ} \mathrm{C}$. Diffusion times of 2 , 4, and 943 seconds were used for the overlap samples, butt joint fatigue samples, and furnace brazed samples, respectively.

5. Silver diffusion was a relaxation of an initial rectangular pulse of the form $C_{0}=45 \%$ (source Ag concentration) for $-a<x<a$ and 0 elsewhere. At $t=0$, the Fourier integral transform for this function is $\sin (\beta a) / \beta$. Thus, according to kirkaldy and young [9], the solution of Fick's second law for the Ag concentration at a distance $x$ from the interface can be written as:

$$
C(x, t)=\left[C_{0} / \pi\right] \int_{-\infty}^{\infty}\left\{[\sin (\beta a) / \beta]\left[\cos (\beta x) \exp \left(-\beta^{2} D t\right)\right]\right\} d \beta \quad \ldots(1)
$$

The calculated silver diffusion coefficient (Eq. 1) at $1000^{\circ} \mathrm{C}$ was between $2 * 10^{-7}$ and $6 * 10^{-7} \mathrm{~cm}^{2} / \mathrm{sec}$, which is between the calculated values for the pure volume diffusion coefficient of $6.3 * 10^{-9} \mathrm{~cm}^{2} / \mathrm{sec}$ and the pure surface diffusion coefficient, $6.3 * 10^{-5} \mathrm{~cm}^{2} / \mathrm{sec}$. In polycrystalline materials there are free surfaces and grain boundaries. The mean jump frequency of an atom in these regions is much higher than that of an atom in the lattice. The diffusivity is therefore higher in these regions. However, the free surface represented a small part of the brazed specimens and, thus, grain boundary diffusion must play an important role during the diffusion process which occurred during brazing.

SS-1 specimens were tested for evaluating the strength of brazed joints in shear. For each specimen, the average unit 
shear stress in the filler metal at failure was determined by dividing the breaking load by the product of the overlap length and the sample width. The average unit tensile stress at failure was calculated by dividing the breaking load by the product of the base metal thickness and the sample width [10]. The average unit shear stress and average unit tensile stress as a function of overlap distance for SS-1 type specimens are shown in Figure 6. For an overlap length of less than 1.5 times the thickness of the base metal, the samples failed in the braze or in the joint. For an overlap length larger than 1.5 times the thickness of the base metal, all specimens failed outside the joint. Figure 6 shows that the unit tensile stress generally increased and tended to become constant at about an overlap to thickness ratio of five. Unit shear stress, on the other hand, generally decreased and never reached a constant value at least in the ratios investigated. These results are similar to those expected by AWS standard samples [10].

Microhardness measurements across an induction brazed lap joint are illustrated in Figure 7. Only a small change in microhardness at the lap joints was observed which suggested that significant recovery of the cold worked Glidcop Al-15 matrix did not occur. An examination of the microstructure did not reveal any noticeable microstructural changes within the matrix. The major cause of concern was the presence of about $40 \%$ voids in the butt joints. Tensile specimens made from butt joints were tested in liquid nitrogen to determine whether the voids were produced during brazing or during fatigue testing. 
These specimens failed in a brittle manner in the joint and also showed about $40 \%$ voids. These results indicated the voids were created during the brazing process. Additional butt joints were designed in an effort to possibly eiiminate the majority of these voids. However, induction brazing configuration could be found which would eliminate or decrease the amount of voids produced.

\section{Conclusions}

The results indicated that a satisfactory induction brazing process could be achieved using a filler material of 45 wt\% silver. The properties obtained by induction brazing were as good as those produced by furnace brazing. One of the main objectives was to minimize the time to conduct the brazing sequence. All Glidcop Al-15 samples were brazed in less than 17 seconds with no protective atmosphere or plating of the surfaces. Also, EDX (SEM) Composition Analysis supported the metallographic evidence that only a minor amount of silver diffusion occurred.

\section{Acknowledgements}

This research was sponsored by the office of Fusion Energy, U.S. Department of Energy, under Grant DEF60586ER52139-91.

\section{References}

[1] A. Nadkarni, E. Klar and W. Shafer, Metals Eugr. Quarterly, 16 (1976) 371.

[2] R. Bild, in: Proc. Materials Research Society Symposium (Pittsburgh, 1986) p. 403. 
[3] E. N. C. Dalder, W. Ludeman and B. Schumacher, Thermal Stakifity of Four High Strength, High Conductivity Copper Sheet Alloys, Lawrence Livermore National Laboratory, UCRL-89034， (April 1984).

[4] 3 . Whitley, et.al. in: Proc. of the 14th symposium on Fusion Technology (Avignon, France, 1986).

[5] Welding, Brazing and Soldering, Metals Handbook, 9th Edition, Vol. 6, (American Society for Metals, Metals Park, 1983) p. $965 \& 1042$.

[6] J. Stephens and D. Schmale, The Effect of High Temperature Braze Thermal Cycles on Mechanical Properties of a Dispersion Strengthened Copper Alloy, ORNL Report, SAND87-1296.

[7] Standard Methods of Tension Testing of Metallic Materials, ASTM Standard E8-84, Vol. 1.02, (American Society for Testing and Materials, Philadelphia, 1985). p. 609.

[8] P. Shewman, Diffusion in Solids, (McGraw-Hill, New York, 1963) p. 111

[9] J. Kirkaldy and D. Young, Diffusion in the condensed state, (The Institute of Metals, London, 1987) p. 25.

[10] Standard Method for Evaluating the Strength of Brazing Joints in Shear, ANSI/AWS Standard C3.2-82, (American Welding Society, Miami, 1982). 


\section{LIST OF FIGURES}

Figure 1. SEM micrograph of an induction brazed lap joint.

Figure 2. SEM micrograph of an furnace brazed joint.

Figure 3. Calculated diffusion of silver (dots) for a furnace brazed joint compared to the measured EDX composition of silver (solid line).

Figure 4. Calculated diffusion of silver (dots) within an induction brazed lap joint compared to the measured EDX composition of silver (solid line).

Figure 5. Calculated diffusion of silver (dots) within an induction brazed butt joint compared to the measured EDX composition of silver (solid line).

Figure 6 . Average unit shear stress (circles) and average unit tensile stress (triangles) as functions of overlap distance for SS-1 specimens. Solid circles and triangles indicated failure within the joint while open circles and triangles represent failure outside of the joints.

Figure 7. Summarized microhardness data for induction brazed lap joints. 


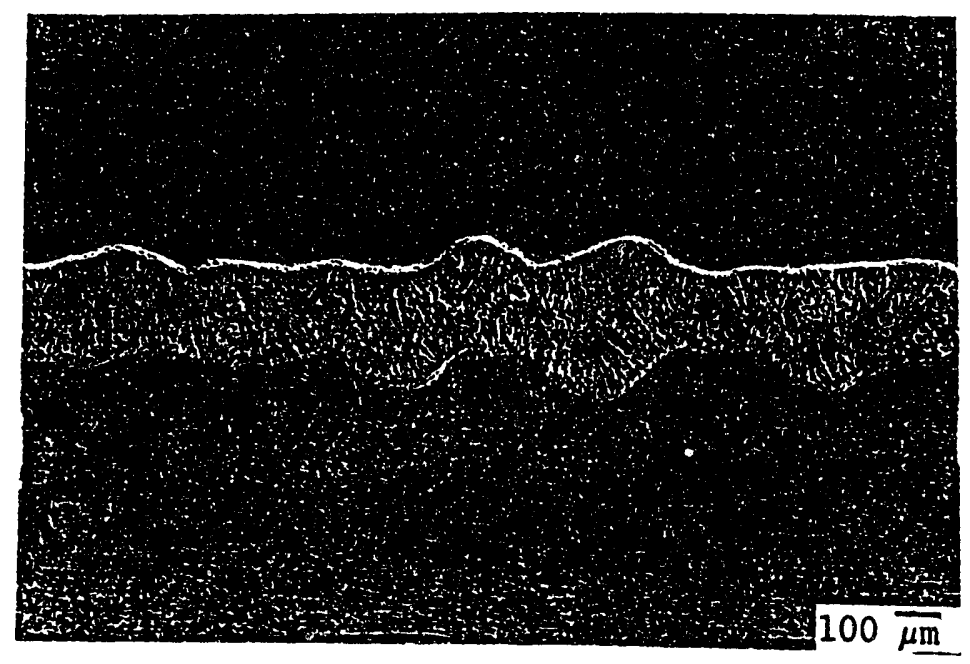

Figure 1. SEM micrograph of an induction brazed lap joint. 


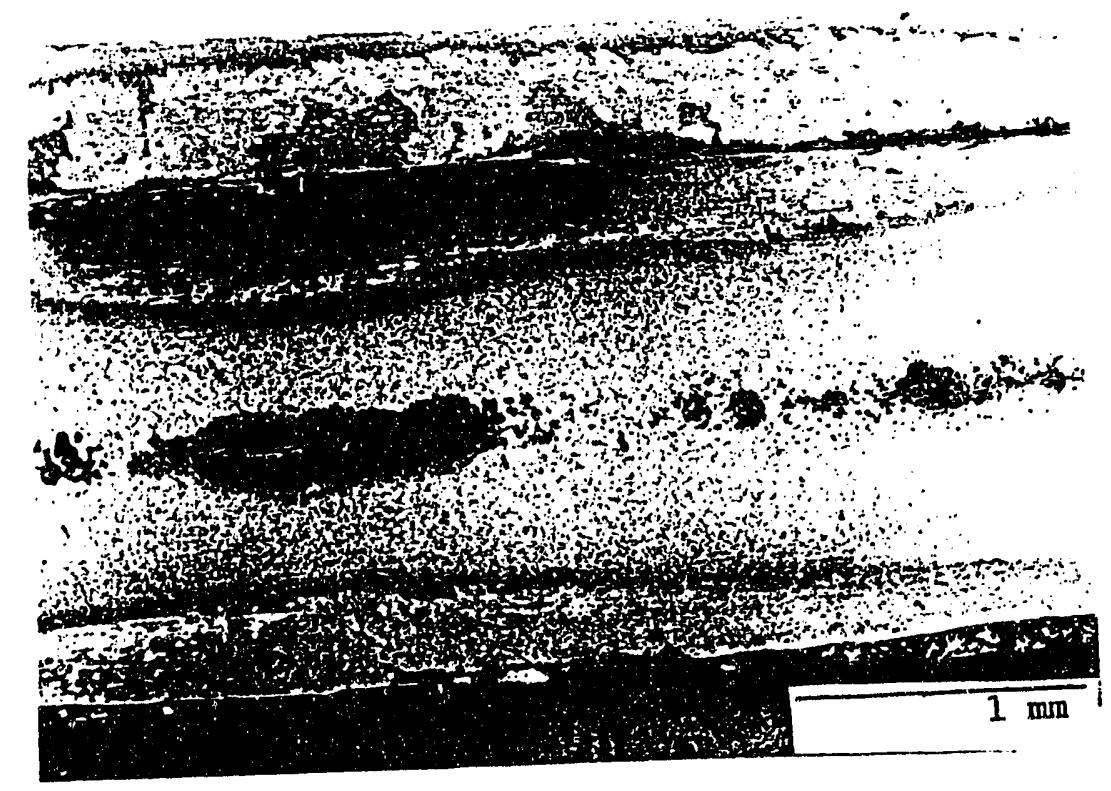

Figure 2. SEM micrograph of an furnace brazed joint. 


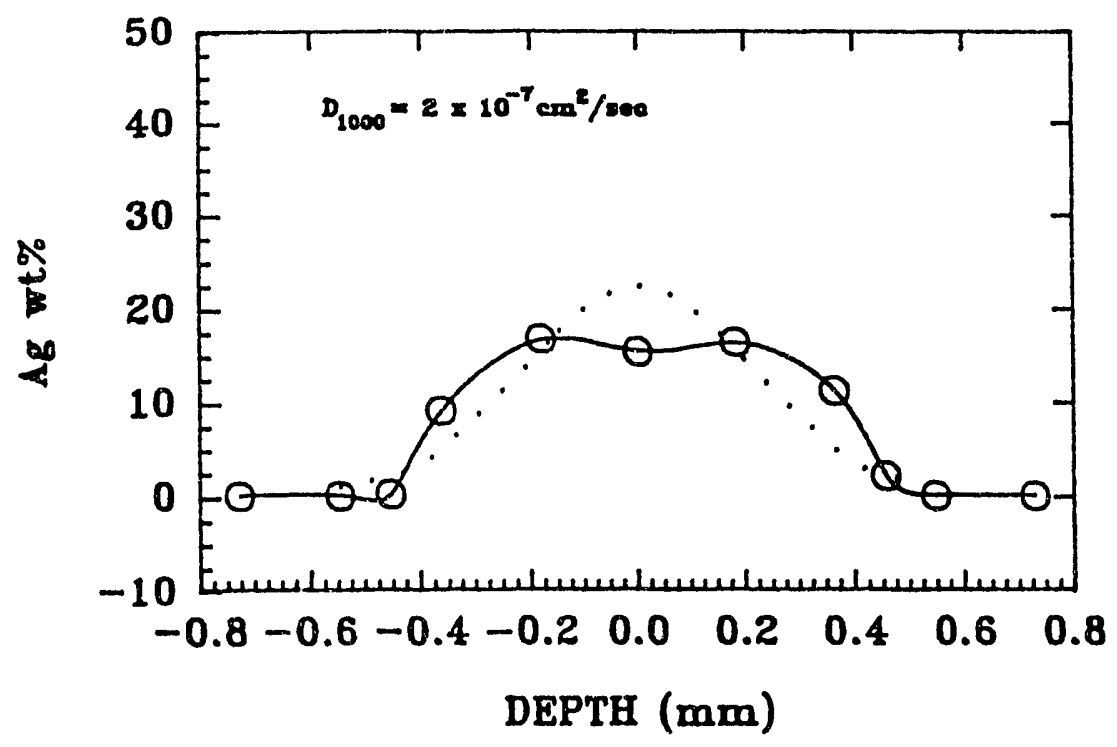

Figure 3. Calculated diffusion of silver (dots) for a furnace brazed joint compared to the measured EDX composition of silver (solid line). 


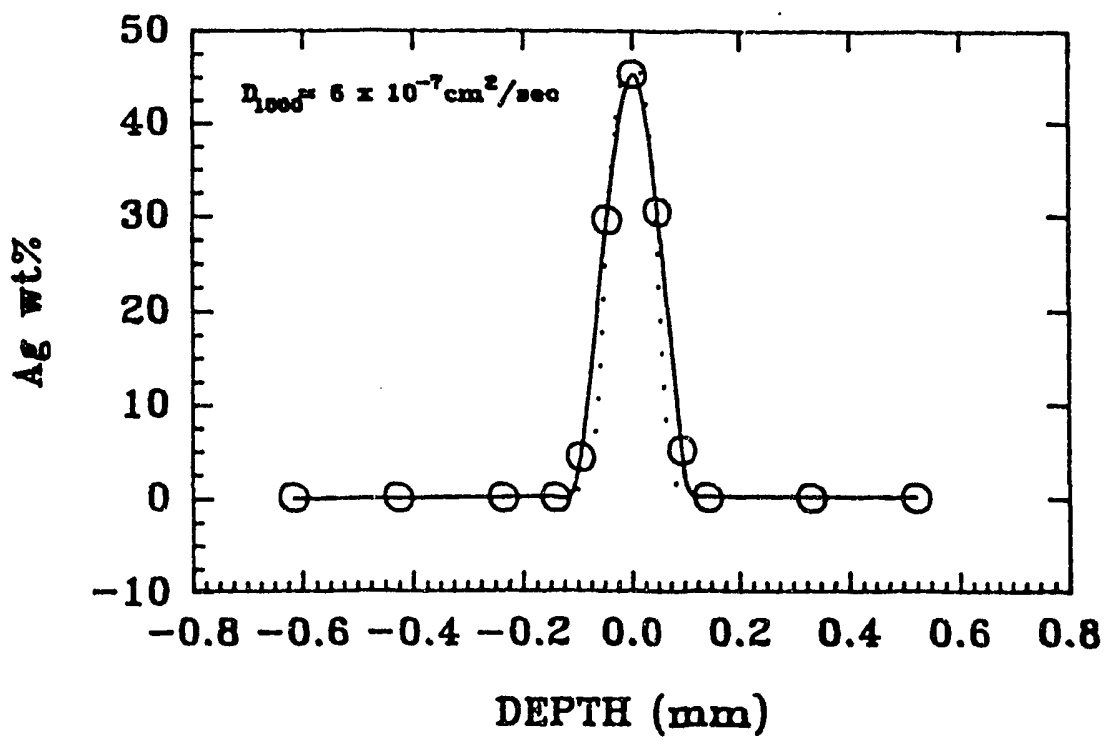

Figure 4. Calculated diffusion of silver (dots) within an induction brazed lap joint compared to the measured EDX composition of silver (solid line). 


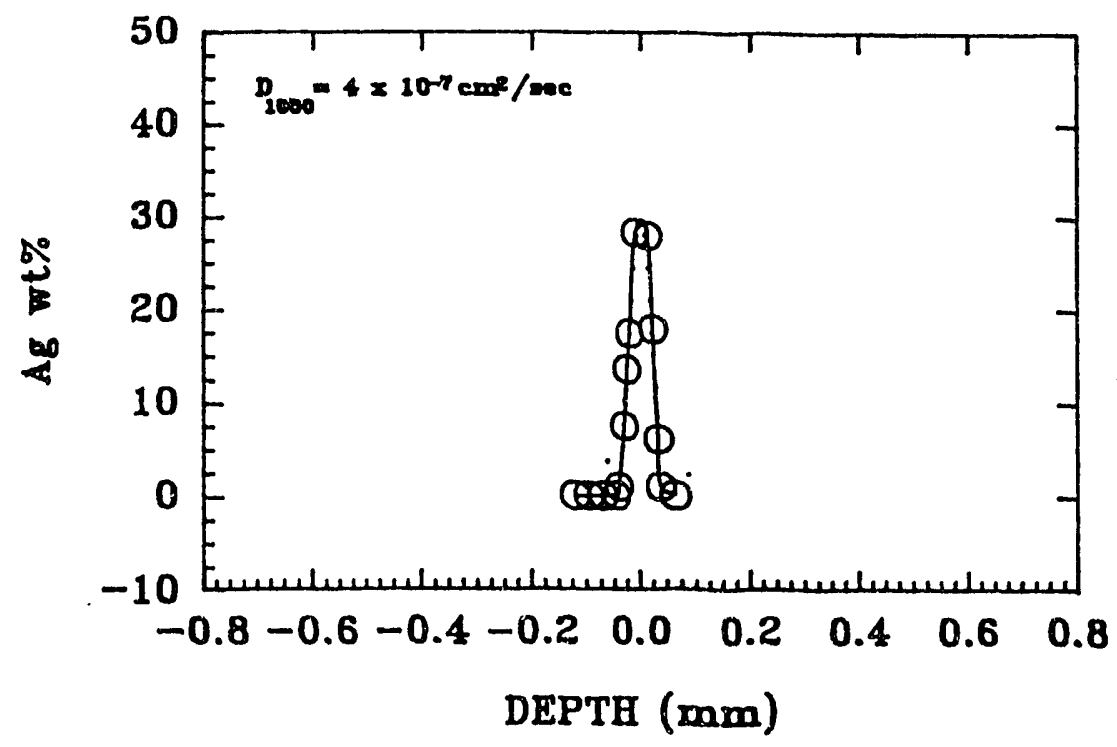

Figure 5. Calculated diffusion of silver (dots) within an induction brazed butt joint compared to the measured EDX composition of silver (solid line). 


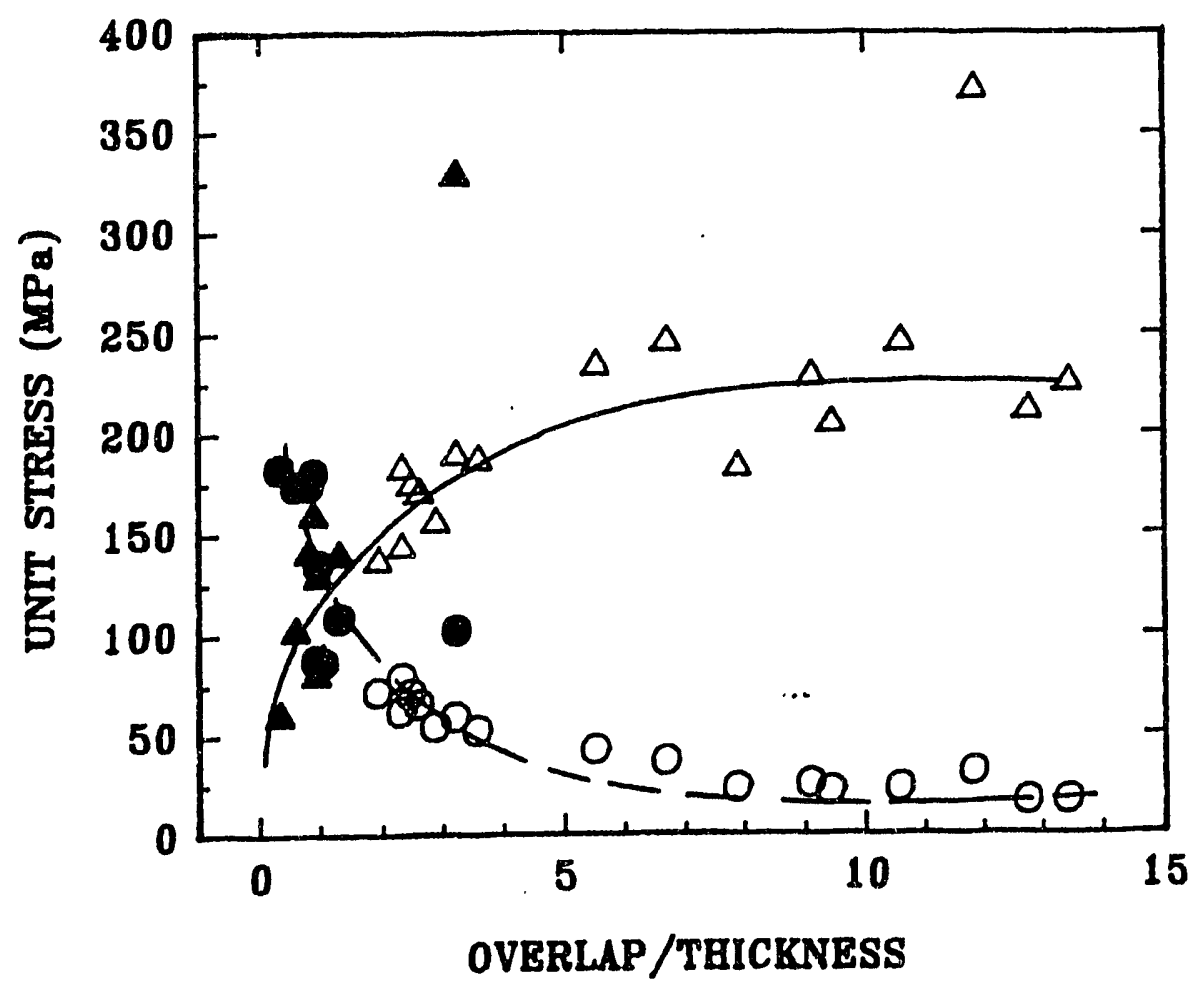

Figure 6. Average unit shear stress (circles) and average unit tensile stress (triangles) as functions of overlap distance for ss-1 specimens. Solid circles and triangles indicated failure within the joint while open circles and triangles represent failure outside of the joints. 


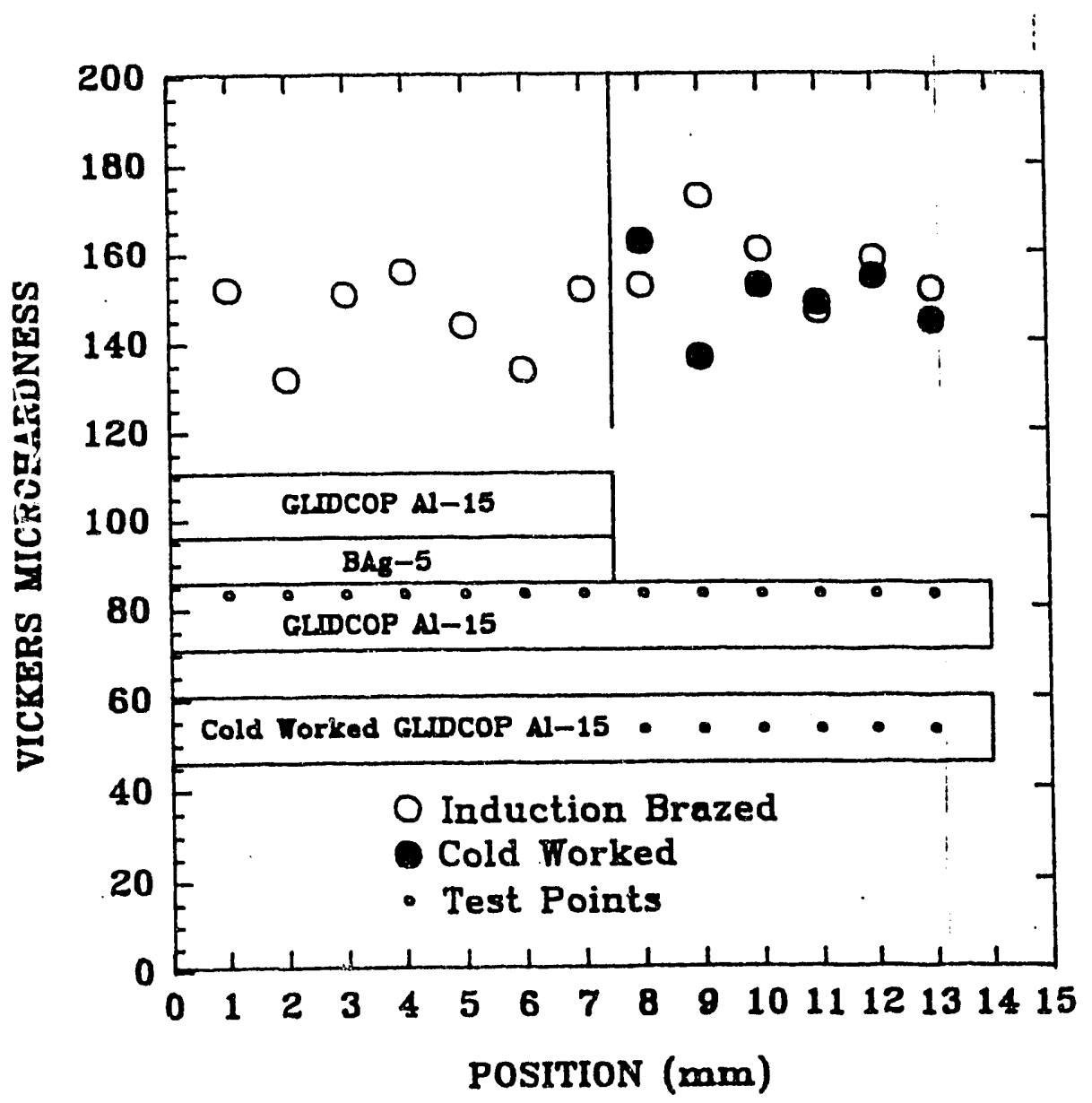

Figure 7. Summarized microhardness data for induction brazed lap joints. 
APPENDIX C 


\section{ABSTRACT \\ INERARED THERMOGRAPHY FOR NON-DESTROCTIVE MONITORING OP WELD PENETRATION VARIATIONB}

P. Banerjee, J. Y. Liu and B. A. Chin

Materials Engineering, Auburn University, Auburn, AL 36849

The thermal distributions obtained during the gas tungsten arc welding process were analyzed using mathematical techniques to determine if changes in the surface temperature distribution could be correlated with changes in weld penetration. An infrared scanning camera was used to obtain the temperature profiles. Analyses were performed on the temperature distribution along a line transverse to the direction of torch motion (1inescan). Three parameters taken from the thermal distributions were found to indicate changes in weld penetration. These are the temperature gradient at a point, the measured bead width and the integrated thermal volume (volume under the thermal temperature distribution). These indicators were found to change almost simultaneously with penetration changes. The integrated thermal volume was found to be related to the instantaneous weld pool volume as measured by decantation. With optimization of the computation techniques, these indicators can be incorporated into an in-process, nondestructive monitoring and correction system for weld quality control in fusion reactor components. 


\section{IMPRARED THERMOGRAPHY FOR NOW-DESTROCTIVE MONITORING OF WELD PENETRATION VARIATIONB}

P. Banerjee, J. Y. Liu and B. A. Chin

Materials Engineering, Auburn University, Auburn, AL 36849

Introduction:

The potential release of hazardous radioactive substances places strict quality control requirements on weldments of fusion devices. Weld penetration is one important parameter which greatly influences the strength and ductility of welds. Dynamic sensory penetration control presents a challenge because penetration is a feature that occurs in the thickness dimension and is therefore normally inaccessible to standard vision devices. Infrared thermography is a potential non-destructive tool for monitoring and controlling the molten metal pool in the thickness dimension.

Automation requires effective sensing techniques to detect weld variations such as those resulting from sudden plate thickness changes [1], changes of trace element contaminants [2-10], shielding gas composition changes [11] and welding current changes. Each of these can individually cause significant alterations in weld penetration. Charge-coupled device cameras have been used in the past to monitor root gap width as well as weld bead height and weld penetration [12]. In the current investigation, an infrared sensor was chosen for process control because, unlike other sensors, an infrared sensor can monitor several variables simultaneously [13-19].

The earliest work using infrared sensors for automatic welding was performed by Ramsey et al. [18] in 1963. More recently, 
investigations using infrared sensors for contaminant and penetration detection were undertaken by $L$ in et al. [13] and Chen et al. [1] respectively. Khan et al. [13] used on-line IR sensing techniques to dynamically monitor the thermal field in front of the weld pool during the welding process and identify surface contaminants.

Doumanidis et al. [19] used a double torch configuration and an infrared camera mounted with its axis transverse to the line of motion. They used the infrared sensors to identify the size of the heat affected zone (HAZ) and its cooling rate. Chen et al. [1] showed that infrared thermography may provide information that could be used to control depth of penetration. The authors mathematically fit measured isotherms to an ellipse and defined the area of the ellipse as the thermal area. This thermal area and the minor axis of the ellipse were found to vary concurrently with variations in depth of penetration caused by plate thickness changes during constant heat input gas tungsten arc welding. However, this technique was limited to analysis of isotherms outside the molten metal pool. The current study focusses on investigating other quantitative approaches for determining the depth, width and shape of the weld pool using surface temperature distributions.

The primary objective of the current investigation was to develop weld penetration indicators that could be used as error signals for on-line penetration control. This meant that the 
indicators had to have a computation time of the order of the system response time. A secondary objective of this study was to test the performance of these indicators by intentionally changing weld parameters which affect the penetration.

Plate thickness changes, welding current changes and minor element content changes were used to induce weld penetration variations. Minor element concentration is known to influence the convective flows in weld pools. Minor elements alter the surface tension coefficient of the molten pool [4, 8]. Sulfur, titanium dioxide and silicon have positive surface tension coefficients. These elements exhibit an increase in the surface tension of the weld pool with increase in temperature. In any weld pool, the surface temperature increases from the edge of the weld pool to the center. A sudden increase in sulfur content therefore results in an increase in surface tension from the edge to the center of the weld pool. Consequently, the convective flow changes from radially outward to radially inward and down to the bottom of the crater containing the weld pool. This results in a narrower, deeper weld pool and hence increased depth of penetration and reduced bead width. Aluminum, oxygen and nitrogen as well as the base metal itself, have negative surface tension coefficients and result in a wider, shallower molten pool and hence reduced penetration and increased bead width. These changes in molten metal convection should be readily visible through changes in temrerature distributions. 


\section{Experimental setup:}

Figure 1 shows the infrared camera mounted on a torch assembly. The camera monitors the temperature distribution around the weld pool. A custom built interface transfers the information from the camera to the computer for analysis and feedback of appropriate corrective action. In all experiments, gas tungsten arc welding was performed with a Miller Synchrowave $500 \mathrm{AC} / \mathrm{DC}$ power source and a water cooled torch. The torch was manipulated by an ESAB X-Y positioning table. This positioning table was controlled by a Hewlett Packard series 320 computer through an HP3497A data acquisition/control unit. The infrared radiation which characterizes the thermal distribution of the plates being welded, was measured by an Inframetrics model 525 infrared camera. The infrared camera determines the temperature distribution by sampling a portion of the emitted energy within a wavelength band of 8 to 12 micrometers. The infrared image from the camera was transferred to the controlling computer in a digital format. Each scan of the camera was transferred as a frame consisting of $250 \times 192$ discrete infrared intensity measurements. These measurements are a function of the local absolute temperatures and are in a digital format, stored as numbers ranging from 0 to 255.

The welding was performed using $6.35 \mathrm{~mm}(0.25 \mathrm{in})$ thick AISI 1008 steel plates of size $304.8 \mathrm{~mm} \times 304.8 \mathrm{~mm}$ (12 in X $12 \mathrm{in}$ ). These plates were prepared by sand blasting before welding. The welding parameters have been given in Table 1 . Three sets of 
experiments were conducted to investigate the relationship between penetration and thermal temperature distribution. These experimental sets involved: current changes, plate thickness changes and minor element composition changes.

The first set of experiments was designed to detect weld penetration variations due to intentionally induced welding current changes. These experiments used an impulse decantation technique [20] to determine the instantaneous weld pool volume. An argon jet at $700 \mathrm{psi}$ was used to decant the molten metal from the crater (Figu:e 3). The decantation is initiated by a computer activated solenoid valve. The measured time delay between the acquisition of the infrared data and the activation of the solenoid valve was found to be of the order of a few milliseconds. Synchronization of the two processes is therefore possible. Post weld optical metallography in the vicinity of the decanted crater did not show any residual weld metal. Thus, the effectiveness of the decanting process was confirmed. The volume of the decanted crater was then determined by making a wax impression and finding its weight which was converted to a volume using a predetermined density. This process was repeated for welds performed at five different current levels - 100 Amps, 120 Amps, 140 Amps, 160 Amps and 180 Amps. At each of these current levels, four welds were performed for statistical accuracy.

The second set of experiments was designed to investigate the effect of plate thickness variations on the penetration indicators. 
Welding was performed on a plate with three step changes in thickness. These changes were from $6.35 \mathrm{~mm}(0.25 \mathrm{in})$ to $4.763 \mathrm{~mm}$ $(0.1875 \mathrm{in})$, from $4.763 \mathrm{~mm}$ to $3.175 \mathrm{~mm}(0.125 \mathrm{in})$ and from $3.175 \mathrm{~mm}$ to $6.35 \mathrm{~mm}$. One hundred and fifty frames of infrared data were acquired during the welding run spanning a distance of $190.5 \mathrm{~mm}$ $(7.5 \mathrm{in})$.

Experiments were also designed to study the influence of minor elements on the temperature gradient. For this set of experiments, $1 \mathrm{~mm}$ diameter holes were drilled into the base metal and either aluminum wires or iron sulfide pieces were force fitted into the holes. Welds were performed along a line passing through three minor element concentration sites. For each weld, one hundred frames of infrared data were acquired and analyzed.

\section{Data Display Modes:}

The surface temperature distributions of the plates being welded can be displayed in different ways. The two methods that were used to display the data for analysis were - isothermal contours (regions of equivalent temperature) and Iinescans (thermal profiles along a line on the plate, transverse to the direction of torch motion). Figure 2 shows the temperature distribution of a weld made on a $6.35 \mathrm{~mm}$ (0.25 in) thick AISI 1008 steel plate. The temperature distribution is displayed in the line scan mode. The isothermal contour map consists of several color bands, each corresponding to a range of temperatures $(\mathrm{Black}=$ coldest, Magenta 
= hottest). Linescans reveal local temperature changes, whereas the isothermal contour maps generally show macroscopic changes in the temperature distribution.

\section{Results and Discussions:}

\section{Weld Current Related Penetration Variation Detection}

The objective of these experiments was to relate penetration to information that could be extracted from the thermal image. It was hypothesized that the depth of penetration could be estimated if the surface area (area of molten metal seen from above the weld) and volume of molten metal were known. From previous experiments it was known that the surface area of the molten metal pool can be easily identified using the infrared imaging gradient tecinique. This technique uses the abrupt change in the temperature gradient at the solid-liquid metal interface (caused by the difference in solid and liquid metal emissivities) to find the molten pool edge. As seen in Figure 2, each linescan shows at least three inflection points on each side of the line of symmetry A-B. The bead width was computed as the largest distance between the left hand side valley and the right hand side peak as measured on the thermal distribution in a direction perpendicular to torch direction. The solidified weld pool front was computed by locating the solidliquid metal interface for regions ahead and behind the welding torch. In this manner the surface area of the weld bead was 
determined.

The integrated thermal volume is defined as the summation of the infrared intensity measurements within the area enclosed by the weld pool. The weld pool boundary was identified using the gradient technique described above. The integrated thermal volume was then compared to the measured volume of molten metal by using an impulse decantation technique described in the experimental section above. The relationship between the computed infrared thermal volume and the decanted crater volume is shown in Figure 3 .

\section{Plate Thickness Related Penetration Variation Detection}

The weld pool front computation technique described above was repeated using a plate with step changes in thickness (Figure 1). The weld pool fronts shown in this figure have been computed from eleven frames of infrared data, acquired at a step change in plate thickness from $3.18 \mathrm{~mm}(0.125 \mathrm{in})$ to $6.35 \mathrm{~mm}(0.25 \mathrm{in.})$ over a distance of $10.3 \mathrm{~mm}$. The straight lines show the measured bead width at this step change in thickness. Once again, the computed fronts resembled the actual weld in both bead width and bead shape. Also, a detailed analysis showed that the location of the peaks and valleys in the first derivative plot of the line scan remained the same as long as the plate thickness was the same. 


\section{Minor Element Related Penetration Variation Detection}

The temperature gradient was computed for all points contained within the weld pool along directions perpendicular to direction of torch travel. These weld pool gradients were then monitored as the weld traversed over intentionally induced impurity inserts as described in the experimental section.

For the weld traversing the aluminum inserts, the temperature gradient was found to decrease at the locations containing the inserts (Figure 5). This can be explained by considering what happens to the weld pool at these locations. Due to surface tension effects $[4,5]$, aluminum increases the width of the weld pool and decreases the depth of penetration. Given the same amount of heat input from the welding torch, a wider weld pool would mean a smaller temperature gradient across the weld pool.

For the weld passing through iron sulfide inserts, the gradient rose suddenly just before the inserts and then dropped sharply before returning to normal (Figure 5). Unlike aluminum, sulfur decreases the width of the weld pool and increases the depth of penetration. This increases the thermal gradient sharply. As soon as the effect of sulfur ceases, base metal surface tension effects come into play. These effects are similar to those of aluminum and hence result in a drop in gradient. It should be noted that this type of change in the gradient at a point is unique to minor element effects and cannot be expected to result from 
other perturbations such as plate thickness changes.

\section{Conclusions:}

Results presented in the above sections show that considerable progress has been made in determining the relationship between penetration variations and plate temperature distributions. The use of infrared sensors to detect penetration changes has resulted in the following conclusions:

- The solid-liquid metal interface and hence the weld pool front, can be identified from inflections in the temperature distribution caused by a difference in the emissivity of solid and liquid metal

- The infrared thermal volume and decanted crater volume can be related through a power law function

- The temperature gradient technique can be used to identify penetration changes due to the presence of minor elements

- The computed bead width technique is suited for detecting weld pool geometry variations arising due to changes in either welding current or plate thickness

\section{REFERENCES:}

[1] W. H. Chen, P. Banerjee and B. A. Chin, in: Proc. on Trends in Welding Research (ASM International, Ohio, 1990) p. 517.

[2] S. S. Glickstein and W. Yeniscavich, A Review of Minor Element Effects on the Welding Arc and Weld Penetration, WRC Bulletin No. 266, Welding Res. Council, (1977).

[3] S. M. Correa and R. E. Sundell, in: Proc. on Modeling and control of Casting and Welding Processes (TMS, Pennsylvania, 1986) p. 211.

[4] Sundell, R. E., L. Harris, D. W. Walsh, H. Solomon, S. Correa and W. F.Savage, Minor Element Effects on Gas Tungsten Arc Weld Penetration, General Electric Report No. 86SRD013, (1986).

[5] C. R. Heiple and J. R. Roper, welding J. 61 (1982) 97-s.

[6] W. F. Savage, E. F. Nippes and G. M. Goodwin, Welding J. 56 (1977) $126-s$.

[7] K. C. Mills and B. J. Keene, International Materials Reviews, 35 (1990) 185.

[8] C. R. Heiple, J. R. Roper, R. T. Stranger and R. J. Aden, Welding J. 62 (1983) 72-s. 
[9] G. Carboni, Welding International, 1 (1987) 750.

[10] B. Heritier and $\mathrm{Ph}$. Maitrepierre, in: Proc. on Inclusions and Residuals in steels: Effects on Fabrication and Service Behavior (Canadian Govt. Publ. Centre for CANMET and CSIRA, Ottawa, 1985) p.395.

[11] J. F. Key, Welding J. 59 (1980) 364-s.

[12] Y. Sugitani, Y. Nishi and T. Sato, in: Proc. on Trends in Welding Research (ASM International, Ohio, 1990) p. 923.

[13] T. T. Lin, H. T. Lin and B. A. Chin, Optical Engineering, 5 (1988).

[14] S. M. Govardhan and B. A. Chin, in: Proc. on Trends in Welding Research (ASM International, Ohio, 1990) p. 383.

[15] S. Nagarajan, P.Banerjee, W. H. Chen and B. A. Chin, IEEE Transactions on Robotics and Automation, Accepted July 1990.

[16] S. Nagarajan, P. Banerjee and B. A. Chin, in: Proc. on Transport Phenomena in Materials Processing, (ASME, New York, 1990) p.171.

[17] P. Banerjee, S. Nagarajan and B. A. Chin, in: Proc. on The 1991 NSF Design and Manufacturing Systems Conference (SME, Michigan, 1991) p. 143.

[18] P. W. Ramsey, J. J. Chyle, J. N. Kuhr, P. S. Myers, M. Weiss and W. Groth, Welding J. 42 (1963) 337-s.

[19] C. Doumanidis and D. E. Hardt, Welding J. 69 (1990) 186-s.

[20] W. F. Savage, E. F. Nippes and F. J. Zanner, Welding Journal, 57 (1978) 201-s. 
Table 1. Welding Conditions in Penetration Measurement Experiments

Torch Speed

Shielding Gas

Current

Voltage

Electrode
$2.667 \mathrm{~mm} / \mathrm{s}(6.3 \mathrm{in} / \mathrm{min})$

Argon, $18.87 \mathrm{lit} / \mathrm{min}$ (40 cfh)

$175 \mathrm{~A}$ DC

$20 \mathrm{~V}$

Negative, EWTh-2, $3.175 \mathrm{~mm}$ 
Table 2. Time Constants

\begin{tabular}{llcl}
\multicolumn{1}{c}{ Parameter } & \multicolumn{2}{c}{ Analyzed for } & Computation Time \\
& 1 Line & Frame & \\
\hline $\begin{array}{l}\text { Fitted Ellipse } \\
\text { Bead width }\end{array}$ & $\mathrm{x}$ & $\mathrm{x}$ & $4 \mathrm{mins}$ \\
$\begin{array}{l}\text { Thermal Volume } \\
\text { Gradient at a Point }\end{array}$ & $\mathrm{x}$ & $\mathrm{x}$ & $\begin{array}{l}.5 \mathrm{sec} \\
.09 \mathrm{~min}\end{array}$ \\
\hline
\end{tabular}




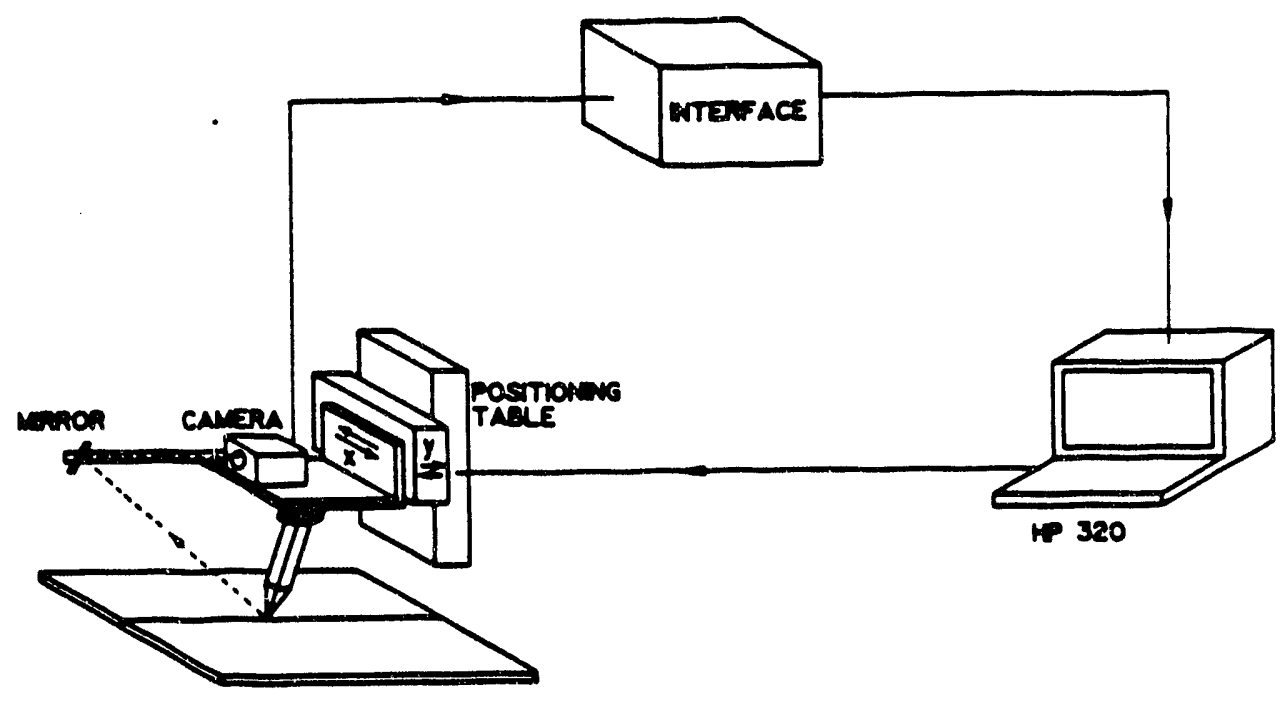

Figure 1. Experimental Setup

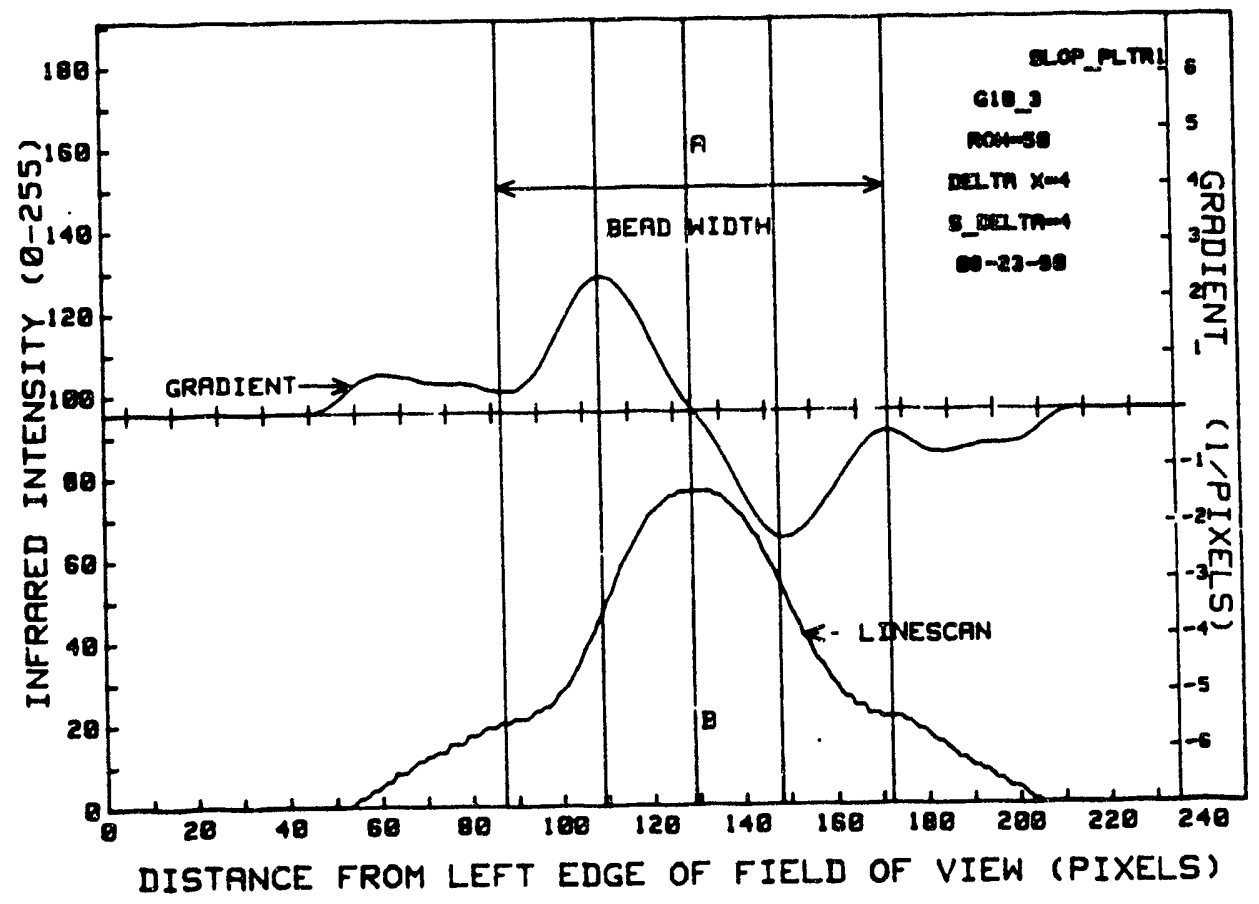

Figure 2. Gradient Technique 


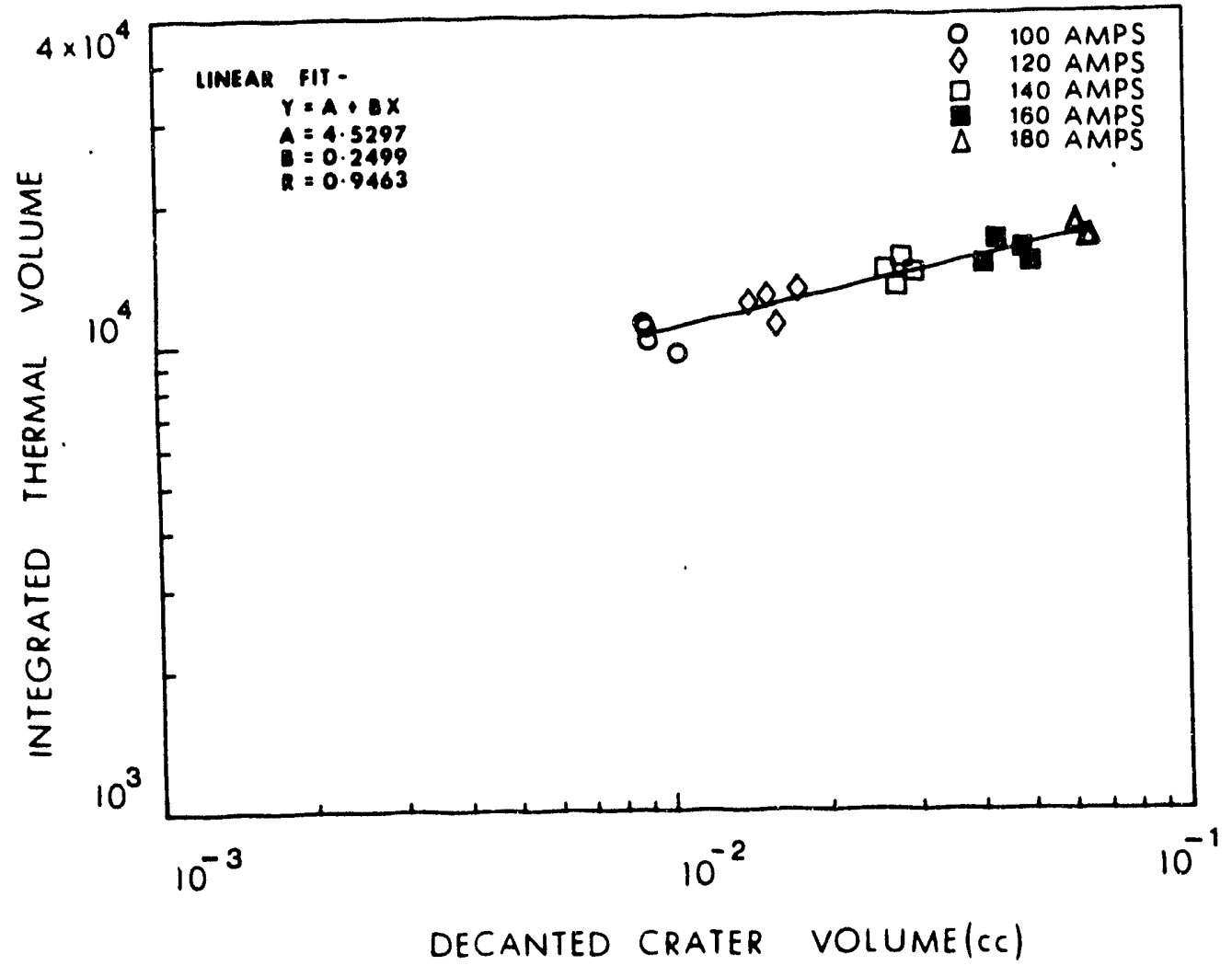

Figure 3. Infrared Thermal Volume vs Decanted Crater Volume

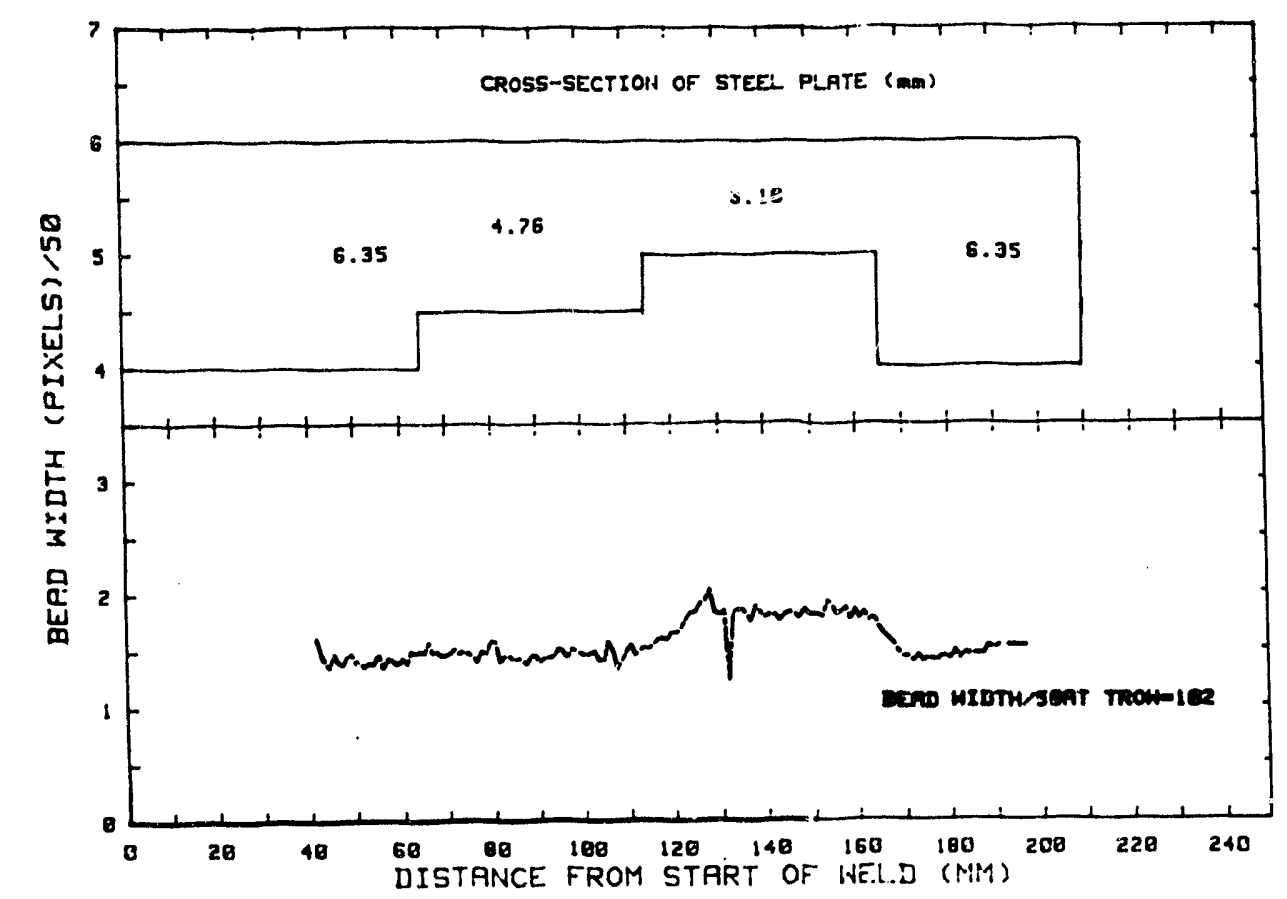

Figure 4. Computed Weld Pool Front - step Change in Thickness 


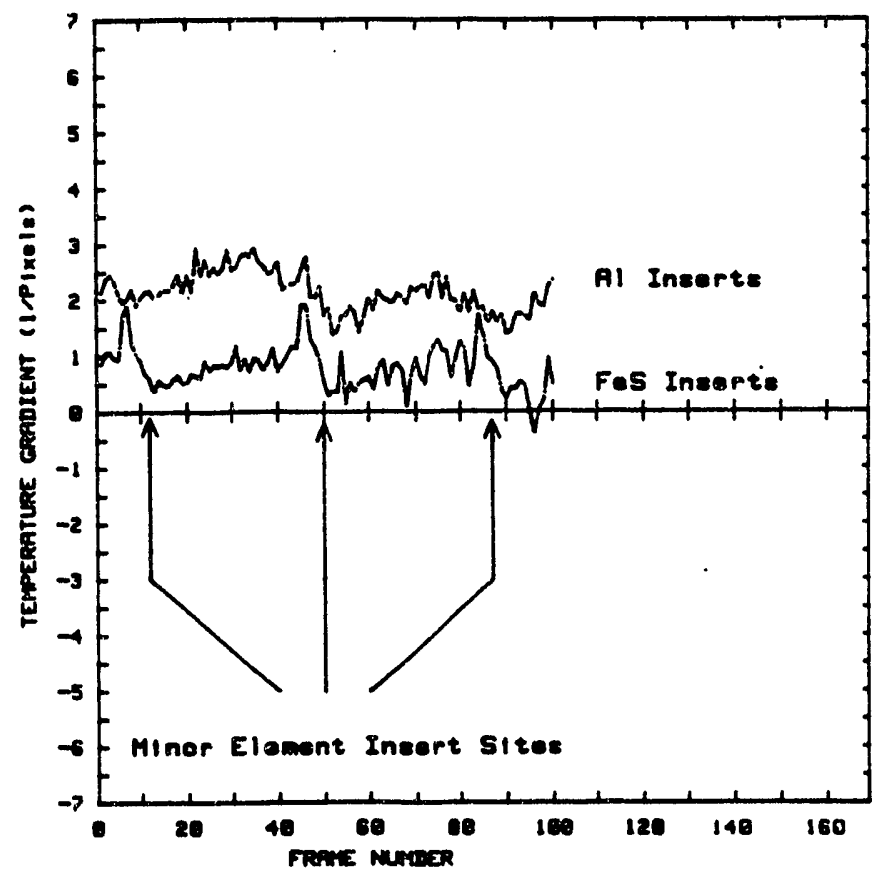

Figure 5. Temperature Gradient Variation - Al and Fes inserts 
APPENDIX' D 


\title{
THE WELDING OF NIOBIUM TO STAINLESS STEEL Shaofeng Chen, Ralph H. Zee and Bryan A. Chin Materials Engineering Auburn University \\ Auburn, AL 36849
}

\begin{abstract}
The joining of Nb-1Zr to austenitic type 316 stainless steel (316SS) with a vanadium interlayer was investigated. Sound welds were produced on sheet metals (1.5 mn thickness) by lap welding $316 \mathrm{SS}$ over $\mathrm{Nb}-1 \mathrm{Zr}$ and pure vanadium using the gas tungsten arc process. Tensile tests of both weld joints showed satisfactory strength and ductility. However metallography showed the formation of an intermetallic layer in the boundary between $316 \mathrm{SS}$ and $\mathrm{Nb}-1 \mathrm{Zr}$. Insertion of a vanadium interlayer between $316 \mathrm{SS}$ and $\mathrm{Nb}-1 \mathrm{Zr}$ was investigated. The vanadium interlayer did not inhibit the formation of the intermetallic. It was found that convection in the weld pool carried the molten vanadium interlayer into the fusion zone thereby exposing niobium directly to liquid ss. Tensile test results showed poor strength and ductility of the joint compared to the direct $316 \mathrm{SS}$ to Nb-12r joint.
\end{abstract}




\section{Introduction}

Refractory metal alloys are potential candidates for fusion reactor components which experience sustained high temperatures (in excess of $1200^{\circ} \mathrm{C}$ ) during their life. In many instances, it is advantageous both technically and economically to join the refractory metal to lower cost, easily fabricated stainless steel. one such application is a cascade coolant system in which the high temperature loop section would be fabricated from $\mathrm{Nb}-1 \mathrm{zr}$ followed by a lower temperature loop which would be fabricated from stainless steel. The main difficulties to be overcome during joining of the Nb-1Zr to $316 \mathrm{SS}$ by fusion welding are joint integrity, formation of brittle intermetallic phases and differential thermal expansion of the two materials.

In order to circumvent the problems of fusion welding other joining methods such as purely mechanical joining, friction welding, diffusion welding and brazing have been investigated to join such dissimilar refractory metals. An evaluation of a coextruded $\mathrm{Nb}-1 \mathrm{Zr}$ to 316 stainless steel bimetal joint was conducted by Cameron [1]. Diffusion welding of refractory metals to stainless steel has also been discussed by Lison and stelzer [2]. Selected filler metals were suggested for diffusion welding joints of several dissimilar metals. Satisfactory friction welded joints of $\mathrm{Nb}$ alloys to stainless steel have been produced by Fedorchenko, although their properties were found to be affected by thermal cycling [3]. Previous attempts to join Nb-1Zr to ss by fusion welding have been made by several investigators. D'Yachenko 
welded niobium to stainless steel using both electron beam and arc welding [4]. He found that the quality of the joint was highly dependent on optimum joint design and precise control of the welding conditions. To avoid intermetallic layer formation he considered the insertion of a third metal as an interlayer during welding. Vanadium is the material which was selected by us for investigation as ar interlayer in the $\mathrm{Nb}-\mathrm{Zr}$ to ss weld joint. Vanadium was selected because it is one of the few materials which displays complete solubility with niobium and considerable solubility with iron. Veinik [5] investigated electron beam welding of niobium to stainless steel with a vanadium interlayer and found that the vanadium layer prevented formation of intermetallic compounds. Lindergren used vanadium as a filler metal when sealing niobium tubes with a stainless steel cap using a laser weld [6]. However, no mechanical properties were reported by either Veinik or Lindergren. Successful steel to niobium joints with a vanadium interlayer were achieved by Kazak using explosion welding methods [7]. In this paper, the results of studies are presented which were performed to provide an understanding of the relationship between microstructure and properties of welded niobium-SS transition joints both with and without vanadium interlayer.

\section{Experimental procedure}

Type 316 stainless steel (316SS) was received in the form of $1.52 \mathrm{~mm}$ cold-rolled sheets. $\mathrm{Nb}-1 \mathrm{Zr}$ and pure vanadium were received 
in the form of $1.52 \mathrm{~mm}$ annealed sheets. Vanadium foil $(99.99 \%$ pure) $0.15 \mathrm{~mm}$ in thickness was used for interlayer studies. Gas tungsten arc welding was conducted by lap welding $316 \mathrm{SS}$ over $\mathrm{Nb}-1 \mathrm{Zr}$ sheets or vanadium sheets with an overlap width of $10 \mathrm{~mm}$. For welds of $316 \mathrm{SS}$ to $\mathrm{Nb}-1 \mathrm{Zr}$ with a $\mathrm{V}$ interlayer, $\mathrm{V}$ foil was clamped between $316 \mathrm{SS}$ and Nb-1Zr sheets and then welded. The welding surface including foil was carefully cleaned using standard techniques just prior to welding. The optimum welding conditions were obtained at $11 \mathrm{VDC}, 60$ to $80 \mathrm{~A}$ at a travel speed of $1.7 \mathrm{~mm} / \mathrm{s}$ with argon cover gas flow of $12 \mathrm{cfm}$.

The metallographic sections were etched in a solution of 3 pct FeCr, 7 pet $\mathrm{HF}, 30$ pet $\mathrm{HCl}$ and 60 pet $\mathrm{H}_{2} \mathrm{O}$. A JEOL 840 scanning Electron Microscope equipped with a Tracor 5500 Energy Dispersive spectrometer system was used for examination.

Tensile tests were performed on an. Instron 1125 testing machine at a crosshead speed of $5 \mathrm{~mm} / \mathrm{min}$. Base metal, as-welded lap joints and ground welded lap joints were tested for all joint materials. The ground joints are lap welds where the remaining overlap is ground away to the weld area to eliminate the preexisting cracks (See Figure 1).

\section{Experimental results}

\section{Metallography of welds}

316SS to Nb-1zr joint: Metallographic examination of the welded joints revealed three characteristic zones that were formed during welding. These zones are: 1) the fusion zone; 2) thin 
intermetallic layer; and 4) the $\mathrm{Nb}-1 \mathrm{Zr}$ base metal (Figure 2). In the fusion zone two types of structure were identified. Near the intermetallic layer a typical eutectic structure was observed which is either $(\alpha+\epsilon)$ or $(\tau+\epsilon)$ where $\epsilon$ is the Laves phase $\mathrm{Fe}_{2} \mathrm{Nb}$. Away from the interface the structure becomes a networked $\epsilon$ phase distributed along the $(\alpha+\tau)$ grain boundaries. The intermetallic layer of Laves phase is approximately $0.2 \mathrm{~mm}$ in thickness which results from the diffusion of iron into the $\mathrm{Nb}$ base metal at about $1773 \mathrm{~K}$. Next to the layer is the annealed Nb-1Zr base metal which is not greatly influenced by welding.

316ss to Vanadium joint: Microscopic analysis showed no intermetallic layer or other non-ductile phase formed between stainless steel and unmelted vanadium base. A small amount of sigma phase was observed on the corner of the joint interface between $V$ and the stainless steel fusion zone. The region in which this second phase was observed is about $0.05 \mathrm{~mm}$ in thickness and $0.5 \mathrm{~mm}$ in length. This sigma phase was identified using microhardness and EDS analyses. Sigma phase contains about 40 w/o vanadium and is very brittle. Figure 3 shows a crack which occurred during the microhardness measurement process. In the fusion zone, a uniform austenitic structure was found with no second phase precipitation. A banded structure was observed in the fusion zone which was caused by regions of different grain size.

$316 \mathrm{sS}$ to $\mathrm{Nb}-1 \mathrm{Zr}$ with $\mathrm{V}$ interlayer: Optical microscopy revealed 
that the $\mathrm{V}$ interlayer was melted by liquid $\mathrm{SS}$ and became $\mathrm{a}$ solidification element in molten pool (Figure 4). As a result, liquid SS contacted directly with the $\mathrm{Nb}-1 \mathrm{Zr}$ surface and an intermetallic layer was formed. Observations showed that the microstructure in the fusion zone was nearly the same as that of welds made without the $\mathrm{V}$ interlayer.

\section{$\mathrm{X}$-ray analysis}

$\mathrm{X}$-ray diffraction analysis was conducted to identify the phases present in the fusion zone. Both $\tau$ and $\alpha$ phase diffraction spectra were found in the $316 \mathrm{SS}$ to $\mathrm{Nb}-1 \mathrm{Zr}$ weld and the $316 \mathrm{SS}$ to $\mathrm{Nb}-$ $\operatorname{lzr}$ with $\mathrm{V}$ interlayer.

Energy Dispersive Spectroscopy (EDS) was used to examine the $\mathrm{Nb}$ and $\mathrm{V}$ content across the welds. Generally the results show that in the $316 \mathrm{SS}$ to $\mathrm{Nb}-1 \mathrm{Zr}$ welds, without or with $\mathrm{V}$ interlayer, the $\mathrm{Nb}$ content decreased with the increasing distance from the interface. Large quantities of $\mathrm{Nb}$ were found to be spread by the convection currents which occur in the molten metal pool. These Nb rich regions are easily identified in the metallography of the weld due to different etching characteristics (light regions). Vanadium content in the fusion zone of the weld with $V$ interlayer was not found to vary substantially with distance to the interface. In the $316 \mathrm{SS}$ to $\mathrm{V}$ weld, $\mathrm{V}$ content sharply decreased in the region near the interface of the fusion zone and $\mathrm{V}$ base with increasing distance. After an initial drop in concentration, there was no significant change in $\mathrm{V}$ content with increasing distance. 


\section{Microhardness}

Microhardness measurement results across the fusion zone of $316 \mathrm{SS}$ to $\mathrm{Nb}-1 \mathrm{Zr}$ joint are shown in Figure 5 . In the Nb-1Zr base metal there is no hardness change until the boundary with intermetallic layer is reached. The intermetallic layer shows the highest hardness of approximately 600 VHN which drops significantly when the fusion zone is reached. Hardness in fusion zone decreased gradually with increasing distance from the boundary and remained constant near the center.

For the 316 SS to $\mathrm{V}$ joints, the hardness remained constant in the base $V$ and increased to a higher level when the fusion zone boundary was reached (Figure 5). Hardness changed less with increasing distance from the boundary. In the region where sigma phase appeared there was a significant hardness increase to a value of 650 VHN.

Figure 5 also shows the microhardness distribution across the $316 \mathrm{SS}$ to $\mathrm{Nb}-1 \mathrm{Zr}$ weld with a $\mathrm{V}$ interlayer. No change in hardness was measured in the Nb-1Zr base metal. A higher hardness value was found in this intermetaliic layer than was found in the intermetallic regions of welds without $\mathrm{V}$ interlayer. This suggests that the intermetallic compounds formed by the ternary $\mathrm{Nb}-\mathrm{Fe}-\mathrm{V}$ possess higher hardness than those formed by the binary $\mathrm{Nb}-\mathrm{Fe}$. In the fusion zone, hardness decreased significantly in the region near to the intermetallic layer and changed slightly in the center of the fusion zone. Comparing with the fusion zone in NB-1Zr to $316 \mathrm{SS}$ weld, the values of hardness in this sandwich geometry were 
generally higher because of the higher vanadium concentrations in the molten pool.

\section{Tensile results}

Satisfactory tensile results (Table 1 ) were obtained for edge ground $\mathrm{Nb}-1 \mathrm{Zr}$ to $316 \mathrm{SS}$ weld samples. Final failure of the edge ground specimens was found to occur in the $\mathrm{Nb}-1 \mathrm{Zr}$ base metal instead of the fusion or heat affected regions of the joints. For unground samples, fractures occurred in the fusion or heat affected regions in either of two ways: along the prior stainless steel to niobium interface or across the weld fusion zone. Both yield strength and ultimate tensile strength were lower than that obtained in the ground samples.

For the $316 \mathrm{SS}$ to $\mathrm{V}$ welds only unground samples were tested. The result shows that the joint possesses higher strength than base $\mathrm{V}$ metal. The fractures were found to occur either in the heat affected vanadium base near the fusion zone or unaffected base metal region away from the fusion zone. Fracture path observations in specimens which failed in the heat affected zone indicate that the crack formed in the region where sigma phase appeared and propagated across the vanadium side instead of across the fusion zone.

Tensile tests of $\mathrm{Nb}-1 \mathrm{ZR}$ to $316 \mathrm{SS}$ welds with $\mathrm{V}$ interlayer revealed that the tensile properties of the weld for both unground and ground samples were worse than that without $\mathrm{V}$ interlayer, especially for the ground samples. In unground samples, cracks 
were observed emanating from the corner of the unwelded interface and propagating across the fusion zore. In ground samples, cracks propagated along the fusion zone to the intermetallic interface. The ductility of the fusion zone was degraded due to the presence of vanadium in the resolidified metal.

\section{Discussion}

Results have been presented which show that satisfactory gas tungsten arc welds can be produced by lap welding $316 \mathrm{ss}$ over Nb-1Zr sheet and $316 \mathrm{SS}$ over $\mathrm{V}$ sheet. Tensile strength of as welded $316 \mathrm{SS}$ to $\mathrm{Nb}-1 \mathrm{Zr}$ joint was poor because the unwelded part in the interface between two sheets acted as a crack when two sheets were placed in tension mode. Satisfactory tensile strength and ductility of the lap welded joints can be obtained by grinding the finished lap welds to eliminate such pre-existing crack. The presence of a large change in the microhardness at the $\mathrm{Nb}-1 \mathrm{Zr}$ interface and the identification of a brittle intermetallic phase by $x$-ray analysis suggest that under impact loading conditions, the fracture toughness of the joint may be less than desired. Fracture toughness tests are in progress but to date no results are yet available. In $316 \mathrm{SS}$ to $\mathrm{V}$ welds, wetting between liquid $\mathrm{Fe}$ and solid $V$ produced a rounded edge at the tip of the lap joint which did not produce a large stress concentration and hence acceptable joint strength was obtained without grinding. Microhardness profiles show no excessive hardness change at the $3165 \mathrm{~S}$ to $\mathrm{V}$ interface. As a result, fracture occurred in the heat affected $V$ 
base metal instead of the solution strengthened fusion zone or joint interface.

The use of a $\mathrm{V}$ interlayer in welding $316 \mathrm{SS}$ over $\mathrm{Nb}-1 \mathrm{ZR}$ was investigated in an attempt seep the brittle phase from forming and at the same time form a continuous composite joint between $\mathrm{Nb}$, $\mathrm{V}$ and $316 \mathrm{SS}$. It should be noted that it is very difficult to find an optimal heat input to form such a continuous joint. Lower heat input lead to poor joining between the $\mathrm{V}$ layer and base $\mathrm{Nb}-1 \mathrm{Zr}$ while higher heat input led to the formation of a large amount of intermetallic phase. The results suggest that diffusion bonding or solid welding methods other than fusion welding may be necessary to develop a transient joint with a $V$ interlayer. This work is currently in progressing.

\section{Concluisions}

The following conclusions resulted from tisis study:

1. Sound welds were produced by lap welding $316 \mathrm{SS}$ over $\mathrm{Nb}-1 \mathrm{Zr}$ and 316SS over $\mathrm{V}$ sheets using gas tungsten arc welding.

2. Satisfactory strength and ductility of the lap welded 3165 s to $\mathrm{V}$ joints were found in tensile tests. Failure occurred in the base metal of welded joints.

3. The use of $a \mathrm{~V}$ interlayer did not prevent the formation of a brittle intermetallic layer at the SS/Nb-IZr interface because convection of the molten pool quickly distributed the $V$ throughout the fusion zone.

4. The strength and ductility of the welded $316 \mathrm{SS}$ over $\mathrm{Nb}-1 \mathrm{Zr}$ 
joint with $V$ interlayer were degraded by the formation of an intermetallic layer and the presence of $\mathrm{V}$ in the resolidified fusion zone.

\section{Acknowledgements}

This work was supported by the Thermionic Space Nuclear Power Program of the U.S. Air Force, Kirtland Air Force Base, NM 87117 through the center for Commercial Development of space Power and Advanced Electronics, located at Auburn University. The authors would like to thank Dr. Frank Jankows'i and Dr. Michael schuller of the U.S. Air Force for their technical guidance.

\section{References}

[1] H. M. Cameron, Thermal Cycling Test on a 3-Inch Diameter Columbium-1 Percent Zirconium to 316 stainless steel Transition Joint, NASA TMX-2118, Nov. 1970.

[2] R. Lison, J. F. Stelzer, Welding Journal, 58, (10), Oct. 1979 pp. $306-314 \mathrm{~s}$.

[3] I. M. Fedorchenko, Welding International, Vol.2, No. 3 , (1988), pp. 638-640.

[4] V. V. D'Yachenko, E. N. Sivov, B. P. Morosov, Welding Production, Vol.13, No.1, Jan. 1966, pp. 2-7.

[5] V. A. Veinik, Welding production, Vol.20, No.5, May 1973, pp. 16-18.

[6] Lars Lindergren, Lars Linderstrom, Tore Persson, Peter Sotkovszki, Zeitschrift fuer Metallkunde, Vol.77, No.4, Apr. 1986 , pp. $245-248$

[7] N. N. Kazak, E. P. Pokataev, V. S. Sedikh, Yu P. Trikov, Welding production, Vol.28, No.4 Apr.1981, pp. 23-25. 
Table 1. Tensile data of the welds

\begin{tabular}{|c|c|c|c|}
\hline & YS (MPa) & UTS (MPa) & Elong. \\
\hline \multicolumn{4}{|l|}{ NblZr-SS } \\
\hline unground & 110 & 165 & $1.2 \%$ \\
\hline ground & 156 & 275 & $7.6 \%$ \\
\hline$V-S S$ & 169 & 241 & $10 \%$ \\
\hline \multicolumn{4}{|c|}{ Nblzr-SS with } \\
\hline $\begin{array}{l}\mathrm{V} \text { interlayer } \\
\text { unground }\end{array}$ & 103 & 155 & $1.4 \%$ \\
\hline ground & 115 & 173 & $2.0 \%$ \\
\hline
\end{tabular}


Figure 1: Weld configuration.

Figure 2: Microstructure of the $316 \mathrm{SS}$ to $\mathrm{Nb}-1 \mathrm{Zr}$ weld.

Figure 3: Microstructure of the $316 \mathrm{SS}$ to $\mathrm{V}$ weld.

Figure 4: Microstructure of the $316 \mathrm{SS}$ to $\mathrm{Nb}-1 . \mathrm{Zr}$ weld with $\mathrm{V}$ interlayer.

Figure 5: Variation of microhardness across the welds. 

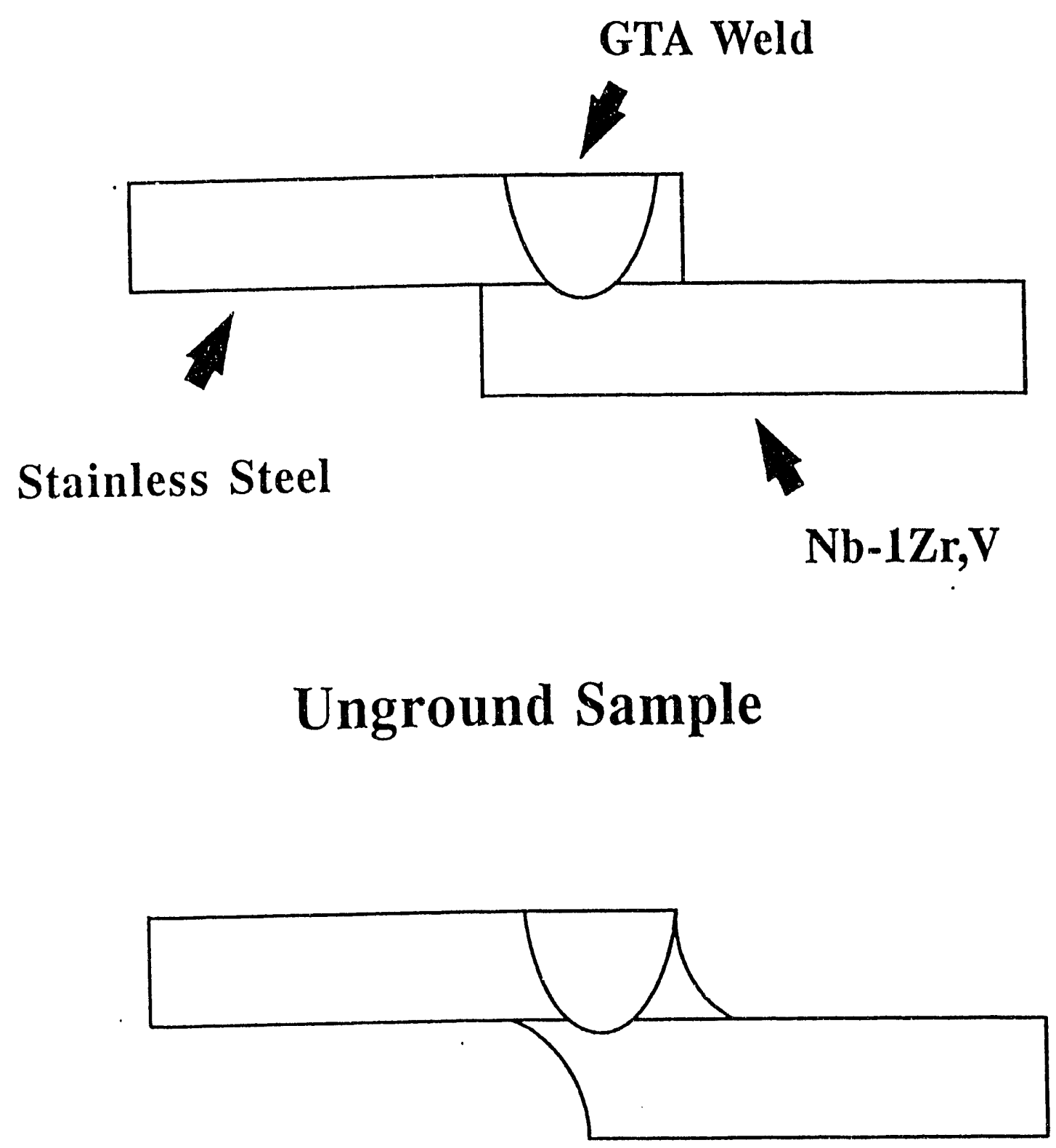

Ground Sample 


$$
\begin{aligned}
& \text { Fig. } 2 \\
& \text { Fig. } 3
\end{aligned}
$$
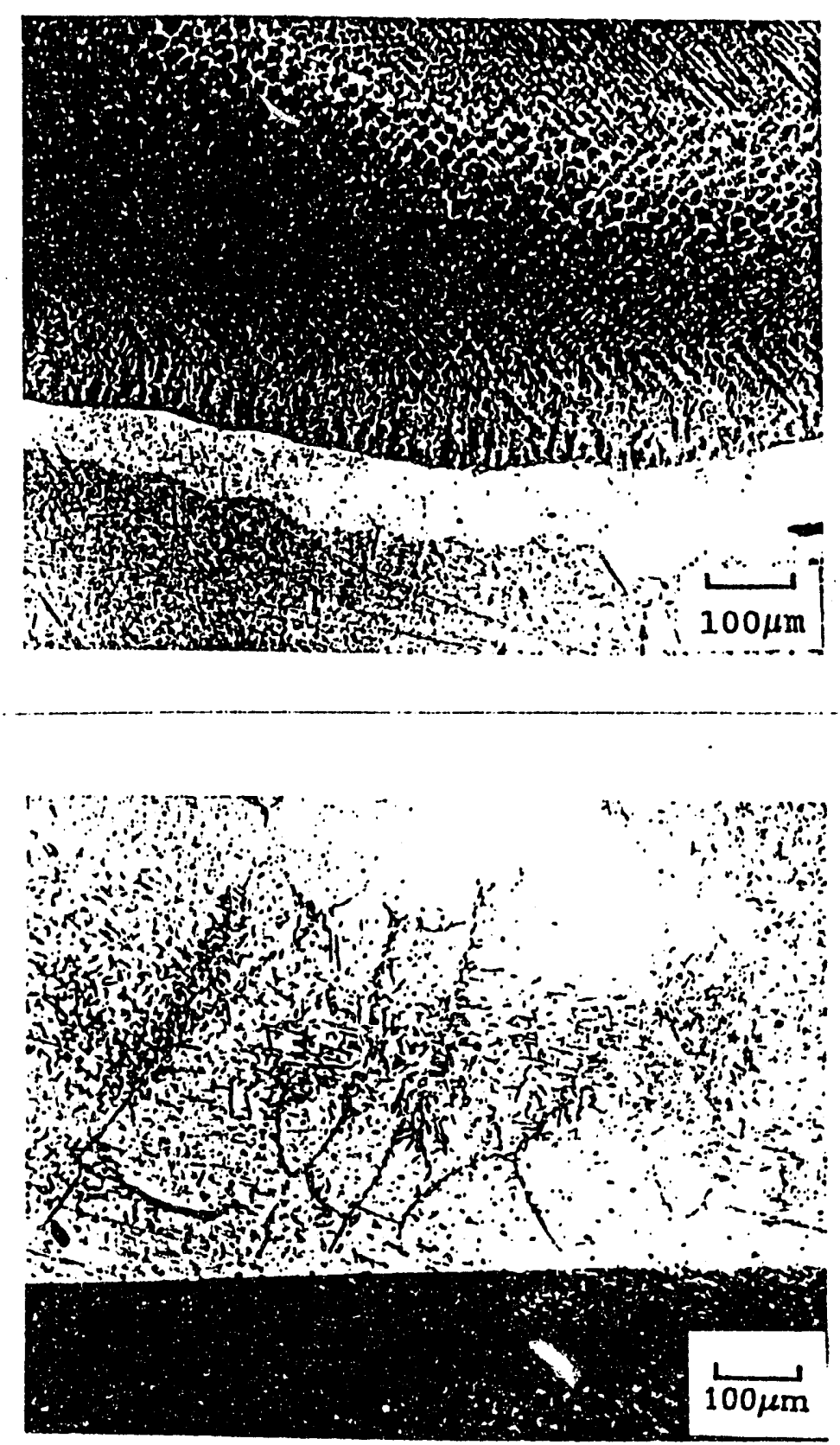

$\because \because 4$

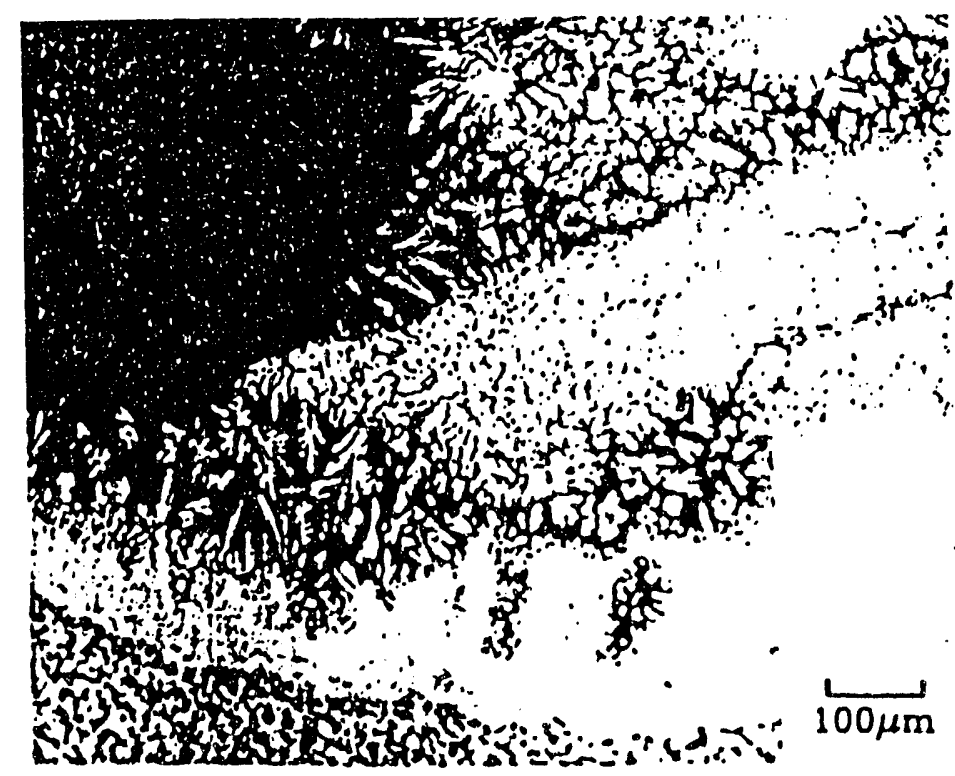




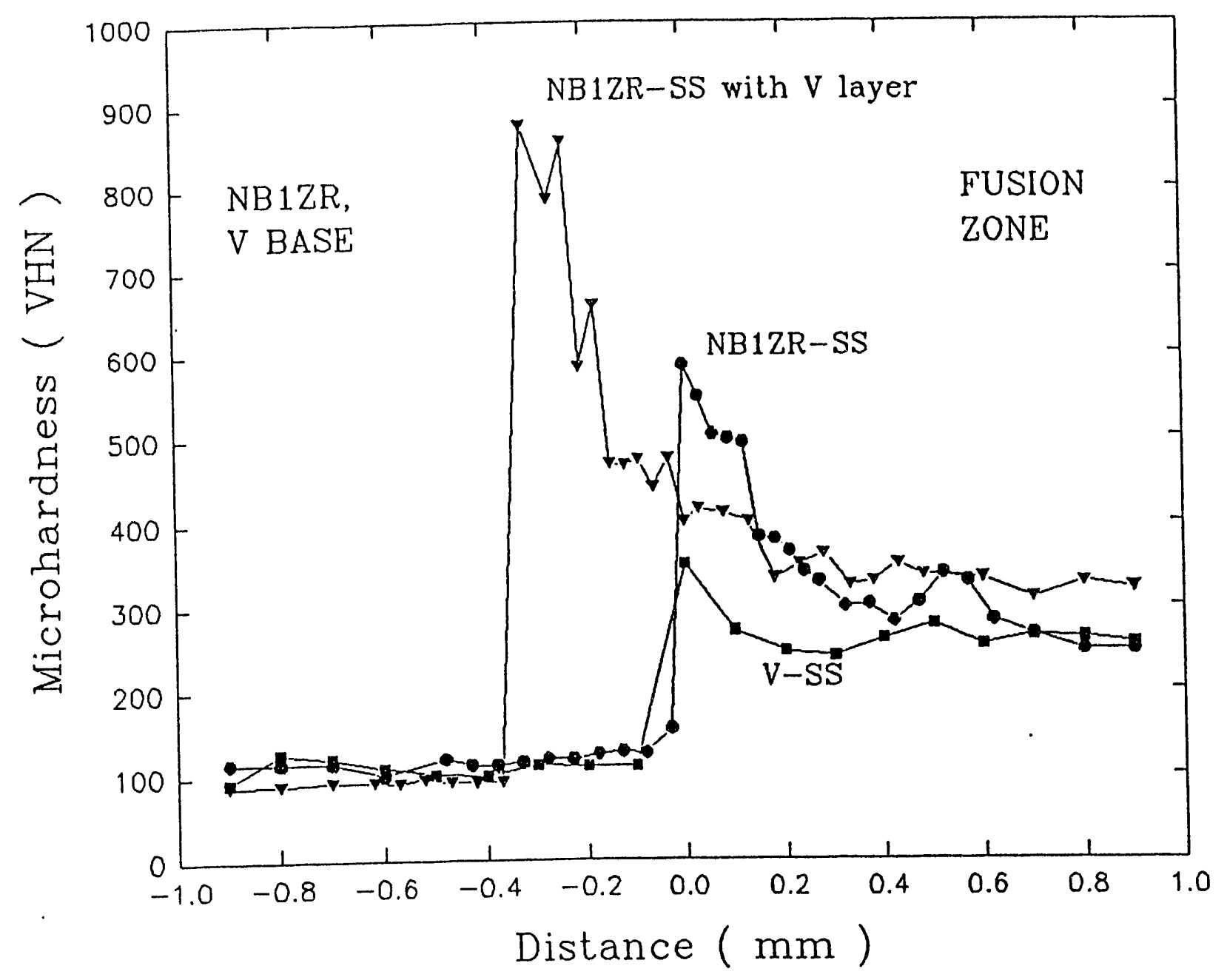

Fig. 5 


\section{ABSTRACT \\ INFRARED THERMOGRAPHY FOR NON-DESTRUCTIVE MONITORING OF WELD PENETRATION VARIATIONS}

P. Banerjee, J. Y. Liu and B. A. Chin

Materials Engineering, Auburn University, Auburn, AL 36849

The thermal distributions obtained during the gas tungsten arc welding process were analyzed using mathematical techniques to determine if changes in the surface temperature distribution could be correlated with changes in weld penetration. An infrared scanning camera was used to obtain the temperature profiles. Analyses were per:formed on the temperature distribution along a line transverse to the direction of torch motion (linescan). Three parameters taken from the thermal distributions were found to indicate changes in weld penetration. These are the temperature gradient at a point, the measured bead width and the integrated thermal volume (volume under the thermal temperature distribution). These indicators were found to change almost simultaneously with penetration changes. The integrated thermal volume was found to be related to the instantaneous weld pool volume as measured by decantation. With optimization of the computation technigues, these indicators can be incorporated into an in-process, nondestructive monitoring and correction system for weld quality control in fusion reactor components. 


\section{INFRARED THERMOGRAPHY FOR NON-DEBTROCTIVE MONITORING OF WELD PENETRATION VARIATIONB}

P. Banerjee, J. Y. Liu and B. A. Chin

Materials Engineering, Auburn University, Auburn, AL 36849

\section{Introduction:}

The potential release of hazardous radioactive substances places strict quality control requirements on weldments of fusion devices. Weld penetration is one important parameter which greatly influences the strength and ductility of welds. Dynamic sensory penetration control presents a challenge because penetration is a feature that occurs in the thickness dimension and is therefore normally inaccessible to standard vision devices. Infrared thermography is a potential non-destructive tool for monitoring and controlling the molten metal pool in the thickness dimension.

Automation requires effective sensing techniques to detect weld variations such as those resulting from sudden plate thickness changes [1], changes of trace element contaminants [2-10], shielding gas composition changes [11] and welding current changes. Each of these can individually cause significant alterations in weld penetration. Charge-coupled device cameras have been used in the past to monitor root gap width as well as weld bead height and weld penetration [12]. In the current investigation, an infrared sensor was chosen for process control because, unlike other sensors, an infrared sensor can monitor several variables simultaneously $[13-19]$.

The earliest work using infrared sensors for automatic welding was performed by Ramsey et al. [18] in 1963. More recently, 
investigations using infrared sensors for contaminant and penetration detection were undertaken by Lin et al. [13] and chen et al. [1] respectively. Khan et al. [13] used on-line IR sensing techniques to dynamically monitor the thermal field in front of the weld pool during the welding process and identify surface contaminants.

Doumanidis et al. [19] used a double torch configuration and an infrared camere mounted with its axis transverse to the line of motion. They used the infrared sensors to identify the size of the heat affected zone (HAZ) and its cooling rate. Chen et al. [1] showed that infrared thermography may provide information that could be used to control depth of penetration. The authors mathematically fit measured isotherms to an ellipse and defined the area of the ellipse as the thermal area. This thermal area and the minor axis of the ellipse were found to vary concurrently with variations in depth of penetration caused by plate thickness changes during constant heat input gas tungsten arc welding. However, this technique was limited to analysis of isotherms outside the molten metal pool. The current study focusses on investigating other quantitative approaches for determining the depth, width and shape of the weld pool using surface temperature distributions.

The primary objective of the current investigation was to develop weld penetration indicators that could be used as error signals for on-line penetration control. This meant that the 
indicators had to have a computation time of the order of the system response time. A secondary objective of this study was to test the performance of these indicators by intentionally changing weld parameters which affect the penetration.

Plate thickness changes, welding current changes and minor element content changes were used to induce weld penetration variations. Minor element concentration is known to influence the convective flows in weld pools. Minor elements alter the surface tension coefficient of the molten pool $[4,8]$. Sulfur, titanium dioxide and silicon have positive surface tension coefficients. These elements exhibit an increase in the surface tension of the weld pool with increase in temperature. In any weld pool, the surface temperature increases from the edge of the weld pool to the center. A sudden increase in sulfur content therefore results in an increase in surface tension from the edge to the center of the weld pool. Consequently, the convective flow changes from radially outward to radially inward and down to the bottom of the crater containing the weld pool. This results in a narrower, deeper weld pool and hence increased depth of penetration and reduced bead width. Aluminum, oxygen and nitrogen as well as the base metal itself, have negative surface tension coefficients and result in a wider, shallower molten pool and hence reduced penetration and increased bead width. These changes in molten metal convection should be readily visible through changes in temperature distributions. 


\section{Experimental setup:}

Figure 1 shows the infrared camera mounted on a torch assembly. The camera monitors the temperature distribution around the weld pool. A custom built interface transfers the information from the camera to the computer for analysis and feedback of appropriate corrective action. In all experiments, gas tungsten arc welding was performed with a Miller Synchrowave $500 \mathrm{AC} / \mathrm{DC}$ power source and a water cooled torch. The torch was manipulated by an ESAB X-Y positioning table. This positioning table was controlled by a Hewlett Packard series 320 computer through an HP3497A data acquisition/control unit. The infrared radiation which characterizes the thermal distribution of the plates being welded, was measured by an Inframetrics model 525 infrared camera. The infrared camera determines the temperature distribution by sampling a portion of the emitted energy within a wavelength band of 8 to 12 micrometers. The infrared image from the camera was transferred to the controlling computer in a digital format. Each scan of the camera was transferred as a frame consisting of $250 \times 192$ discrete infrared intensity measurements. These measurements are a function of the local absolute temperatures and are in a digital format, stored as numbers ranging from 0 to 255 .

The welding was performed using $6.35 \mathrm{~mm}(0.25 \mathrm{in})$ thick AISI 1008 steel plates of size $304.8 \mathrm{~mm} \times 304.8 \mathrm{~mm}(12$ in $X 12$ in). These plates were prepared by sand blasting before welding. The welding parameters have been given in Table 1 . Three sets of 
experiments were conducted to investigate the relationship between penetration and thermal temperature distribution. These experimental sets involved: current changes, plate thickness changes and minor element composition changes.

The first set of experiments was designed to detect weld penetration variations due to intentionally induced welding current changes. These experiments used an impulse decantation technique [20] to determine the instantaneous weld pool volume. An argon jet. at $700 \mathrm{psi}$ was used to decant the molten metal from the cratex (Figure 3). The decantation is initiated by a computer activated solenoid valve. The measured time delay between the acquisition of the infrared data and the activation of the solenoid valve was found to be of the order of a few milliseconds. Synchronization of the two processes is therefore possible. Post weld optical metallography in the vicinity of the decanted crater did not show any residual weld metal. Thus, the effectiveness of the decanting process was confirmed. The volume of the decanted crater was then determined by making a wax impression and finding its weight which was converted to a volume using a predetermined density. This process was repeated for welds performed at five different current levels - 100 Amps, 120 Amps, 140 Amps, 160 Amps and 180 Amps. At each of these current levels, four welds were performed for statistical accuracy.

The second set of experiments was designed to investigate the effect of plate thickness variations on the penetration indicators. 
Welding was performed on a plate with three step changes in thickness. These changes were from $6.35 \mathrm{~mm}(0.25 \mathrm{in})$ to $4.763 \mathrm{~mm}$ $(0.1875 \mathrm{in})$, from $4.763 \mathrm{~mm}$ to $3.175 \mathrm{~mm}(0.125 \mathrm{in})$ and from $3.175 \mathrm{~mm}$ to $6.35 \mathrm{~mm}$. One hundred and fifty frames of infrared data were acquired during the welding run spanning a distance of $190.5 \mathrm{~mm}$ $(7.5 \mathrm{in})$.

Experiments were also designed to study the influence of minor elements on the temperature gradient. For this set of experiments, $1 \mathrm{~mm}$ diameter holes were drilled into the base metal and either aluminum wires or iron sulfide pieces were force fitted into the holes. Welds were performed along a line passing through three minor element concentration sites. For each weld, one hundred frames of infrared data were acquired and analyzed.

\section{Data Display Modes:}

The surface temperature distributions of the plates being welded can be displayed in different ways. The two methods that were used to display the data for analysis were - isothermal contours (regions of equivalent temperature) and linescans (thermal profiles along a line on the plate, transverse to the direction of torch motion). Figure 2 shows the temperature distribution of a weld made on a $6.35 \mathrm{~mm}(0.25 \mathrm{in})$ thick AISI 1008 steel plate. The temperature distribution is displayed in the line scan mode. The isothermal contour map consists of several color bands, each corresponding to a range of temperatures $($ Black = coldest, Magenta 
= hottest). Linescans reveal local temperature changes, whereas the isothermal contour maps generally show macroscopic changes in the temperature distribution.

\section{Results and Discussions:}

\section{Weld Current Related Penetration Variation Detection}

The objective of these experiments was to relate penetration to information that could be extracted from the thermal image. It was hypothesized that the depth of penetration could be estimated if the surface area (area of molten metal seen from above the weld) and volume of molten metal were known. From previous experiments it was known that the surface area of the molten metal pool can be easily identified using the infrared imaging gradient technique. This technique uses the abrupt change in the temperature gradient at the solid-liquid metal interface (caused by the difference in solid and liquid metal emissivities) to find the molten pool edge. As seen in Figure 2, each linescan shows at least three inflection points on each side of the line of symmetry $A-B$. The bead width was computed as the largest distance between the left hand side valley and the right hand side peak as measured on the thermal distribution in a direction perpendicular to torch direction. The solidified weld pool front was computed by locating the solidliquid metal interface for regions ahead and behind the welding torch. In this manner the surface area of the weld bead was 
determined.

The integrated thermal volume is defined as the summation of the infrared intensity measurements within the area enclosed by the weld pool. The weld pool boundary was identified using the gradient technique described above. The integrated thermal volume was then compared to the measured volume of molten metal by using an impulse decantation technique described in the experimental section above. The relationship between the computed infrared thermal volume and the decanted crater volume is shown in Figure 3.

\section{Plate Thickness Related Penetration Variation Detection}

The weld pool front computation technique described above was repeated using a plate with step changes in thickness (Figure 4). The weld pool fronts shown in this figure have been computed from eleven frames of infrared data, acquired at a step change in plate thickness from $3.18 \mathrm{~mm}(0.125 \mathrm{in})$ to $6.35 \mathrm{~mm}(0.25 \mathrm{in.})$ over a distance of $10.3 \mathrm{~mm}$. The straight lines show the measured bead width at this step change in thickness. Once again, the computed fronts resembled the actual weld in both bead width and bead shape. Also, a detailed analysis showed that the location of the peaks and valleys in the first derivative plot of the line scan remained the same as long as the plate thickness was the same. 


\section{Minor Element Related Penetration Variation Detection}

The temperature gradient was computed for all points contained within the weld pool along directions perpendicular to direction of torch travel. These weld pool gradients were then monitored as the weld traversed over intentionally induced impurity inserts as described in the experimental section.

For the weld traversing the aluminum inserts, the temperature gradient was found to decrease at the locations containing the inserts (Figure 5). This can be explained by considering what happens to the weld pool at these locations. Due to surface tension effects $[4,5]$, aluminum increases the width of the weld pool and decreases the depth of penetration. Given the same amount of heat input from the welding torch, a wider weld pool would mean a smaller temperature gradient across the weld pool.

For the weld passing through iron sulfide inserts, the gradient rose suddenly just before the inserts and then dropped sharply before returning to normal (Figure 5). Unlike aluminum, sulfur decreases the width of the weld pool and increases the depth of penetration. This increases the thermal gradient sharply. As soon as the effect of sulfur ceases, base metal surface tension effects come into play. These effects are similar to those of aluminum and hence result in a drop in gradient. It should be noted that this type of change in the gradient at a point is unique to minor element effects and cannot be expected to result from 
other perturbations such as plate thickness changes.

\section{Conclusions:}

Results presented in the above sections show that considerable progress has been made in determining the relationship between penetration variations and plate temperature distributions. The use of infrarec sensors to detect penetration changes has resulted in the following conclusions:

- The solid-liquid metal interface and hence the weld pool front, can be identified from inflections in the temperature distribution caused by a difference in the emissivity of solid and liquid metal

- The infrared thermal volume and decanted crater volume can be related through a power law function

- The temperature gradient technique can be used to identify penetration changes due to the presence of minor elements

- The computed bead width technique is suited for detecting weld pool geometry variations arising due to changes in either welding current or plate thickness

RETERENCES :

[1] W. H. Chen, P. Banerjee and B. A. Chin, in: Proc. on Trends in Welding Research (ASM International, Ohio, 1990) p. 517.

[2] S. S. Glickstein and W. Yeniscavich, A Review of Minor Element Effects on the Welding Arc and Weld Penetration, WRC Bulletin No. 266, Welding Res. Council, (1977).

[3] S. M. Correa and R. E. Sundell, in: Proc. on Modeling and Contro? of Casting and Welding Processes (TMS, rennsylvania, 1986) p. 211.

[Aj Sundell, R. E., L. Harris, D. W'. Walsh, H. Solomon, S. Correa and W. F.Savage, Minor Element Effects on Gas Tungsten Arc Weld Penetration, General Electric Report No. 86SRD013, (1986).

[5] C. R. Heiple and J. R. Roper, Welding J. 61 (1982) 97-s.

[6] W. F. Savage, E. F. Nippes and G. M. Goodwin, Welding J. 56 (1977) 126-s.

[i, K. C. Mills and B. J. Keene, International Materials Reviews, 35 (1990) 185.

[8] C. R. Heiple, J. R. Roper, R. T. Stranger and K. J. Aden, Welding J. 62 (1983) 72-s. 
[9] G. Carboni, Welding International, 1 (1987) 750.

[10] B. Heritier and $\mathrm{Ph}$. Maitrepierre, in: Proc. on Inclusions and Residuals in steels: Effects on Fabrication and service Behavior (Canadian Govt. Publ. Centre for CANMET and CSIRA, Ottawa, 1985) p.395.

[11] J. F. Key, Welding J. 59 (1980) 364-s.

[12] Y. Sugitani, Y. Nishi and T. Sato, in: Proc. on Trends in Welding Research (ASM International, Ohio, 1990) p. 923.

[13] T. T. Lin, H. T. Lin and B. A. Chin, Optical Engineering, 5 (1988).

[14] S. M. Govardhan and B. A. Chin, in: Proc. on Trends in Welding Research (ASM International, ohio, 1990) p. 383.

[15] S. Nagarajan, P.Banerjee, W. H. Chen and B. A. Chin, IEEE Transactions on Robotics and Automation, Accepted July 1990.

[16] S. Nagarajan, P. Banerjee and B. A. Chin, in: Proc. on Transport Phenomena in Materials Processing, (ASME, New York, 1990) p.171.

[17] P. Banerjee, S. Nagarajan and B. A. Chin, in: Proc. on The 1991 NSF Design and Manufacturing Systems Conference (SME, Michigan, 1991) p. 143.

[18] P. W. Ramsey, J. J. Chyle, J. N. Kuhr, P. S. Myers, M. Weiss and W. Groth, Welding J. 42 (1963) 337-s.

[19] C. Doumanidis and D. E. Hardt, Welding J. 69 (1990) 186-s.

[20] W. F. Savage, E. F. Nippes and F. J. Zanner, Welding Journal, 57 (1978) 201-s. 
Table 1. Welding Conditions in Penetration Measurement Experiments

Torch speed

Shielding Gas

Current

Voltage

Electrode
$2.667 \mathrm{~mm} / \mathrm{s}(6.3 \mathrm{in} / \mathrm{min})$

Argon, $18.87 \mathrm{lit} / \mathrm{min}$ (40 cfh)

$175 \mathrm{~A}$ DC

$20 \mathrm{~V}$

Negative, EWTh-2, $3.175 \mathrm{~mm}$ 
Table 2. Time Constants

\begin{tabular}{|c|c|c|c|}
\hline Parameter & $\begin{array}{l}\text { Analyzed } \\
\text { Iine } 1\end{array}$ & $\begin{array}{l}\text { for } \\
\text { Frame }\end{array}$ & Computation Time \\
\hline $\begin{array}{l}\text { Fitted Ellipse } \\
\text { Bead Width } \\
\text { Thermal Volume } \\
\text { Gradient at a point }\end{array}$ & $\begin{array}{l}x \\
x\end{array}$ & $\begin{array}{l}\mathrm{X} \\
\mathrm{x}\end{array}$ & $\begin{array}{l}4 \mathrm{mins} \\
.5 \mathrm{sec} \\
1 \mathrm{~min} \\
.09 \mathrm{sec}\end{array}$ \\
\hline
\end{tabular}




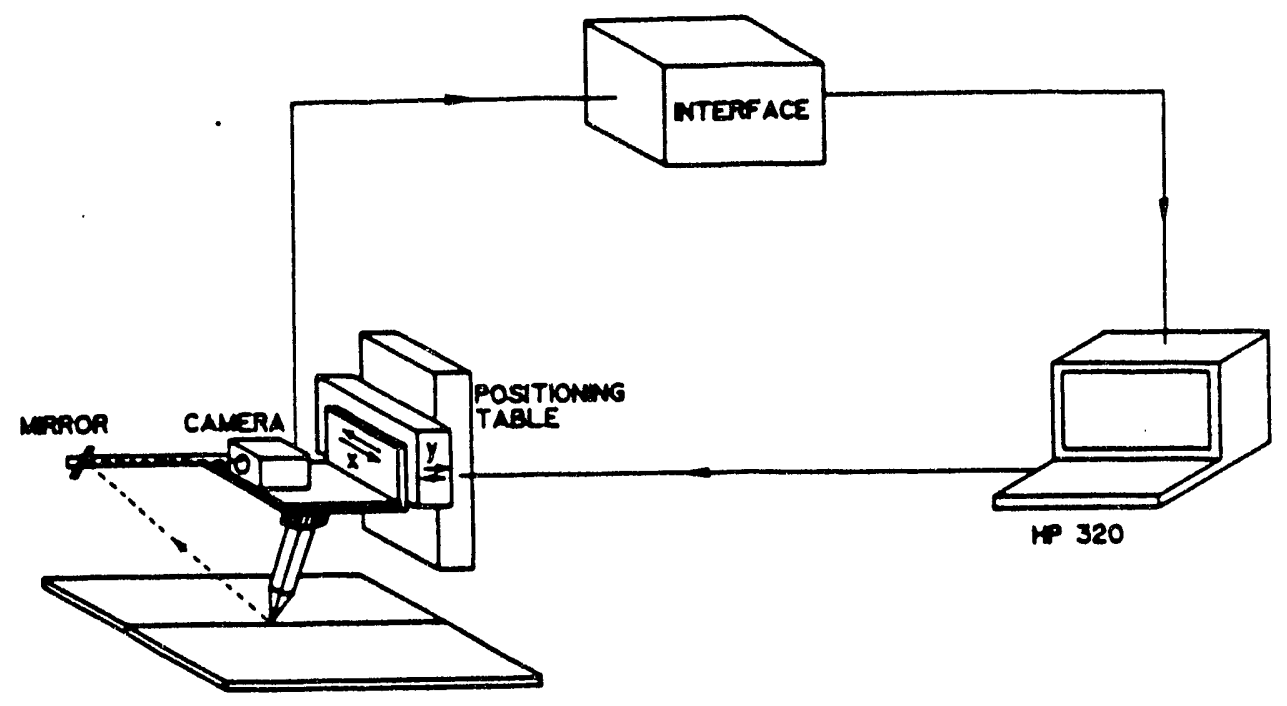

Figure 1. Experimental setup

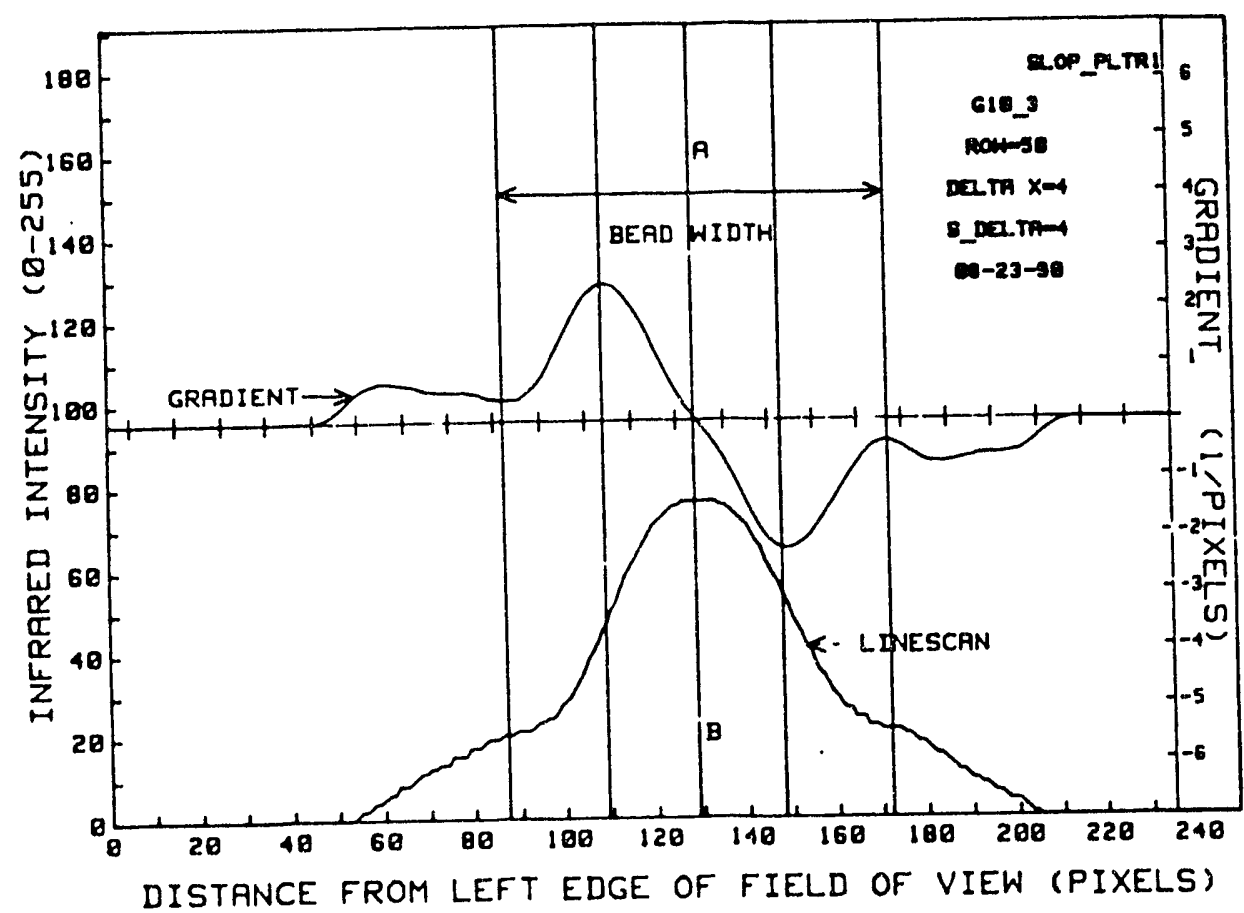

Figure 2. Gradient Technique 


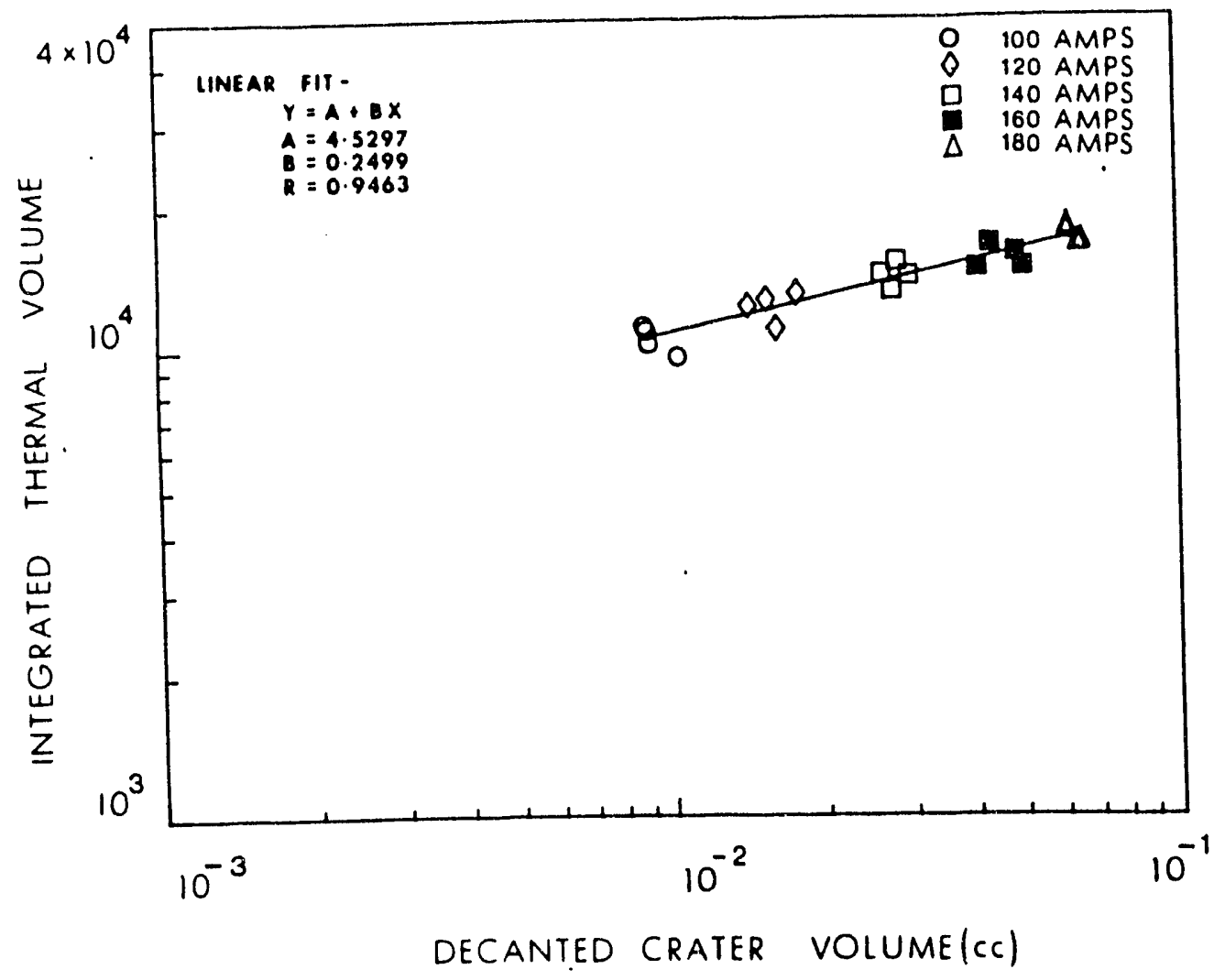

Figure 3. Infrared Thermal Volume vs Decanted Crater Volume

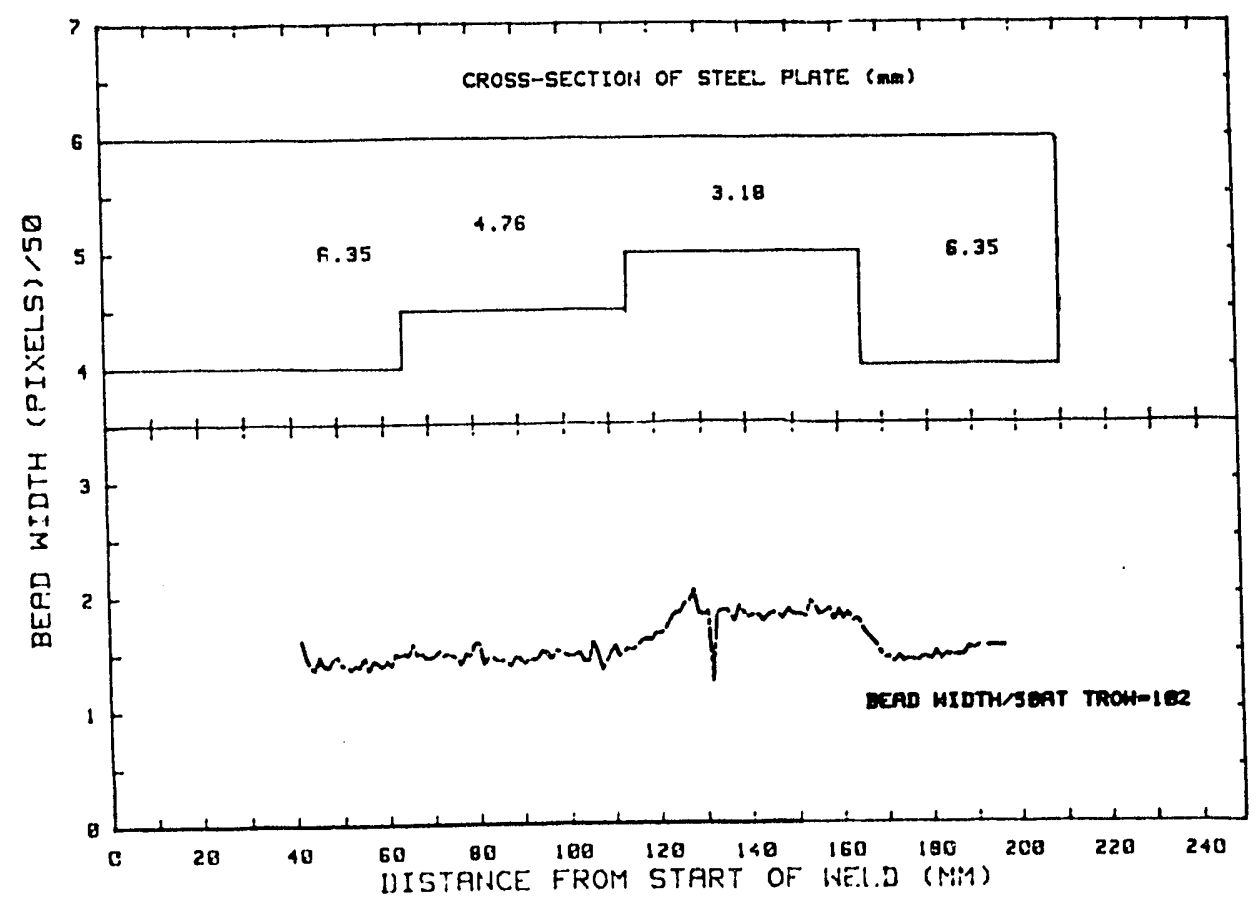

Figure 4. Computed Weld Pool Front - step Change in Thickness 


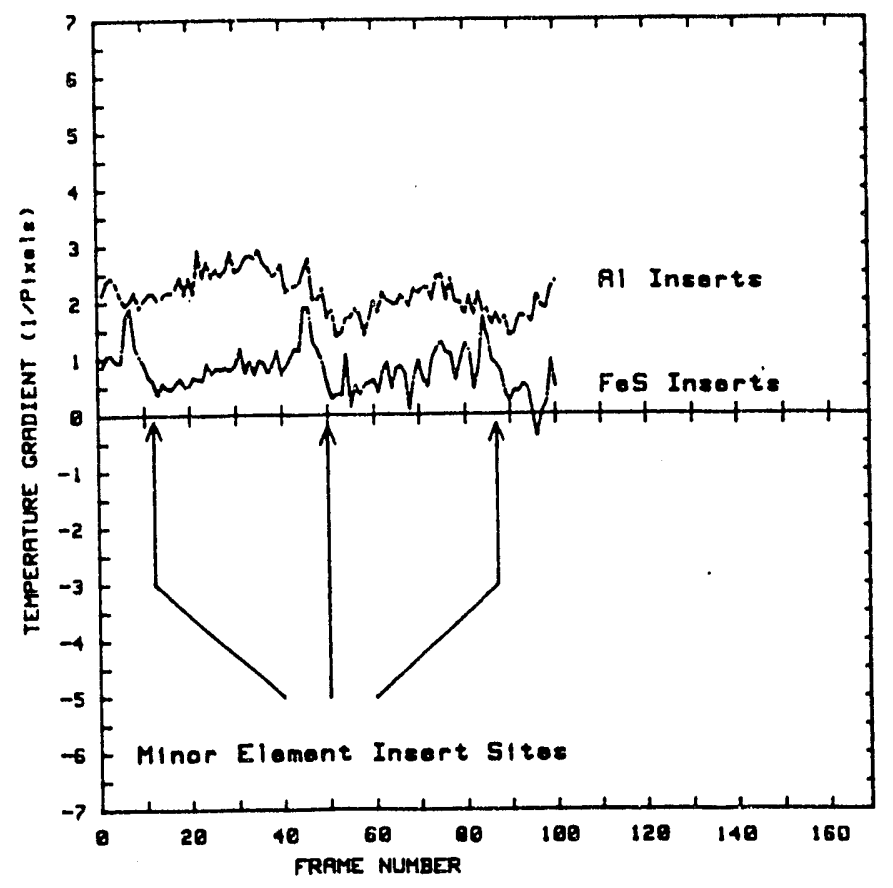

Figure 5. Temperature Gradient Variation - Al and Fes inserts 
APPENDIX E 


\title{
SUPPRESSION OF HAZ CRACKING DURING WELDING OF HELIUM-CONTAINING MATERIALS
}

\author{
C. A. Wang ${ }^{1}$ H. T. Lin ${ }^{2}$, M. L. Grossbeck ${ }^{2}$ and B. A. Chin
}

${ }^{1}$ Research Assistant, Auburn University. Present address: Oak Ridge National Laboratory, Oak Ridge, TN 37831-6376.

${ }^{2}$ Research Staff Members, Oak Ridge National Laboratory, Oak Ridge,

TN 37831-6376. ${ }^{3}$ Professor, Materials Engineering, Auburn University, Auburn, AL 36849 .

\section{ABSTRACT}

Catastrophic intergranular failures of the heat-affected zone have been observed in gas tungsten arc (GTA) welds of type 316 stainless steel containing helium greater than 2.5 appm. The failures have been attributed to helium bubble growth along grain boundaries during cooling of the weld. In this study, autogenous single pass, full penetration welds without cracking were produced in type 316 stainless steel, containing 256 appm helium. These successful welds were produced by applying a compressive stress (approximately $25 \%$ of the room temperature yield stress) perpendicular to the weld joint. Experimental results show that grain boundary helium bubble growth has been effectively reoriented from grain boundaries parallel to the weld path to grain boundaries perpendicular to the weld path. These results suggest that the application of a compressive stress during welding may be used to obtain successful welds in heliumcontaining irradiated materials. 


\section{Introduction}

The first wall of a fusion reactor will be subjected to irradiation by high energy neutrons [1-3]. One of the principal consequences of this bombardment will be the generation of helium within the material from $n-\alpha$ reactions. Subsequently helium will diffuse and agglomerate to form bubbles which nucleate and grow at point defects, dislocations and on grain boundaries due to the extremely low solubility of helium in metals. Such helium bubbles are known to degrade the properties of materials [4-13].

Helium bubbles have been shown to grow and coalesce rapidly along grain boundaries subjected to a tensile stress [14-16]. This situation is found typically in autogenous welding upon cooling. During the welding process, the metal is heated past its melting point and then rapidly cooled. Internal tensile stresses are generated during the cooling and resolidification process due to the volume contraction upon solidification and subsequent thermal contraction in the solid state. Catastrophic heat-affected zone (HAZ) intergranular cracking following GTA welding was observed by Lin et al. in type 316 stainless steel with helium levels greater than $2.5 \mathrm{appm}$ [10-13]. This HAZ cracking was found to occur at grain boundaries about 2 to 3 grain diameters from the fusion boundary. Centerline interdendritic fractures in the fusion zone have also been observed in GTA welds of alloys containing greater than 100 appm helium. These severe failures are attributed to the growth of helium bubbles at the HAZ grain boundaries and weld dendrite boundaries. In addition to their intergranular nature, all 
cracks were found to be parallel to the welding direction.

The objective of this study was to study techniques which might be used to eliminate heat-affected zone cracking in heliumcontaining steels. These techniques need to be identified to enable repair and maintenance of the first wall of a fusion reactor through GTA welding. This work investigated modification of the stress field during cooling by the application of compressive stress perpendicular to the weld direction prior to welding.

\section{Experimental Procedure}

The material investigated in this study was $0.76 \mathrm{~mm}$ thick type 316 stainless steel sheet. Following a solution anneal at $1050^{\circ} \mathrm{C}$ for one hour, average grain size was about $70 \mu \mathrm{m}$, helium was implanted into the steel to a level of 256 appm using tritium doping and decay ${ }^{\star}$. To obtain this helium level, the steel was exposed to tritium gas at $125 \mathrm{MPa}$ pressure at $300^{\circ} \mathrm{C}$ for 30 days. The dissolved tritium was then allowed to decay to helium at $40^{\circ} \mathrm{C}$ for six months. The excess tritium was then pumped off under a vacuum $\left(10^{-3} \mathrm{~Pa}\right)$ at $400^{\circ} \mathrm{C}$. The treatment resulted in the nucleation of stable helium bubbles about $4.5 \times 10^{20} / \mathrm{m}^{3}$ in density and approximately $1.7 \mathrm{~nm}$ in diameter in the matrix while a density of $8.8 \times 10^{14} / \mathrm{m}^{3}$ and $2.0 \mathrm{~nm}$ diameter bubbles were observed in the grain boundaries.

\footnotetext{
*The tritium doping was done at Sandia National Laboratory, Livermore, CA.
} 
Single pass GTA welds were produced under fully constrained conditions to simulate the structural restraint encountered in practical weld repair and maintenance. Welding was performed at $10 \mathrm{~V}-\mathrm{DC}, 24 \mathrm{~A}$ with a torch travel speed of $3.6 \mathrm{~mm} / \mathrm{s}$ under a protective argon atmosphere. The resulting heat input was 66.7 $\mathrm{J} / \mathrm{mm}$, which produced a full penetration weld approximately $3 \mathrm{~mm}$ wide.

Simplified theoretical models describing the helium bubble growth during the welding process have been proposed by Lin et al. $[10-13]$. These models indicate that the growth of helium bubbles should be significantly altered by a change in the stress state during cooling of the weld. To investigate this hypothesis, a weld plate fixture system was constructed to apply a controlled compressive stress perpendicular to the weld path. After the weld was completed, both optical microscopy and scanning electron microscopy were used to examine weld integrity of the heat-affected zone. Transmission electron microscope (TEM) specimens were removed from the fusion/heat-affected zone interface for both standard and stress-modified welds.

Results and discussion

According to Lin's model, more than $90 \%$ of the bubble growth, occurring as a result of the welding process, is stress assisted [10-13]. Figure 1 schematically shows the bubble growth mechanisms during welding. In regime $I$, the heat up regime before the material reaches its melting temperature, compressive stresses are introduced due to thermal expansion of the plates. 
This compressive stress retards bubble growth. In regime II, where the material reaches the melting temperature, a stress-free state is obtained and the bubbles grow mainly by thermal vacancy absorption. Finally, in regime III, stresses become tensile due to contraction, and most of the growth occurs in this regime.

Figure 2 shows the catastrophic heat-affected zone cracking that occurs in type 316 stainless steel containing 256 appm helium. The crack runs parallel to the welding direction and is within 2 to 3 grain diameters of the fusion/heat-affected zone boundary. Helium bubbles have migrated, coalesced, and grown rapidly at grain boundaries under the combined actions of high temperature and internal tensile stress, which occur during the welding process. Brittle rupture occurs as the cohesive strength of the grain boundary (weakened by growing helium bubbles) can no longer bear the shrinkage-induced internal tensile stress during cooling of the weld.

Satisfactory welds were obtained by application of a compressive stress. A compressive stress of $25 \%$ of the room temperature yield stress $(225 \mathrm{MPa})$ was applied in these experiments as measured by strain gauges attached to the weld plates. As seen in the scanning electron microscope (SEM) micrographs (Figure 3), there are no visible cracks observed in the HAZ. This result is consistent with the conclusion from the previous study that the high-temperature alone is not sufficient to cause significant growth of grain boundary helium bubbles. Rather, a combination of both high-temperature and high tensile shrinkage stress is the key factor for intergranular HAZ cracking. 
SEM examination of the TEM discs was conducted after jet thinning, and the results are shown in Figures 4 and 5 for the standard and stress-modified welds, respectively. Welding directions in both welds are indicated by the large arrows. The magnified grain boundary features for the marked regions in Figures $4 \mathrm{a}$ and $5 \mathrm{a}$ are also presented. The results show that the grain boundary helium bubble growth has been effectively suppressed in the stress-modified welds. Additionally, the bubble growth has been altered such that the bubbles occurred predominantly on grain boundaries perpendicular to the weld direction, whereas previously they occurred principally on grain boundaries parallel to the weld direction. It should be pointed out that jet polishing attacks the grain boundaries and opens up grain boundary holes. Hence the grain boundary bubble size shown on the graphs is exaggerated as compared to the as-welded material.

During weld solidification, the principle shrinkage-induced internal tensile stress is perpendicular to the welding direction. This stress causes the helium bubbles to grow rapidly at the grain boundaries at high temperatures and to align preferentially along grain boundaries perpendicular to the stress (parallel to the weld). When the internal tensile stress is altered by applying an initial compressive stress perpendicular to the welding direction, the helium bubble growth process is retarded along grain boundaries oriented parallel to the welding direction; therefore, HAZ cracking is less likely to occur. However, a small number of helium bubbles still grow 
preferentially along the direction perpendicular to the weld due to internal tensile stresses generated by bulk body constraint along the weld direction.

\section{Conclusions}

The following conclusions can be drawn from this study: 1. A combination of high temperature and shrinkage-induced tensile stress is the key factor for bubble growth and subsequent heat-affected zone cracking.

2. Sound autogenous gas tungsten arc weids can be produced in helium-containing type 316 stainless steel by the application of a compressive stress to alter grain boundary helium bubble growth.

3. A compressive stress of $25 \%$ of the room temperature yield stress effectively suppresses helium bubble growth parallel to the weld direction and eliminates $\mathrm{HAZ}$ cracking. 4. This compressive stress also leads to the preferential growth of helium bubbles along grain boundaries perpendicular to the weld direction.

\section{Acknowledgment}

Research sponsored by the Office of Fusion Energy, U.S. Department of Energy, under contract DE-AC05-840R21400 with the Martin Marietta Energy System, Inc. 


\section{REFERENCES}

[1] R. W. Conn, Journal of Nuclear Materials, 85\&86(1979)9-16.

[2] J. O. Stiegler and L. K. Mansur, Ann. Rev. Mater. Sci., 9 (1979) 405-454.

[3] M. M. Hall, Jr. et al., in: Proceedings of the Fifth Bolton Landing Conference, (1978) 365-378.

[4] J. P. Maloney, et al., DP-1199, E. I. du Pont de Nemours \& Co., Savannah River Laboratory, Aiken, SC, June 1969.

[5] M. M. Hall, Jr. et al., ibid. ref.[3], pp. 365-378.

[6] S. D. Atkin, Sept. 30, 1981, DOE/ER-0045/7, pp. 110-117, U.S. DOE, Office of Fusion Energy.

[7] W. K. Kanne, C. L. Angerman and B. J. Eberhard, DP-1740, E. I. du Pont de Nemours \& Co., Savannah River Laboratory, Aiken, SC, February 1987.

[8] W. R. Kanne, DPMS-8940, E. I. Dupont Co., Savannah River Laboratory, Aiken, SC, 1989.

[9] A. K. Birchenall, DPMS-8941, E. I. Dupont Co., Savannah River Laboratory, Aiken, SC, 1989.

[10] H. T. Lin, M. L. Grossbeck and B. A. Chin, Metallurgical Transactions A, 21A(1990)2585-2596.

[11] H. T. Lin, Ph.D. Dissertation, Auburn University, 1989.

[12] H. T. Iin et al., in: 14th International symposium, Volume I, ASTM STP 1064, ASTM, Philadelphia,(1989) 301-314.

[13] H. T. Lin, ORNL/TM-11158, Oak Ridge National Laboratory, Oak Ridge, TN, 1989.

[14] D. Hull and D. E. Rimmer, Philosophical Magazine, $4(1959) 673-687$.

[15] M. V. Speight and J. E. Harris, Metal Science Journal, $1(1967) 83-85$.

[16] H. Trinkaus, Ber. Bunsenges. Phys. Chem., 82(1978) 249-253. 
Figure 1. Schematic of grain boundary bubble growth during welding (after Lin[10-13]).

Figure 2. As-welded helium-doped 316 stainless steel HAZ intergranular rupture in a standard GTA weld.

Figure 3. As-welded morphology of helium-doped 316 stainless steel in a modified $G T$ A weld.

Figure 4. SEM Photographs of the jet polished TEM discs from (a) standard GTA weld, (b) marked region 1, (c) marked region 2, (d) marked region 3 . Arrow indicates the welding direction.

Figure 5. SEM Photographs of the jet polished TEM discs from (a) modified GTA weld, (b) marked region 1, (c) marked region 2, (d) marked region 3 . Arrow indicates the welding direction. 

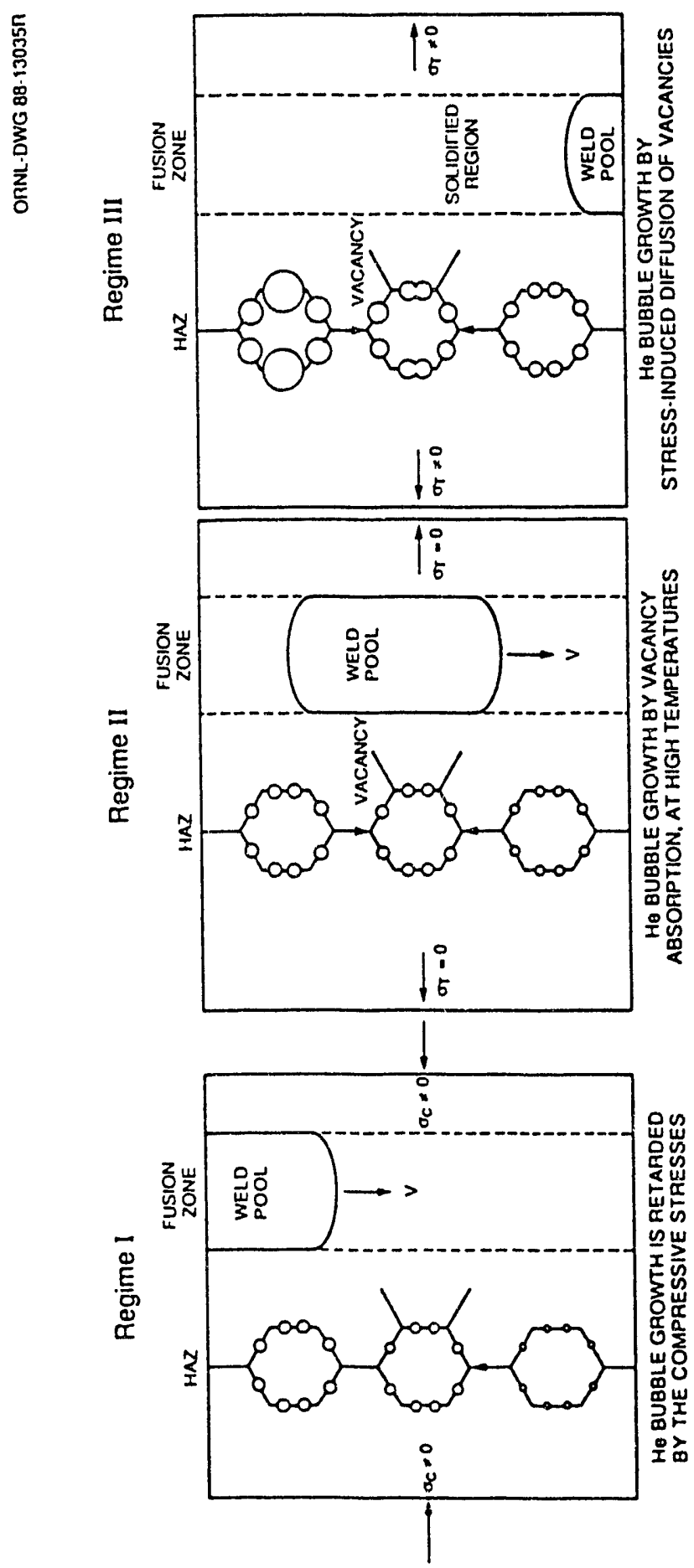
Fig 3
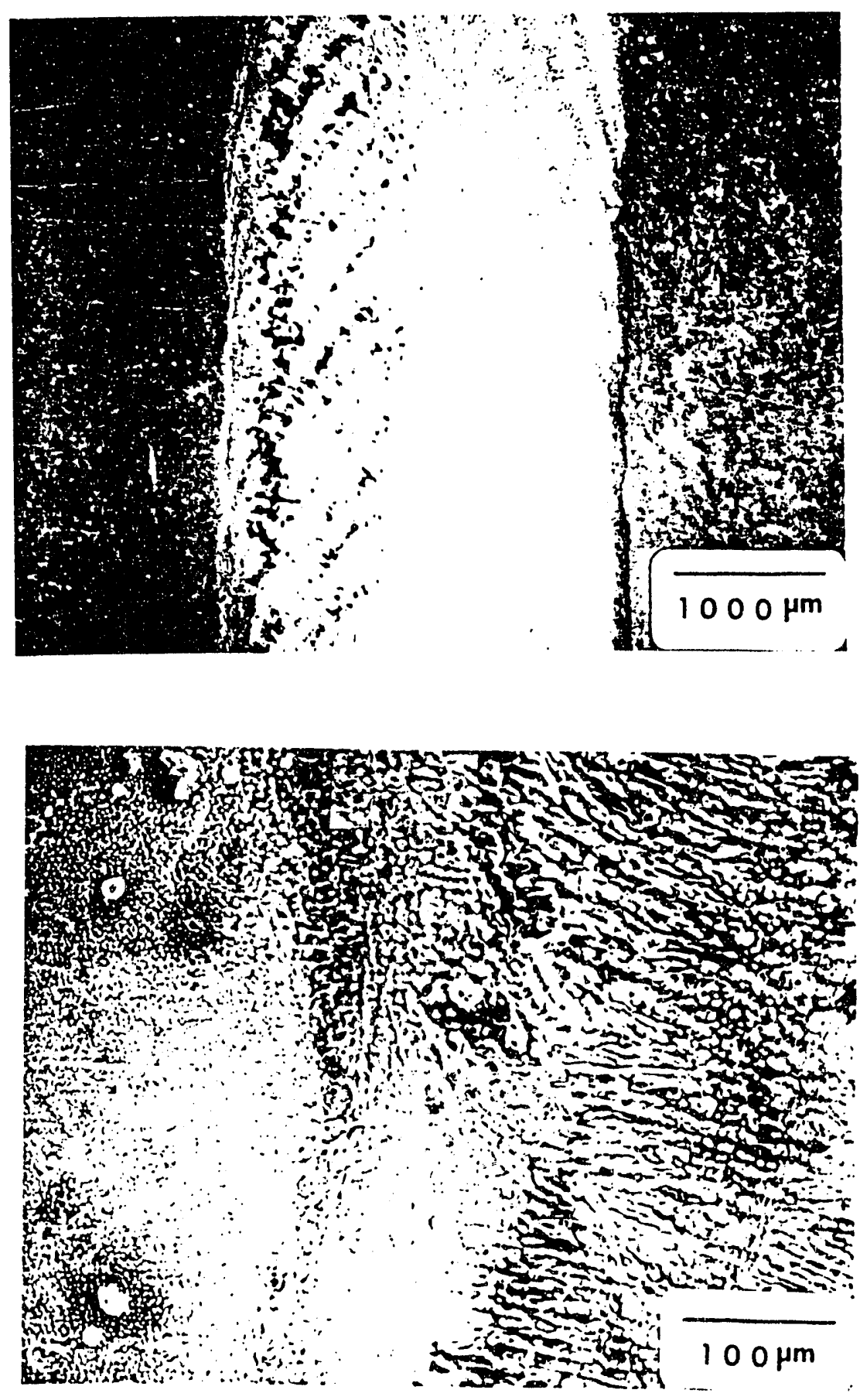

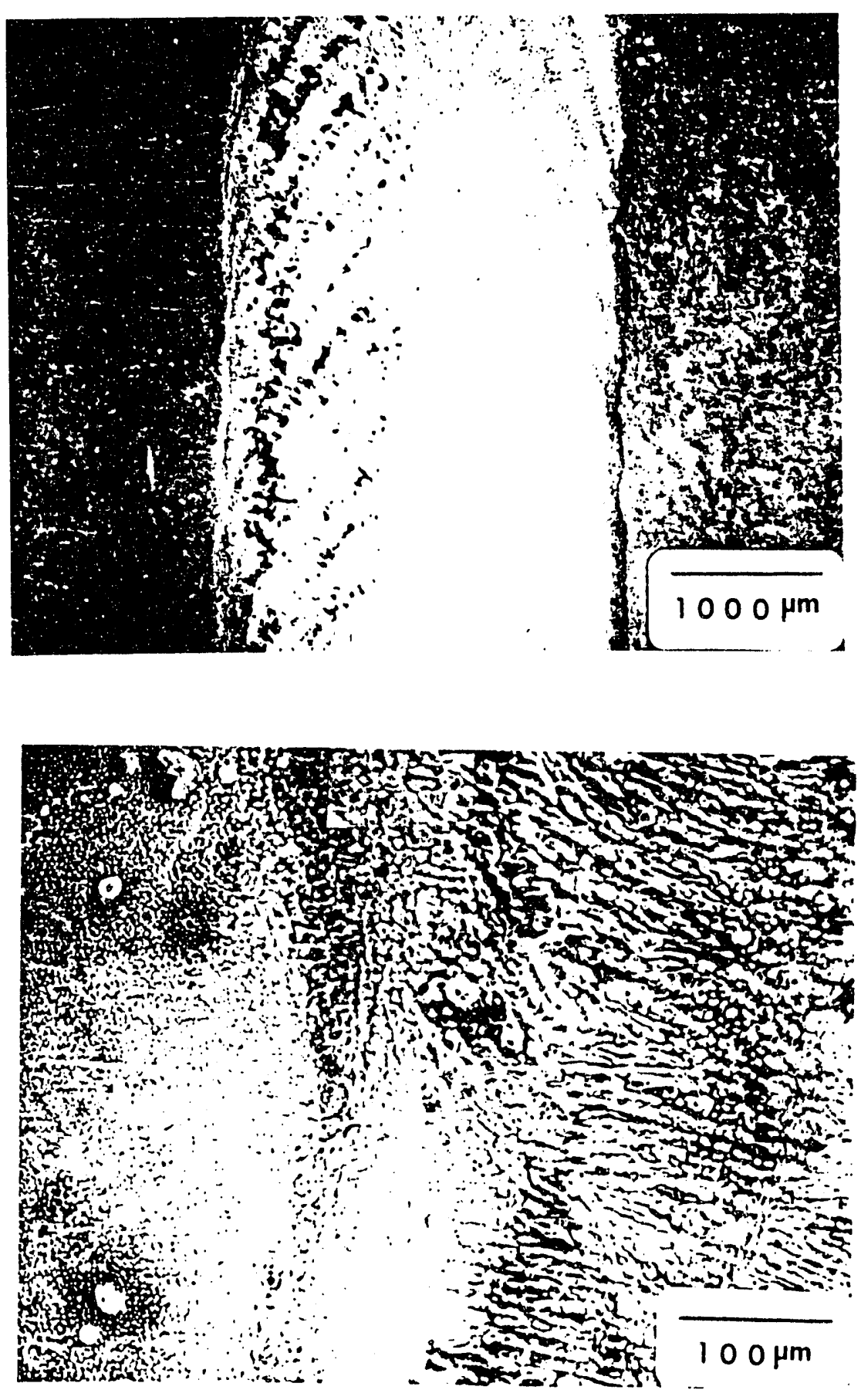

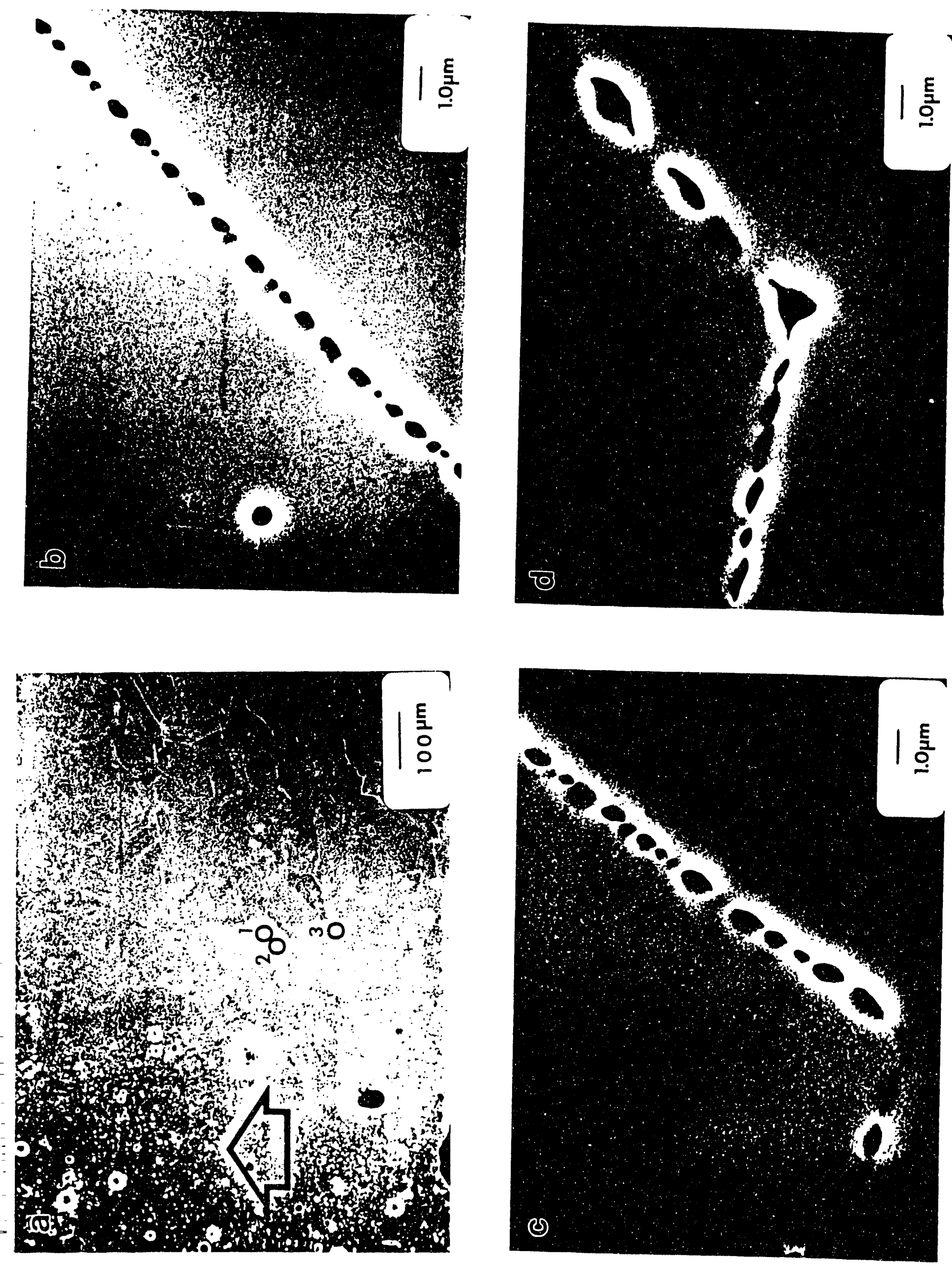
APPENDIX F 


\title{
THE WELDABILITY OF LOW ACTIVATION Cr-W STEELS
}

\author{
C. A. Wang ${ }^{1}$, R. L. Klueh ${ }^{2}$ and B. A. $\mathrm{Chin}^{3}$
}

${ }^{1}$ Research Assistant, Auburn University. Present address: Oak Ridge National Laboratory, Oak Ridge, TN 37831-6376.

${ }^{2}$ Research staff Member, Oak Ridge National Laboratory, Oak Ridge, TN 37831-6376

${ }^{3}$ Professor, Materials Engineering, Auburn University, Auburn, AL 36849 .

Abstract

A series of chromium-tungsten ferritic steels patterned on the chromium-molybdenum alloys, 2 icr-1Mo, $9 \mathrm{Cr}-1 \mathrm{MovNb}$ and $12 \mathrm{Cr}-1 \mathrm{M} 0 \mathrm{VW}$, were tested for weldability. These steels are being developed as candidates for the first wall and blanket structure of fusion reactors. Use of these materials will minimize the long term radioactive hazards associated with disposal after service. In these low activation alloys, long half life elements (Mo and $\mathrm{Nb}$ ), which become activated during irradiation, are replaced. Autogenous bead-on-plate welds were performed using the gas tungsten arc welding process. Experimental results showed that all welds were free of cracks. Sound welds were achieved in 2 and $5 \% \mathrm{Cr}-\mathrm{W}$ low activation steels while loss of ductility was observed in 9 and $12 \% \mathrm{Cr}-\mathrm{W}$ steels. This result suggests that post-weld heat treatment is necessary to restore toughness to the $9-12 \% \mathrm{Cr}-\mathrm{W}$ steels. 


\section{Introduction}

In a Tokamak fusion reactor, the inner most structural components, first wall and blanket, will experience the highest neutron flux and become highly radioactive ${ }^{1.3}$. Public safety and environmental contamination concerns arise from the long term radioactive hazards associated with disposal of these structural components after service. These concerns led the office of Fusion Energy of the U.S. Depar ent of Energy to establish a program to develop steels with fast induced-radioactivity decay for fusion reactor applications ${ }^{4}$. Several criteria have been proposed and discussed for the development of these materials. one of the requirements which must be examined prior to selection of such an alloy is its weldability ${ }^{1}$.

In this study, a series of ferritic steels patterned on the chromium-molybdenum alloys were tested for weldability. Use of these materials will minimize the radiological impact in the area of disposal of radioactive waste. In these steels, elements which become activated during irradiation with long half lives (Mo, $\mathrm{Nb}$ and Co etc.) are replaced ${ }^{5}$. These steels with fast induced-radioactivity decay characteristics are also known as low activation steels.

\section{Experimental Procedure}

The nominal chemical compositions of the eight low activation ferritic steels investigated are shown in Table 1. All heats except $2 \frac{1}{4} \mathrm{Cr}-2 \mathrm{~W}$ were austenitized at $1050^{\circ} \mathrm{C}$ for $0.5 \mathrm{~h}$ and water quenched. $2 \frac{1}{4} \mathrm{Cr}-2 \mathrm{~W}$ was annealed at $900^{\circ} \mathrm{C}$ for $0.5 \mathrm{~h}$ and quenched. Higher austenitization temperatures were used for all vanadium containing steels, except $2 \frac{1}{4} \mathrm{Cr}-2 \mathrm{~W}$, to ensure that the vanadium carbides present were dissolved ${ }^{5 \cdot 10}$. Tempering was performed for $1 \mathrm{~h}$ at $700^{\circ} \mathrm{C}$ for all heats. Autogenous bead-onplate welds were produced using the GTA welding process to evaluate the weldability. Welds were produced under a fully constrained condition to simulate the anticipated conditions that will be encountered in the maintenance of structural components. The welding conditions used were $10 \mathrm{~V}-D C, 38 \mathrm{~A}$ at a torch speed of $4.6 \mathrm{~mm} / \mathrm{s}$ with an argon shielding gas and tungsten electrode size of $1.5875 \mathrm{~mm}$ diameter. A heat input of $82.6 \mathrm{~J} / \mathrm{mm}$ was used to obtain a $2.5 \mathrm{~mm}$ wide full penetration weld perpendicular to the rolling direction.

Microstructures were observed using optical microscopy and an image analysis system was used to measure ferrite volume fractions. Transverse diamond pyramid microhardness (dph) measurements were made across the weld to investigate the microstructure-property relationships. The three-point guidebend test was used as one index of weld integrity. The initial three-point bend was made at a speed of $0.508 \mathrm{~mm} / \mathrm{min}$ over a $25 \mathrm{~mm}$ span distance to produce a $100^{\circ}$ angle around the fusion $z$ one. The final $180^{\circ}$ bend was performed using a vise with a $1.5 \mathrm{~mm}$ thick space bar. Tensile test specimens were prepared perpendicular to the weld direction and had a reduced gauge section of $12.7 \mathrm{~mm}$ length by $3.175 \mathrm{~mm}$ width by $0.76 \mathrm{~mm}$ thickness. Tensile tests were performed at a speed of $0.508 \mathrm{~mm} / \mathrm{min}$, which resulted in a strain rate of $6.67 \times 10^{.4} \mathrm{~s}^{-1}$. The fracture modes 
were investigated with a scanning electron microscope equipped with energy dispersive spectrometers.

Results and Discussion

Experimental results showed that all the steels were free of cracks and readily weldable. The low carbon content in all heats tested contributes to this excellent weldability. Steels with a higher carbon-equivalent will be more susceptible to HAZ cracking due to martensitic transformations. Satisfactory GTA welds were obtained for all steels in this study, including the 12Cr-2WV steel. This low susceptibility to HAZ cracking is believed to be a consequence of the delta-ferrite present in the microstructure of the modified alloys. Commercial $12 \mathrm{Cr}$-Mo steels have been reported to crack extensively in the HAZ when no preheating is done ${ }^{11}$.

Microhardness measurements for each heat across the weld with corresponding microstructures are presented in Figures 1. The alloying additions were found to have a significant effect on the base metal microstructure of the $2 \neq \% \mathrm{Cr}$ steels. The $2 \% \mathrm{Cr}$ steels are typically composed of a bainitic structure. Without tungsten additions, $2 \frac{1}{7} \mathrm{Cr}-\mathrm{V}$ steel contains $8-12 \%$ proeutectoid polygonal ferrite. As tungsten is added, $2 \Varangle \mathrm{Cr}-1 \mathrm{WV}$ has $5-10 \%$ ferrite and 3-8\% ferrite is observed in the $2 \% \mathrm{Cr}-2 \mathrm{WV}$ steel. No ferrite was observed in the $2 \neq \mathrm{Cr}-2 \mathrm{~W}$ steel. This result suggests that the addition of tungsten reduces the formation of polygonal ferrite. Nevertheless, it was experimentally found that the 2 : Cr-2WV steel contained polygonal ferrite. This phenomenon probably resulted from the presence of vanadium carbides that did not completely dissolve during austenitization ${ }^{6 \cdot 10}$.

A martensitic structure was observed in the $5-12 \% \mathrm{Cr}$ steels. This result implies that chromium effectively promotes martensite formation instead of bainite. The 5-9\% $\mathrm{Cr}$ steels are fully martensitic, whereas the $12 \mathrm{Cr}-2 \mathrm{WV}$ steel contains $12-17 \% \delta-$ ferrite. The reason for the presence of ferrite is insufficient austenite-stabilizing elements such as carbon, nickel and manganese ${ }^{13 \cdot 15}$.

In the 9Cr-2WVTa steel, a finer martensitic structure is found than in the $9 \mathrm{Cr}-2 \mathrm{WV}$ steel. Tantalum behaves similar to niobium in the commercial 9Cr-Mo steels. Tantalum exists in $9 \mathrm{Cr}-$ 2 WVTa steel in the form of carbide precipitates with a high melting point. During the austenitization process, tantalum carbide precipitates dissolve slowly or even remain in the solid form and act as pinning particles to confine grain growth. Therefore, a finer structure is obtained after solidification.

Results of bending tests show specimens were free of cracks for all control steels under quenched and tempered conditions. The weld bend tests show that all $2 \% \mathrm{Cr}$ steels have excellent ductility in the welds. No failure was observed in the steels investigated. The microstructure of these steels consists of a bainite structure which has high strength and excellent toughness. Similar properties were obtained for the $5 \mathrm{Cr}-2 \mathrm{WV}$ steel despite its martensite structure. Fusion zone failures were observed in the $9 \% \mathrm{Cr}$ steels during final bend tests due to the presence of brittle untempered martensite present in the 
fusion zone of the weld.

Fusion zone failures in initial three point bend tests show that the $12 \mathrm{Cr}-2 \mathrm{WV}$ steels display poor ductility in the weld region. The material failed typically at a deflection of between 1.6 to $2.0 \mathrm{~mm}$ during the initial bend test. Two reasons can be given for this deterioration of the $12 \% \mathrm{Cr}$ steels during welding. First, untempered martensite present in the fusion zone of the weld is brittle and restricts deformation. Second, the presence of delta ferrite reduces the toughness substantially ${ }^{16}$. Anderko has concluded that elements which suppress the formation of delta ferrite produce lower DBTT than elements, such as Cr, that promote delta-ferrite formation ${ }^{17}$. The nonuniformity in structure and strength easily leads to crack formation. Fracture surfaces of the weld bend test specimens, as shown in Figure 2, indicate that brittle fracture is predominant in the $9 \% \mathrm{Cr}$ steels. Failure generally occurs by a transgranular cleavage mode. Some dimple rupture can be seen near the rim of the brittle cleavage facets in both steel fracture surfaces. This is probably where the soft ferrite phase is located. The brittle fracture mode in $12 \mathrm{Cr}-2 \mathrm{WV}$ steel is attributed to its high hardenability and the presence of delta ferrite.

Results of tensile tests are shown in Table 2 . Without vanadium additions, the tempered $2 \frac{1}{4} \mathrm{Cr}-2 \mathrm{~W}$ steel appears to have the lowest strength but possesses excellent ductility. Extensive deformation is observed during tensile tests, even after cracks initiated in the $2 \frac{1}{4} \mathrm{Cr}-2 \mathrm{~W}$ steel, as seen from the total elongation data. Tempered $2: \mathrm{Cr}-\mathrm{V}$ steel has a strength greater than $2 \mathrm{Cr}-2 \mathrm{~W}$ steel. Extensive elongation is also observed for the 2 icr $-\mathrm{V}$ steel. This difference in strength suggests that $V$ has a greater effect on strengthening the tensile properties than $W$.

The $2 \mathrm{Cr}-2 \mathrm{WV}$ steel has both the highest ultimate tensile strength and $0.2 \%$ offset yield stress of the $2 \% \mathrm{Cr}$ steels for both control and as welded conditions. The lowest value of strength was found in the $2 / \mathrm{Cr}-2 \mathrm{~W}$ steel. This is consistent with microhardness observations. The $2 \frac{1}{4} \mathrm{Cr}-1 \mathrm{WV}$ steel shows a slightly lower strength than $2 \frac{1}{4} \mathrm{Cr}-2 W \mathrm{WV}$ but a much greater strength than $2 \div \mathrm{Cr}-\mathrm{V}$ steel. The highest uniform elongation is found in $2 \frac{1}{4} \mathrm{Cr}-\mathrm{V}$ steel, while $2 \frac{1}{4} \mathrm{Cr}-2 \mathrm{WV}$ steel appears to have the lowest ductility of the $2 \frac{1}{4} \mathrm{Cr}$ steels. Failures occurred either in the base metal or heat-affected zone/base metal interface for all $2 \% \mathrm{Cr}$ steels. The combined use of $W$ and $V$ in these steels results in high tensile strength, accompanied by adequate ductility. The 2 l CrIWV steel has a much greater tensile strength than both the 2 icr$\mathrm{V}$ and $2 \frac{1}{4} \mathrm{Cr}-2 \mathrm{~W}$ steels, but the tensile strength is slightly lower than the $2 \frac{1}{\mathrm{Cr}}-2 \mathrm{WV}$ steel. Observations reveal that coarse carbide precipitates are found in 2 l Cr-V steel ${ }^{10}$. An increase in $W$ content decreases the size of carbide precipitates. The transformation temperature is effectively decreased by $W$ additions and therefore finer precipitates are observed. Finely dispersed precipitates significantly impede dislocation motion and increase the strength. However, the addition of $W$ or $V$ alone does not yield satisfactory strength. The steel with tungsten additions, 2 lCr-2W, has a coarser carbide precipitate distribution than that of steels without tungsten, 2 Cr-V, or 
steels containing $\mathrm{V}, 2 \nmid \mathrm{Cr}-2 \mathrm{WV}$. This explains why the lowest strength is found in $2+\mathrm{Cr}-2 \mathrm{~W}$ steel and shows the remarkable additive effect of $W$ and $V$.

The 9Cr-2WVTa steel has the highest tensile strength of all heats for both the control and welded conditions. This steel also possesses a relatively high uniform elongation. The $5 \mathrm{Cr}-2 \mathrm{WV}$ steel. shows the lowest values of both strength and elongation for the 5-12\% Cr steels. Even though the 12Cr-2WV steel has only slightly lower strength than the $9 \mathrm{Cr}-2 \mathrm{WV}$ steels, it shows the highest ductility in uniform elongation of the $5-12 \% \mathrm{Cr}$ steels. Base metal failures were observed for all the $5-12 \% \mathrm{Cr}$ steels in tensile tests. The mechanical properties of these steels had degraded after gas tungsten arc welding. The area under the stress-strain curve, a measure of toughness, also decreased for all heats of the 5-12\% Cr steels after welding, while the Young's modulus remained practically the same.

The tensile test results show that strength increases with increasing chromium content. However, a different result is presented by Klueh et $a 1^{7 \cdot 10}$. They concluded that chromium had a nonlinear strengthening effect on these steels and showed a minimum strength in 5Cr-2WV steel due to the coarser carbide distribution ${ }^{10}$. The lower strength in the $12 \mathrm{Cr}-2 \mathrm{WV}$ steel is attributed to the large amount of delta ferrite present in the microstructure, which also results in adequate ductility. With tantalum additions, the grain size of 9Cr-2WVTa is effectively reduced by the precipitate pinning process and strength, therefore, is increased.

Conclusions

From the results of this study, the following conclusions were drawn:

1. Sound autogenous welds can be achieved by conventional gas tungsten arc welding in 2 and $5 \% \mathrm{Cr}$ low activation ferritic steels.

2 . Post-wela heat treatment is necessary in the $9-12 \%$ Cr low activation steels to restore toughness.

3. Chromium, vanadium and tungsten additions strengthen all steels tested. $V$ and $W$ show significant additive effects. 


\section{References}

[1] D. R. Harries, in: Proc. of Topical Conference on Ferritic Alloys for use in Nuclear Energy Technology, TME/AIME, Snowbird, Utah, 1983, pp. 141-155.

[2] R. W. Conn, Journal of Nuclear Materials, 85\&86(1979)9-16.

[3] M. M. Hall, Jr. et al., in: Proceedings of the Fifth Bolton Landing Conference, August 1978, pp.365-378.

[4] Kenneth Evans, Jr. et al., Nuclear Technology/Fusion, Vol. 4, No. 2, Part 1, Sep. 1983, pp.226-236.

[5] R. I. Klueh and W. R. Corwin, Journal of Materials Engineering, Vol. 11, No. 2, 1989, pp. 169-175.

[6] H. T. Lin and B. A. Chin, Mar. 31, 1987, DOE/ER/0313/2, pp. 135-150, Office of Fusion Energy.

[7] R. I. Klueh, Nucl. Eng and Design, 2(1985) 383 .

[8] R. L. Klueh, Met. Trans A, 20A(1989) 463.

[9] R. I. Klueh and P. J. Maziasz, Met. Trans A, 20A(1989) 373 .

[10] R. I. Klueh, P. J. Maziasz and W. R. Corwin, ORNL-6472, Oak Ridge National Laboratory, Oak Ridge, TN, 1988.

[11] E. J. Vineberg et al., in: Conference Proceedings on Welding in energy Related Projects, Welding Institute of Canada, 1984 , pp. 235-245.

[12] K. E. Thelning, steel and its Heat Treatment, Butterworths, London, 1984, pp. 90-97.

[13] Edgar C. Bain and Harold W. Paxton, Alloying Elements in Steel, ASM, Metals Park, OHIO, 1961, pp. 242-249.

[14] R. W. K. Honeycombe, Steels-Microstructure and Properties, Edward Arnold Ltd. and ASM, Metals Park, OHIO, 1982, pp. 211-235.

[15] W. W. Cias, Phase Transformation Kinetics and Hardenability of Medium-Carbon Alloy Steels, Climax Molybdenum Co., Greenwich, Conn., 1972, pp. 3-11.

[16] B. A. Chin and R. C. Wilcox, ibid. ref.[1], pp.347-356.

[17] K. Anderko et al., ibid. ref. [15], pp. 299-306. 

Figure 1. Diamond Pyramid Hardness across the Welds in Fusion
Zone, HAZ and Base Metal with Corresponding Microstructures.

Figure 2. SEM Fracture surface Photographs after Bending Test for (a) $9 \mathrm{Cr}-2 \mathrm{WV}$ Steel (b) $9 \mathrm{Cr}-2 \mathrm{WVTa}$ steel (c) $12 \mathrm{Cr}-2 \mathrm{WV}$ steel. 
Table 1

Chemical Composition (wt\%) of $\mathrm{Cr} \cdot \mathrm{W}$ Steels

\begin{tabular}{llllllll}
\hline Steels & Cr & $W$ & $V$ & C & Mn & si & Ta \\
\hline $21 / C r-V$ & 2.36 & & 0.25 & 0.11 & 0.40 & 0.17 & \\
$21 / C r-1 W V$ & 2.30 & 0.93 & 0.25 & 0.10 & 0.34 & 0.13 & \\
$21 / C r-2 W$ & 2.48 & 1.99 & 0.009 & 0.11 & 0.39 & 0.15 & \\
$21 / C r-2 W V$ & 2.42 & 1.98 & 0.24 & 0.11 & 0.42 & 0.20 & \\
$5 C r-2 W V$ & 5.00 & 2.07 & 0.25 & 0.13 & 0.47 & 0.25 & \\
$9 C r-2 W V$ & 8.73 & 2.09 & 0.24 & 0.12 & 0.51 & 0.25 & \\
9Cr-2WVTa & 8.72 & 2.09 & 0.23 & 0.10 & 0.43 & 0.23 & 0.075 \\
$12 C r-2 W V$ & 11.49 & 2.12 & 0.23 & 0.10 & 0.46 & 0.24 & \\
\hline \hline
\end{tabular}

${ }^{a} P=0.014 \cdot 0.016, S=0.005-0.006, C_{O}=0.005 \cdot 0.008$

$\mathrm{Cu}=0.002-0.03, \mathrm{Al}=0.02 \cdot 0.03, \mathrm{Ni}<0.01, \mathrm{M}_{0}<0.01$

$\mathrm{Nb}<0.01, \mathrm{~T} i<0.01, B<0.001$.

Balance iron.

Table 2

Results of Room Temperature Tensile Test

\begin{tabular}{|c|c|c|c|c|c|}
\hline \multirow[b]{2}{*}{ Steel } & \multicolumn{3}{|c|}{ strength (MPa) } & \multicolumn{2}{|c|}{ Elongation $(\%)$} \\
\hline & & UTS & $0.2 \%$ YS & Uniform & Total \\
\hline $2 \mathrm{~K} / \mathrm{Cr} \cdot \mathrm{V}$ & $\begin{array}{l}\text { c } \\
\text { W }\end{array}$ & $\begin{array}{l}516 \\
443\end{array}$ & $\begin{array}{l}428 \\
326\end{array}$ & $\begin{array}{l}7.2 \\
6.5\end{array}$ & $\begin{array}{l}18.0 \\
15.0\end{array}$ \\
\hline $21 / 4 C r \cdot 1 W V$ & c & 719 & 550 & 7.2 & 14.5 \\
\hline & $w$ & 686 & 524 & 5.8 & 9.8 \\
\hline $2 \mathrm{KCr}-2 \mathrm{~W}$ & c & 441 & 368 & 7.0 & 17.8 \\
\hline & $\omega$ & 403 & 330 & 6.9 & 17.6 \\
\hline $2 \% \mathrm{Cr}-2 \mathrm{WV}$ & c & $\begin{array}{l}727 \\
719\end{array}$ & $\begin{array}{l}588 \\
567\end{array}$ & $\begin{array}{l}6.6 \\
5.7\end{array}$ & $\begin{array}{r}12.4 \\
9.4\end{array}$ \\
\hline $5 \mathrm{Cr} \cdot 2 \mathrm{WV}$ & c & 806 & 535 & 7.1 & 13.5 \\
\hline & $w$ & 783 & 526 & 5.4 & 8.8 \\
\hline $9 \mathrm{Cr}-2 \mathrm{WN}$ & c & 842 & 595 & 7.2 & 12.2 \\
\hline & $w$ & 786 & 572 & 5.7 & 10.5 \\
\hline 9Cr-2WVTa & c & 874 & 615 & 8.1 & 13.6 \\
\hline & $w$ & 864 & 586 & 6.7 & 11.4 \\
\hline $12 \mathrm{Cr}-2 \mathrm{WN}$ & E & $\begin{array}{l}832 \\
802\end{array}$ & $\begin{array}{l}578 \\
556\end{array}$ & $\begin{array}{l}9.4 \\
6.4\end{array}$ & $\begin{array}{l}13.2 \\
11.2\end{array}$ \\
\hline
\end{tabular}

$c=$ control, $w=$ weld 
$\begin{array}{llll}\text { F.Z. DPH H.A.Z. DPH B. DPH } & \text { B. D. D }\end{array}$

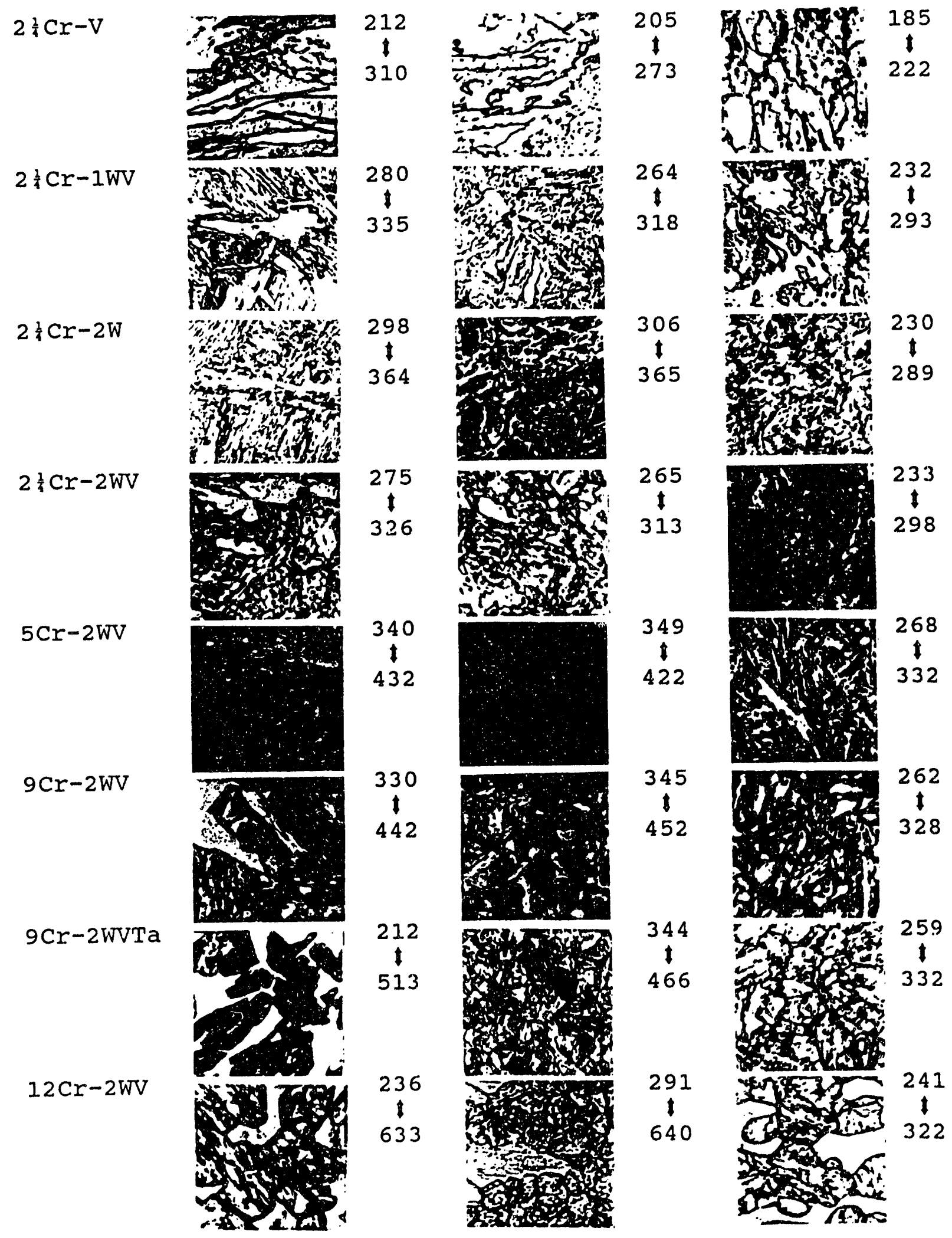



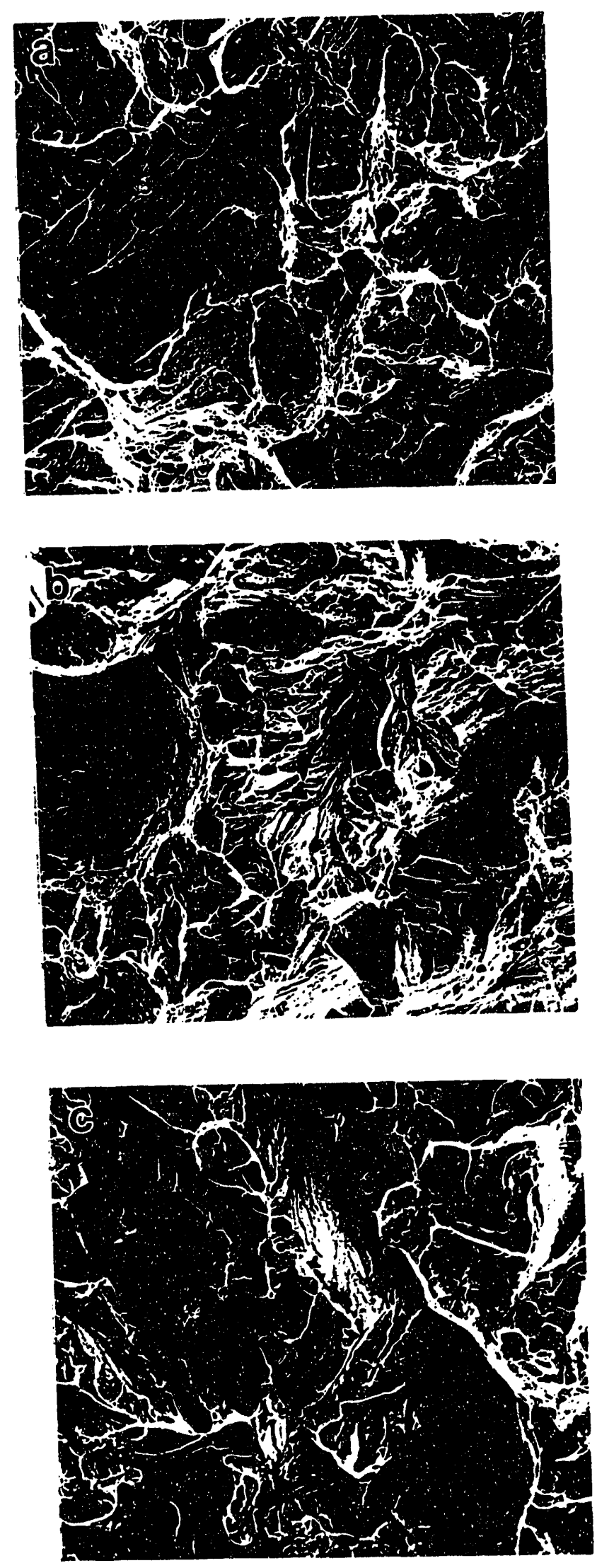

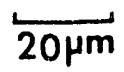


APPENDIX G 


\title{
MULTIPLE ION IMPLANTATION EFFECTS ON FATIGUE PROPERTIES OF Fe-13Cr-15Ni ALLOYS
}

\author{
G. R. Rao ${ }^{1,4}$, E. H. Lee ${ }^{1}$, L. A. Boatner ${ }^{2}$, B. A. Chin ${ }^{3}$ and L. K. Mansur ${ }^{1}$
}

${ }^{1}$ Metals and Ceramics Division, Oak Ridge National Laboratory, Oak Ridge, TN 37831

${ }^{2}$ Solid State Division, Oak Ridge National Laboratory, Oak Ridge, TN 37831

${ }^{3}$ Materials Engineering Program, Auburn University, Auburn, AL 36849

${ }^{4}$ On Assignment to ORNL from Auburn University

\begin{abstract}
Eight complex alloys based on the composition Fe-13Cr-15Ni-2Mo-2Mn-0.2Ti-0.8Si-0.06C were implanted simultaneously with $400 \mathrm{keV}$ boron and $550 \mathrm{keV}$ nitrogen, and investigated for bending fatigue life and microhardness changes. The dual implantation was found to decrease the fatigue life of all eight alloys. This result was in contrast to the significant improvements found in the fatigue life of four $\mathrm{B}, \mathrm{N}$ implanted simple $\mathrm{Fe}-13 \mathrm{Cr}-15 \mathrm{Ni}$ alloys. It was determined that the implantation suppressed surface slip-band formation, the usual crack initiation site, but in the complex alloys, this suppression promoted a shift to grain boundary cracking. A similar phenomenon was also observed when the simple $\mathrm{Fe}-13 \mathrm{Cr}-15 \mathrm{Ni}$ alloys were simultaneously implanted with boron, nitrogen and carbon wherein fatigue life decreased, and again, grain boundary cracks were observed. To test the hypothesis that ion implantation made the overall surface more fatigue-resistant but led to a shift to grain-boundary cracking, single crystal specimens of the ternary $\mathrm{Fe}-15 \mathrm{Cr}-15 \mathrm{Ni}$ were also implanted with boron and nitrogen ions. The fatigue life decreased for the single-crystal specimens also, due to concentration of applied stress along fewer slip bands as compared to the control single crystal specimens where applied stress was relieved by slip band formation over the entire gauge region. Fatigue life improvement by ion implantation at intermediate strain levels has a sensitive dependence un grain size as well as extent of slip band suppression.
\end{abstract}

This research was sponsored by the Division of Materials Sciences, United States Department of Energy, under contract No. DE-AC05-840R21400 with Martin Marietta Energy Systems, Inc. 


\section{Introduction}

Ion implantation of metals has previously been shown to be an effective technique in many cases for improving fatigue properties. Implanting the metal surface with energetic ions delays and suppresses the formation of slip bands (the preferred initiation site for fatigue cracks) at the surface, thereby increasing the overall fatigue life [1,2]. An earlier study by Lee and Mansur showed that simultaneous dual implantation of four $\mathrm{Fe}-13 \mathrm{Cr}-15 \mathrm{Ni}$ model alloys with boron and nitrogen improved fatigue life to a greater extent than did single implantation with either ion species [3]. Their results indicated that multiple ion implantation could be an effective technique for significantly improving fatigue properties.

In the present study, the fatigue properties of eight complex engineering $\mathrm{Fe}-13 \mathrm{Cr}-15 \mathrm{Ni}$ alloys implanted simultaneously with boron and nitrogen were investigated. These alloys are based on the composition $\mathrm{Fe}-13 \mathrm{Cr}-15 \mathrm{Ni}-2 \mathrm{Mo}-2 \mathrm{Mn}-0.2 \mathrm{Ti}-0.8 \mathrm{Si}-0.06 \mathrm{C}$. In an earlier paper, we showed that the fatigue life of these alloys actually decreased after the dual implantation [4]. This decrease was attributed to a shift to grain boundary cracking instead of slip-band crack formation. To further explore this hypothesis, single-crystal specimens of an $\mathrm{Fe}-15 \mathrm{Cr}-15 \mathrm{Ni}$ alloy were implanted with boron and nitrogen ions and tested for fatigue life. In the present paper, the single-crystal results are compared with the earlier results obtained using polycrystalline specimens, and possible mechanisms of fatigue-crack initiation in ion-implanted metals are examined.

\section{Experimental Procedure}

The compositions of the alloys, designated as E-1 through E-8 are given in table 1. The singlecrystal specimens were grown using the Czochralski method and had a composition close to $\mathrm{Fe}-15 \mathrm{Cr}$ $15 \mathrm{Ni}$ as determined by chemical analysis. The single-crystal samples were oriented using $\mathrm{x}$-ray back reflection and then machined using electric-discharge erosion. The longitudinal sample axis was oriented along [100]. All specimens were implanted simultaneously with $400 \mathrm{keV}$ boron and $550 \mathrm{keV}$ 
nitrogen to a dose of $2.3 \times 10^{16}$ ions $/ \mathrm{cm}^{2}$ for each ion corresponding to 1 atomic $\%$ at the peak in the implant profile. The implantations were carried out at the triple ion irradiation facility [5] in the Metals and Ceramics Division at Oak Ridge National Laboratory using the $400 \mathrm{kV}$ and $2.5 \mathrm{MV}$ Van de Graaff accelerators, respectively, for boron and nitrogen. The mean projected ranges of the implanted species were determined to be approximately $0.5 \mu \mathrm{m}$ for all of the implantations as estimated by TRIM90 calculations [6].

Miniature bending-fatigue specimens with the configuration shown in figure 1 were used for the fatigue tests. In the case of the implanted specimens, only the hourglass-shaped gauge region was implanted. Special holders were designed for irradiating the specimens in the accelerator chamber. Separate holders were required to implant the edges and surfaces; each specimen was subjected to four irradiations, one for each surface and edge. The specimens were electrochemically polished using a perchloric acid-ethanol electrolyte and then annealed for 15 minutes at $1150^{\circ} \mathrm{C}$ in vacuum prior to implantation.

Fatigue tests were performed using a specially designed test machine developed at Auburn University. The specimen is a cantilever beam with a bending load applied at the free end. Specimens were tested at constant amplitude at a flexing frequency of $8.33 \mathrm{Hertz}$ (500 cycles per minute) with a total deflection of $4.8 \mathrm{~mm}$ at the point of loading corresponding to a strain range of $0.21 \%$ in the necked region with a zero mean stress representing an intermediate strain level. All specimens were tested at a single value of deflection for comparison purposes. The tests were terminated when the load experienced by the specimen decayed to $80 \%$ of the original load, as detected by the load cell. Further details concerning the special test machine may be obtained from reference [7]. Knoop microhardness measurements were carried out on a Leitz Metalloplan optical microscope with a video camera attachment and television screen to image and accurately measure the diagonal of the Knoop diamond indents. Optical microscopy was also used to study the crack initiation and slip-band morphology on the surface of the specimens after fatigue testing. 


\section{Results}

The results of the fatigue tests using the eight E-series alloys as well as the single-crystal specimens are shown in figure 2. The control specimen results are the average of 2 to 4 specimens while the implanted-specimen results were obtained using one specimen per alloy. It can be seen that the fatigue life of the eight complex alloys decreased after dual implantation, ranging from a $15 \%$ decrease for alloys E-1 (base) and E-6 (50 wt\% less Si) to $45 \%$ for alloy E-7 (no Si). On the other hand, the fatigue life of the single-crystal specimen also decreased after implantation by about $8 \%$ for one specimen and $26 \%$ for the other. Knoop hardness results are also shown in figure 2 for all alloys. A load of $5 \mathrm{gms}$ was used for the Knoop tests. A lower load would have made it difficult to accurately estimate the indent diagonal length while a higher load would have included effects from the unimplanted deeper regions in the hardness measurement. Thus the $5 \mathrm{gm}$ load was chosen as the best compromise for the Knoop tests. It can be seen in figure 2 that, as expected, the surface hardness increased for all the alloys after implantation, indicating a strengthening of the implanted layer.

Optical microscopy revealed a definite suppression of slip bands in all the implanted specimens as compared to the control specimens. Figure 3 shows typical micrographs of the fatigue cracked surface in the gauge region of the unimplanted and implanted specimens for the polycrystalline specimens as well as for the single crystal specimens. In the control specimens, slip bands were visible throughout the entire gauge region. The control specimens showed one-to-three major cracks and a number of microcracks. In the polycrystalline control specimens, the extent of slip-band formation varied from grain-to- grain depending on the orientation with respect to the loading axis. Since the single-crystal specimens were oriented with the longitudinal axis along the [100] direction, two sets of slip bands were observed in the gauge region. These slip-bands were exactly perpendicular to each uther and both were oriented $45^{\circ}$ with respect to the [100] crystallographic direction. These sliphands correspond to two $\{111\}<110>$ systems, the preferred silp system for fcc metals, each of which 
is active during the tension and compression cycles, respectively. Slip bands were observed to be present over the entire gauge region of the control single-crystal specimens. In case of the implanted specimens, typically one major crack and a few microcracks were visible. As seen in figure 3, slip bands were confined to the immediate vicinity of the major crack where the applied strain had the greatest value. The area covered by slip bands was much lower as compared to the control specimens.

Fatigue cracks can initiate at slip bands, twins, grain boundaries and precipitate particles. For the single-crystal specimens, both control and implanted, the cracks always initiated at slip bands. Twin bands were also observed in the implanted single-crystal specimens although fatigue cracks did not initiate at twin bands. Interrupted tests were conducted on control polycrystalline specimens with the test stopped at various intervals and the specimen examined in the optical microscope in order to examine crack-initiation sites. For the control polycrystalline specimens, cracks were found to initiate mainly at slip bands. A number of grain-boundary cracks were also formed in the later stages of the test. The final major crack was found to originate from cracks initiated at slip bands. Interrupted tests were not performed on the implanted specimens. However, observations of failed implanted polycrystalline specimens using the optical microscope revealed a number of grain boundary cracks in the gauge section as shown in figure 4. Fatigue cracks in implanted single-crystal specimens always initiated at intense slip bands.

\section{Discussion}

In earlier studies, fatigue cracks have been shown to initiate at persistent slip bands (PSBs) [8]. The PSBs, which penetrate the surface of the specimen, have intrusion-extrusion topographies, and fatigue cracks were shown to initiate at the edge where the PSB emerges from the surface under some of the intrusions [8]. Ion implantation causes the formation of a thin, hard layer with an increased yield strength on the surface causing a reduction in the surface plastic strain, thereby 
preventing slip bands in the bulk from penetrating to the surface. Thus, slip bands could penetrate the implanted layer only in a small region of maximum applied stress but were effectively prevented from appearing at the surface in the rest of the gauge region by the implanted layer. This suppression of slip band formation at the surface with the consequent delay and suppression of fatigue crack initiation has been determined to be responsible for improvements in the fatigue life $[9,10]$.

The microstructure of the implanted layer is of significance for achieving an understanding of the mechanisms responsible for the prevention of slip-band penetration in the implanted layer. Radiation damage is an important factor, and the ion implantation process creates several point defects that can form clusters and Frank loops which hinder dislocation motion and prevent slip-band penetration. Self (i.e. $\mathrm{Fe}^{++}$) ion implantation of $\mathrm{Fe}-13 \mathrm{Cr}-15 \mathrm{Ni}$ alloys, however, caused no significant changes in the fatigue life indicating that in this case, radiation damage may not be a dominant factor [4]. Self implantation did cause an increase in surface hardness as has also been shown in other studies $[9,11]$.

The formation of precipitate particles can hinder dislocation motion, thereby preventing slip bands from penetrating the implanted layer. Transmission electron microscopy of the $\mathrm{B}, \mathrm{N}$ implanted layer, however, did not reveal the presence of precipitates [4]. The failure to observe precipitate particles in the earlier study was attributed to the obscuring effects of overlapping strain fields due to a high concentration of point defects and to the modest implant doses employed. The results suggest that any precipitates that may have formed were too small to be detected. Earlier studies of nitrogenimplanted $\mathrm{Fe}-\mathrm{Ni}-\mathrm{Cr}$ alloys [12] and 304 type stainless steel [13] did, however, reveal the presence of nitride clusters.

It is clear from figure 3 that slip-band formation was obviously suppressed at the surface. The reduction in fatigue life due to the dual implantation can be explained in terms of a transformation to grain boundary cracking from slip-band crack initiation. Grain-boundary cracks were observed even in the unimplanted E-alloy specimens after fatigue tests, and many grain-boundary cracks were 
evident in the gauge region of the implanted specimens. Slip bands in the implanted specimens were suppressed from penetrating the implanted layer to such an extent that the applied stress was relieved by cracking of favorably oriented grain boundaries where the adjacent grains had a high degree of misorientation and the grain boundary was oriented approximately $90^{\circ}$ relative to the load axis.

In our previous study, four simple $\mathrm{Fe}-13 \mathrm{Cr}-15 \mathrm{Ni}$ alloys (B-series alloys; see table 2 for compositions) were either singly implanted with boron and nitrogen, simultaneously implanted with boron and nitrogen, or simultaneously implanted with boron, nitrogen, and carbon $[3,4]$. The fatiguespecimen configuration as well as implant and test conditions were identical to those used in this study. The energy for carbon implantation was $400 \mathrm{keV}$. The fatigue test results are shown in figure 5. Single ion implantation caused at most modest improvements in the fatigue life whereas dual implantation yielded significant improvements (up to $250 \%$ for alloy B-6). Interestingly, triple ion implantation caused a decrease in fatigue life. Optical microcopy revealed the presence of grain boundary cracks only in the triple-implanted specimens [4]. Since the E-alloys are inherently stronger due to solute and precipitate strengthening, dual implantation was sufficient to cause he transformation to grain-boundary cracking whereas in the B-series alloys, only triple implantation caused sufficient strengthening for such a transformation.

Such an effect is not possible in the single crystal specimens due to the absence of grain boundaries. However, while slip was suppressed to a great extent in the $\mathrm{BN}$ implanted single-crystal specimens, some slip bands did manage to penetrate the implanted layer to the surface. Thus, further applied stress was concentrated in these slip bands leading to crack initiation earlier than that for the control specimens. In the implanted B alloys, which are similar to the ternary, fatigue life improved due to two possible reasons: Firstly, only some of the grains were oriented favorably for forming slip bands and consequently, cracks. Secondly, slip bands that did form were probably blocked by grain houndaries delaying, crack initiation and propagation. Only in the triple implanted specimens were the slip bands suppressed to such an extent as to cause grain boundary cracking. 
It is clear that there is an optimum level of surface strengthening by ion implantation for suppressing slip band penetration and improving fatigue life. Further strengthening causes grain boundaries, which can be viewed as pre-existing flaws, to come into play. This result was also shown in a dose-dependence study by Hohmuth et. al. [14] where polycrystalline nickel was implanted with boron at different doses. These authors found an optimum dose for the maximum fatigue-life improvement while higher doses caused a reduction in fatigue life. This observation was again attributed to the promotion of grain-boundary crack formation.

The fatigue test results presented here are limited to a single strain level and to a single dose for each ion. However, there is a clear dependence on grain size as evinced by the single crystal results. The single crystal specimens had stress concentrated along some slip bands leading to an earlier crack initiation at these bands. The more effective strengthening of the E-alloys preferentially initiated cracks at grain boundaries again decreasing fatigue life. Thus, improving strain-controlled fatigue properties of metal alloys at intermediate strain levels by ion implantation has a sensitive dependence on grain size as well as extent of suppression of slip at the surface.

\section{Conclusions}

The primary conclusions resulting from the present investigation are:

(1) Simultaneous implantation of boron and nitrogen in eight $\mathrm{Fe}-13 \mathrm{Cr}-15 \mathrm{Ni}-2 \mathrm{Mo}-2 \mathrm{Mn}-0.2 \mathrm{Ti}-0.8 \mathrm{Si}-$ $0.06 \mathrm{C}$ based complex alloys caused a significant increase in hardness. However, the fatigue life of all eight alloys decreased.

(2) The decrease in the fatigue life of the implanted E-alloys was attributed to a transformation to grain-boundary cracking from slip-band crack initiation which is the operative failure mechanism in the unimplanted alloys.

(3) Supporting evidence was obtained from an earlier study of multiple-ion implantation of four simple $\mathrm{Fe}-13 \mathrm{Cr}-15 \mathrm{Ni}$ alloys. Dual implantation of these alloys with $\mathrm{B}$ and $\mathrm{N}$ significantly improved 
the fatigue life, but triple ion implantation with $\mathrm{B}, \mathrm{N}$, and $\mathrm{C}$ decreased fatigue life. Only the triple implanted specimens showed grain-boundary cracks.

(4) Single-crystal $\mathrm{Fe}-15 \mathrm{Cr}-15 \mathrm{Ni}$ specimens were used in order to eliminate grain-boundary effects. The single-crystal specimens were also implanted with boron and nitrogen ions. The fatigue life of single-crystal specimens also decreased after implantation. This was at ributed to concentration of stress along fewer slip bands leading to earlier crack initiation as compared to the control specimen.

(5) The present results indicate that there is an optimum level of strengthening by ion implantation for the prevention of slip-band penetration of the implanted layer and corresponding improvement of fatigue life. Any further strengthening causes the stress to be relieved by grain boundary failure which then becomes the fatigue crack-initiation site leading to an overall lower fatigue life.

(6) Improving strain-controlled fatigue properties of alloys by ion implantation has a sensitive dependence on grain size as well as on extent of suppression of slip at the surface.

\section{References}

1. H. Bakhru, W. Gibson, C. Burr, A. J. Kumnick and G. E. Welsch, Nucl. Instrum. and Methods, $182 / 183(1981) 959-964$.

2. K. V. Jata and E. A. Starke, Jr., J. of Metals, 8 (1983) 23-27.

3. E. H. Lee and L. K. Mansur, J. of Mater. Res., 4 (1989) 1371-1378.

4. G. R. Rao, E. H. Lee and B. A. Chin, Presented at the seventh Intl. Conf. on Surface Modification of Metals by Ion Beams, Washington D. C., July 1991; To be published in Surface and Coatings Technology.

5. M. B. Lewis, W. R. Allen, R. A. Buhl, N. H. Packan, S. W. Cook and L. K. Mansur, Nucl. Instrum. and Methods, B 43 (1989) 243-253.

6. J. F. Ziegler, J. P. Biersack and U. Littmark, The Stopping and Range of lons in Solids, Pergamon Press (1985). 
7. G. R. Rao, M. S. Thesis, Auburn University, AL, 1988, pp. 23-32.

8. A. Hunsche and P. Neumann, Acta Metall., 34 (2) (1986) 216.

9. D. J. Morrison, J. W. Jones, D. E. Alexander and G. S. Was, Met. Trans, 22A (1991) 1633-1646.

10. U. Essmann, U. Gosele and H. Mughrabi, Phil. Mag. A, 44 (1981) 405-426.

11. W. C. Oliver, Thin Solid Films 153 (1987) 185-196.

12. J. '. Spitznagel, B. O. Hall, N. J. Doyle, Raman Jayram, R. W. Wallace, J. R. Townsend and M. Miller, in G. K. Hubler, O. W. Holland, C. R. Clayton and C. W. White (ed.), Ion Implantation and Implantat .n, 27, Mat. Res. Soc. Symp. Proc., North Holland, New York, (1984), 597-601. 13. S. Fayeulle and D. Treheux, Nucl. Instrum. and Methods in Phys. Res., B19/20 (1987) 216.

14. K. Hohmuth, E. Richter, B. Rauschenbach and C. Blochwitz, Mater. Sci. and Engr., 69 (1985) 191-201. 


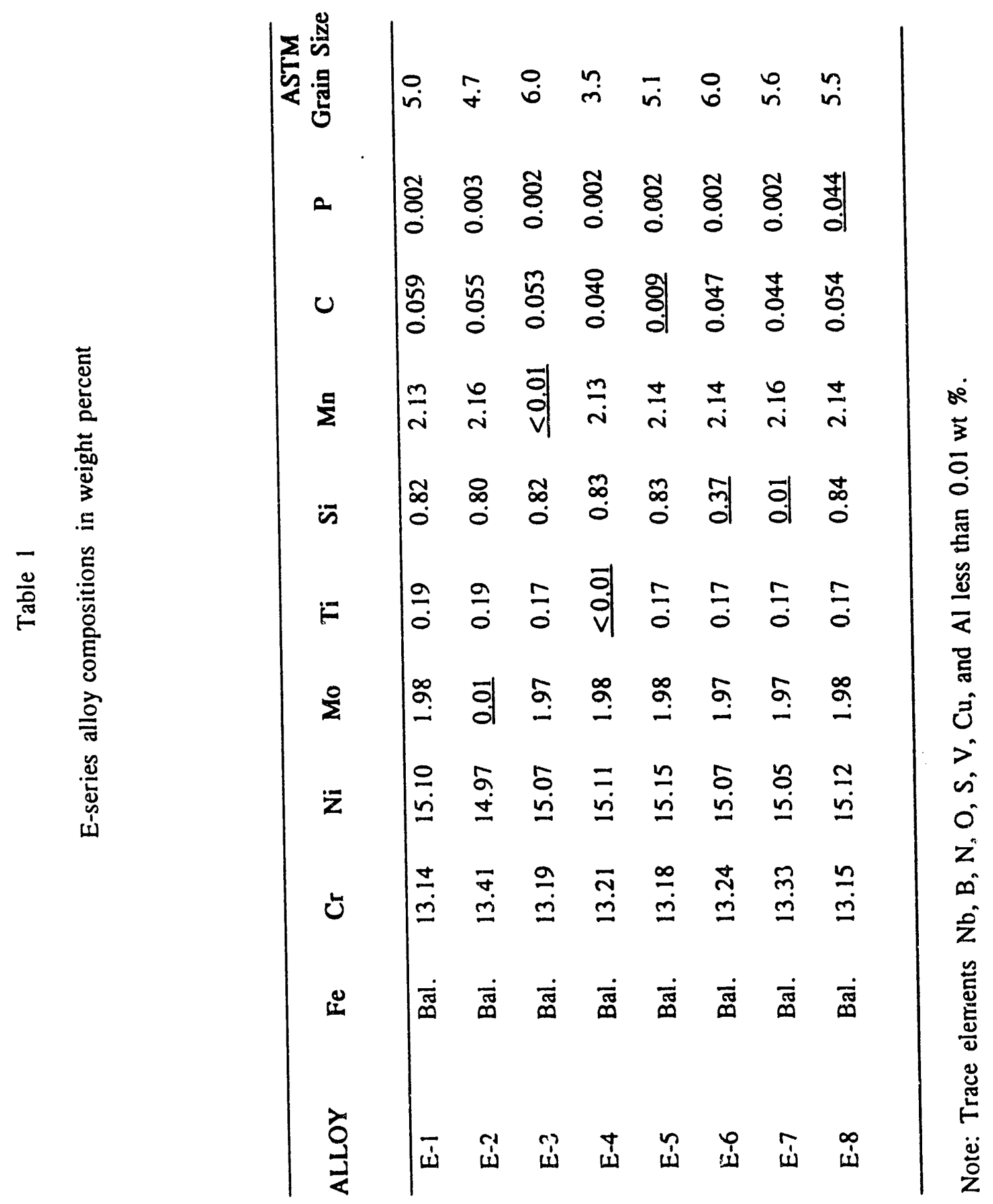




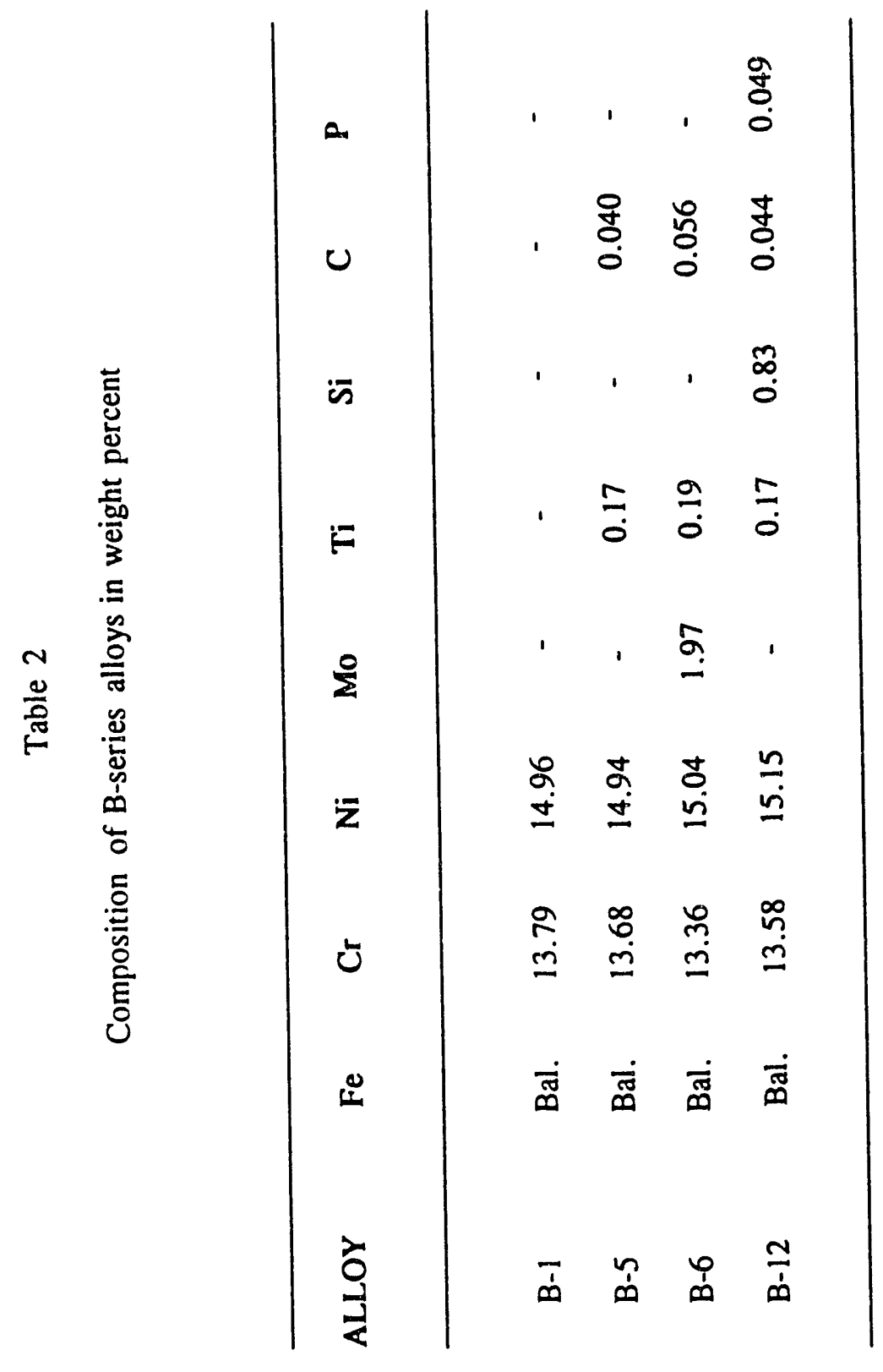




\section{Figure Captions}

1. Miniature bending fatigue specimen configuration used in this study.

2. Fatigue test and microhardness results for the unimplanted and implanted complex E-alloys and the single crystal specimens showing the increase in hardness for all specimens but a decrease in fatigue life for the implanted specimens (SC indicates a single crystal specimen; two specimens, SC7 and SC8 were implanted and tested).

3. Typical optical micrographs of the gauge regions of unimplanted and implanted E-alloys and the single crystal specimens showing the suppression of slip bands. Note the symmetric pattern of slip bands in two $<111>\{110\}$ systems active in the tension and compression cycles, respectively, in the single crystal specimen.

4. Typical grain boundary cracks observed in the implanted specimens after fatigue testing which probably lead to earlier failure of the specimen.

5. Fatigue test results for the simple B-alloys showing that dual implantation significantly improves fatigue life but triple implantation decreases fatigue life due to the shift to grain boundary cracking. 

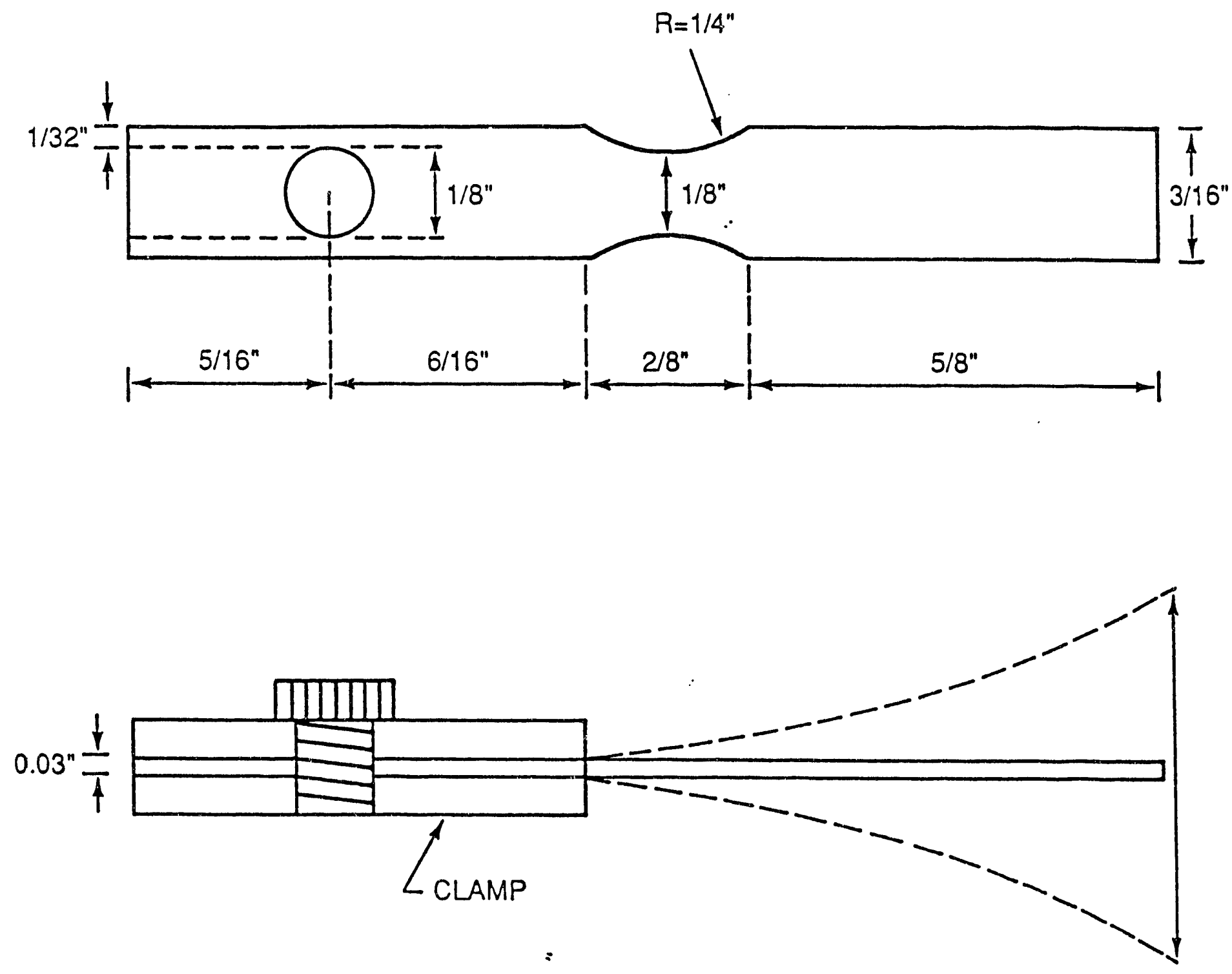

Fatigue Specimen Configuration

Fin:ro: 

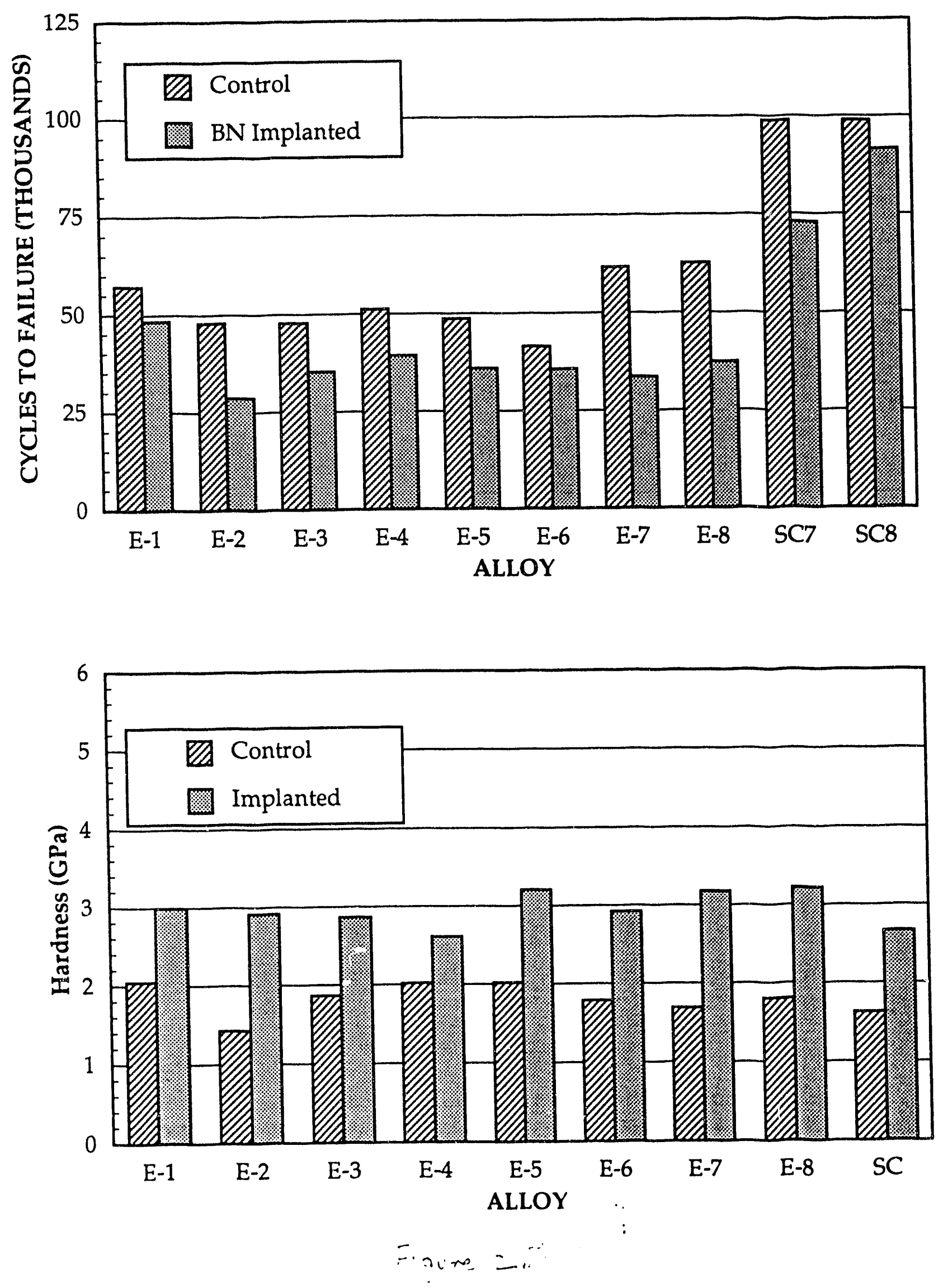


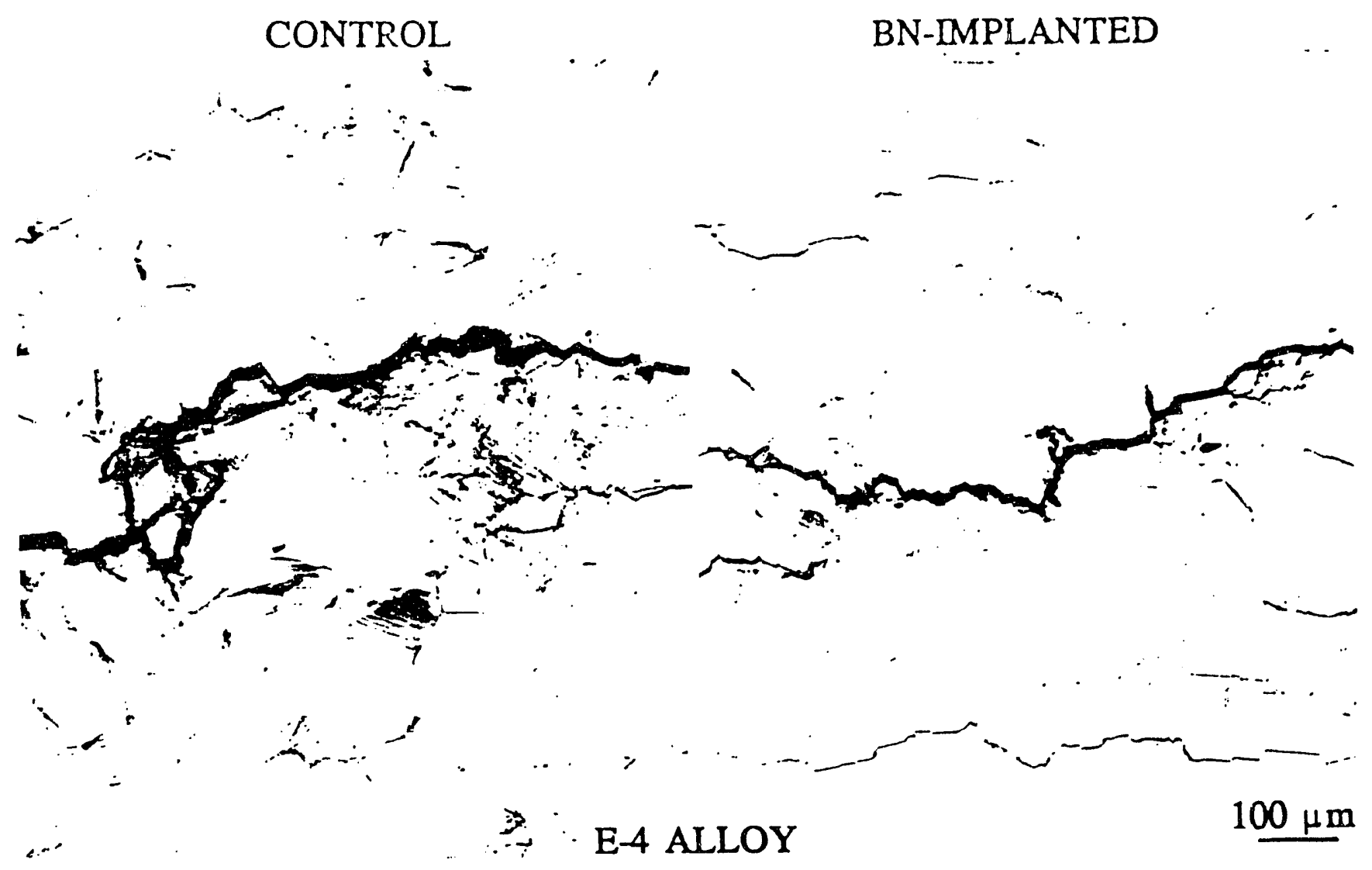

CONTROL

BN-IMPLANTED

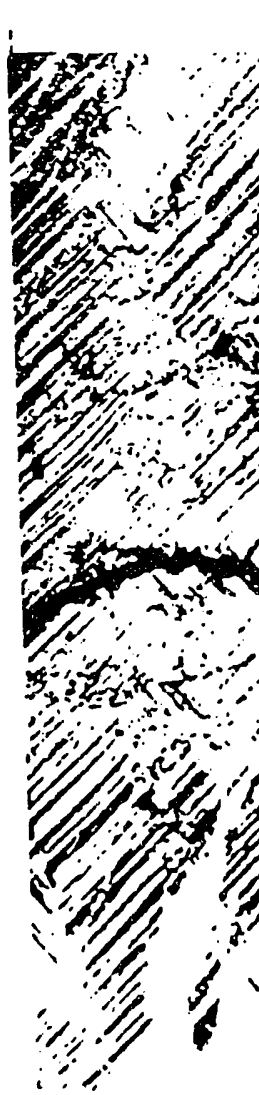

CONTROL 

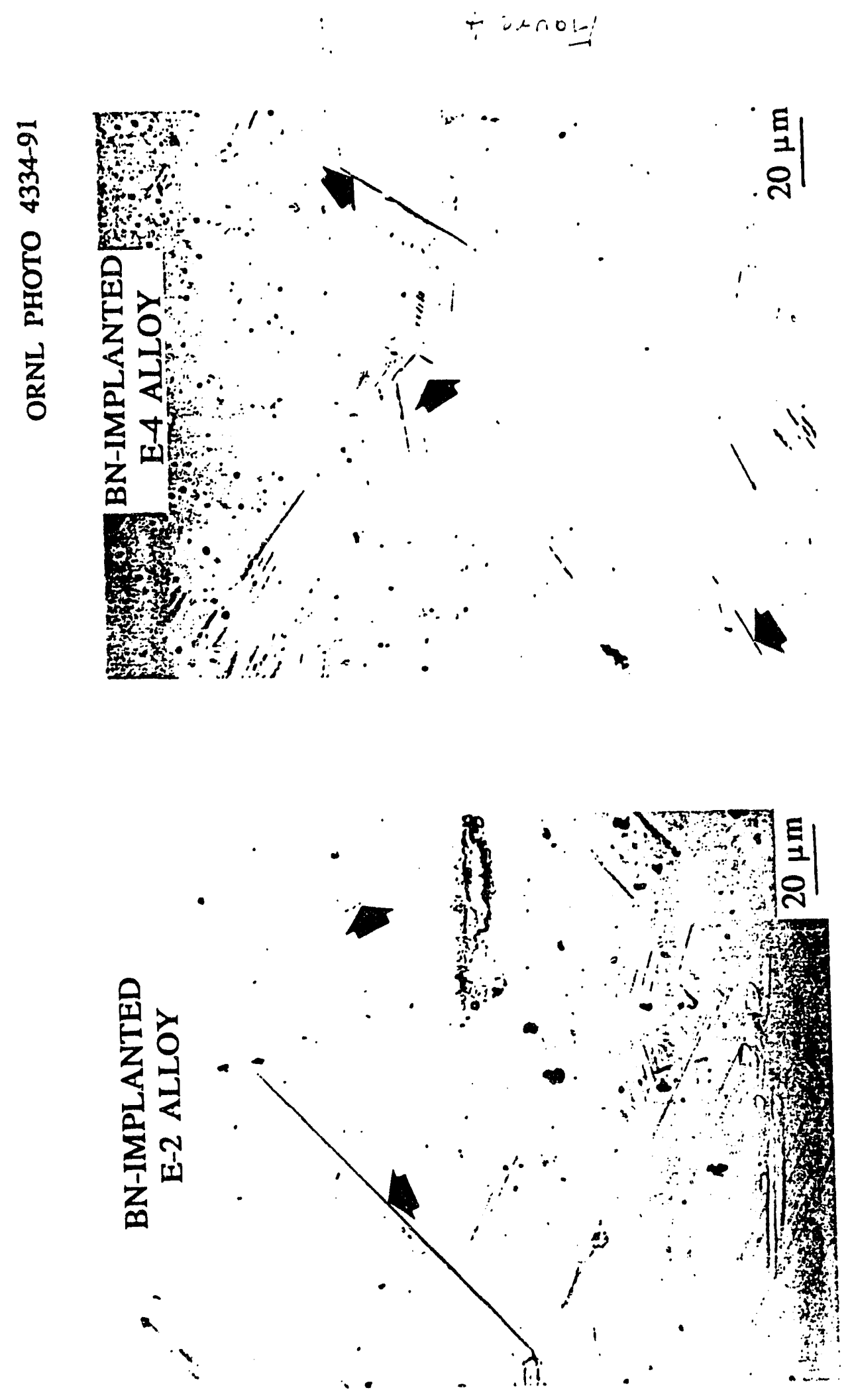


$$
\Xi \cdots
$$

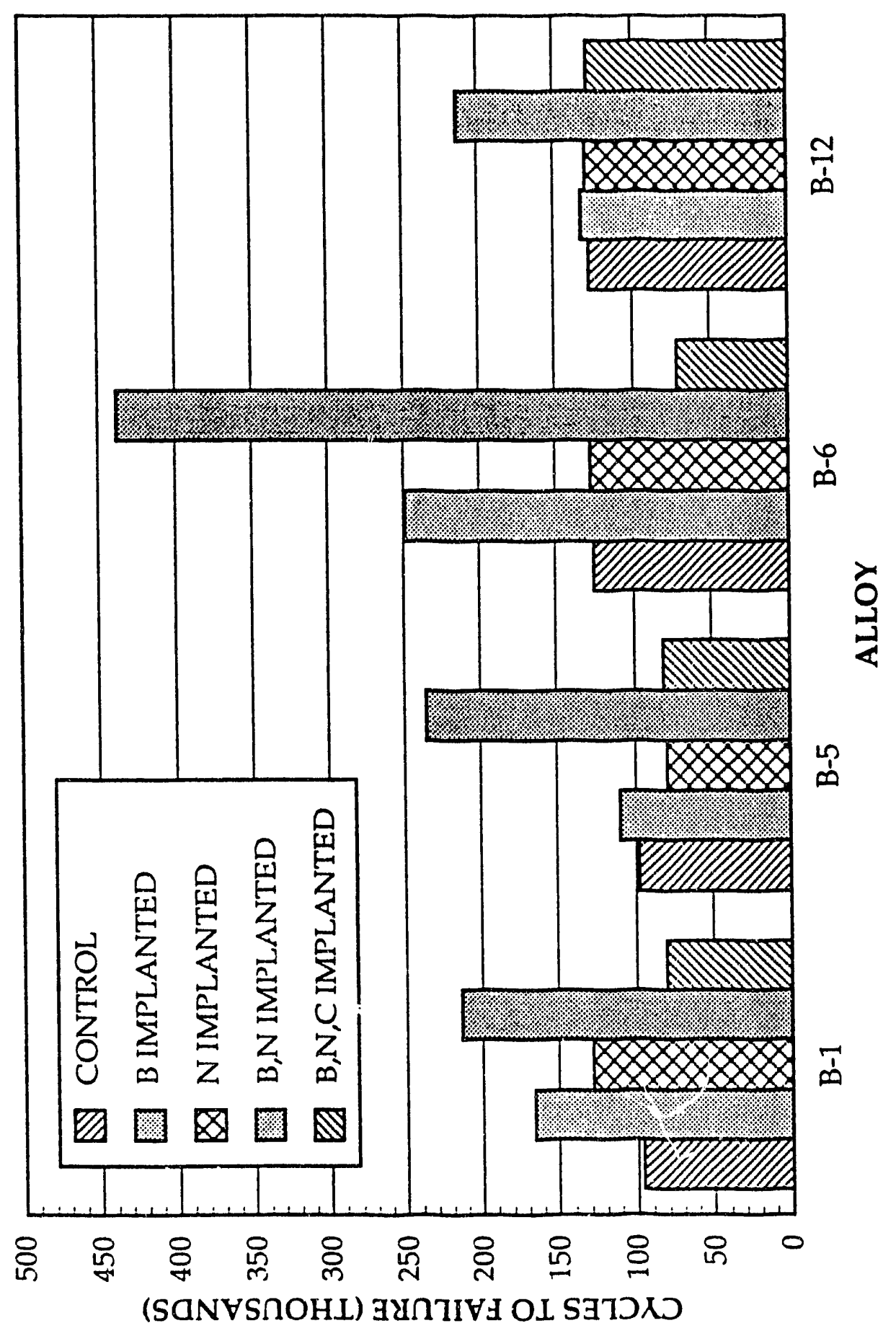



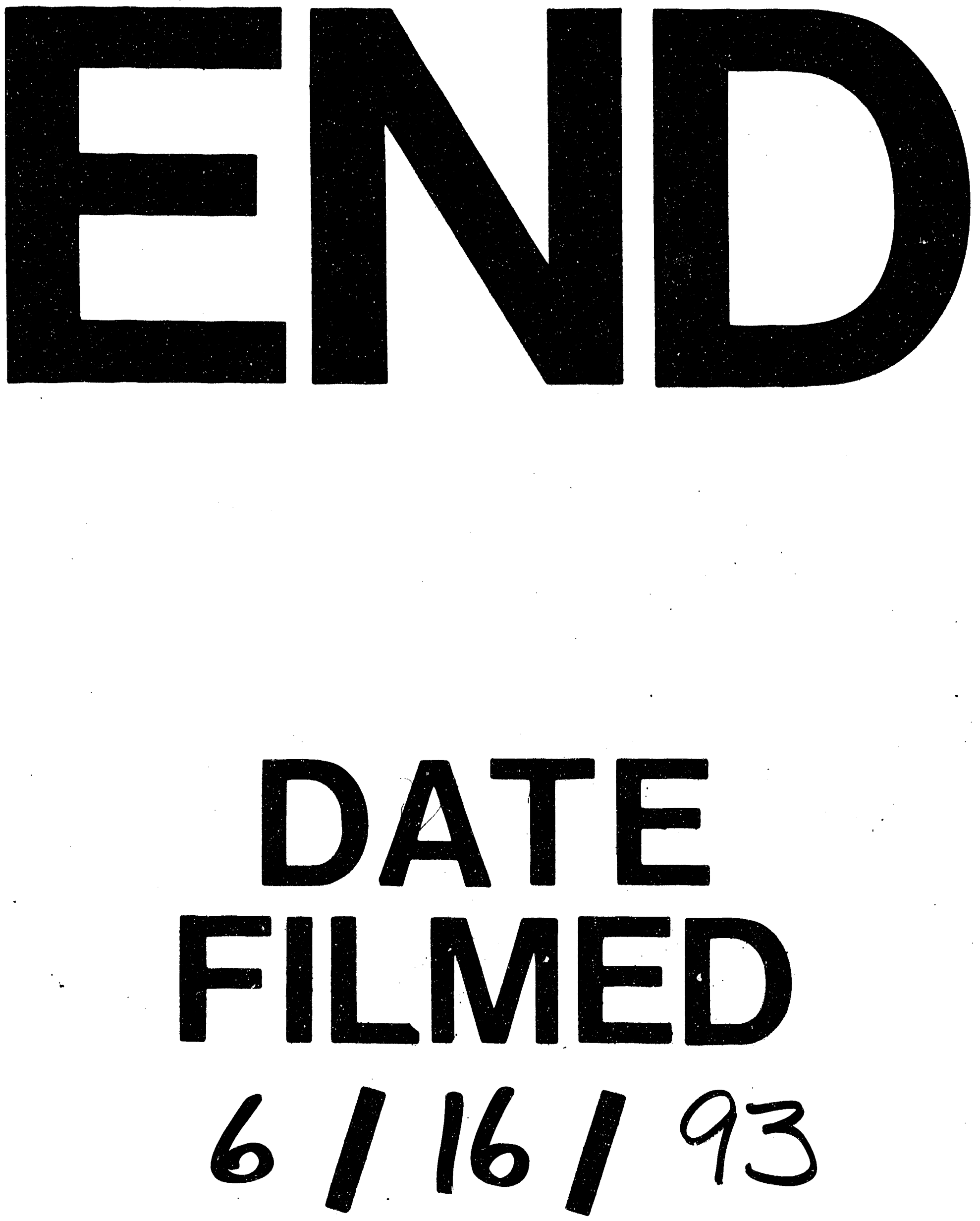
